University of Missouri, St. Louis

IRL@ UMSL

$12-12-2016$

\title{
Impact of a Growth Mindset Intervention on Academic Performance of Students at Two Urban High Schools
}

Lisa Brougham

University of Missouri-St. Louis, labtpc@umsl.edu

Follow this and additional works at: https://irl.umsl.edu/dissertation

Part of the Education Commons

\section{Recommended Citation}

Brougham, Lisa, "Impact of a Growth Mindset Intervention on Academic Performance of Students at Two Urban High Schools" (2016). Dissertations. 48.

https://irl.umsl.edu/dissertation/48

This Dissertation is brought to you for free and open access by the UMSL Graduate Works at IRL @ UMSL. It has been accepted for inclusion in Dissertations by an authorized administrator of IRL @ UMSL. For more information, please contact marvinh@umsl.edu. 
Impact of a Growth Mindset Intervention on Academic Performance of Students at Two Urban High Schools

\section{Lisa Brougham}

B.S. in Public Relations, Boston University, 1982

M.Ed. in Counseling, University of Missouri - St. Louis, 2006

A Dissertation Submitted to The Graduate School at the University of Missouri - St. Louis in partial fulfillment of the requirements for the degree of Doctor of Philosophy in Education with an emphasis in Counseling

December 2016

Advisory Committee

Chair: Susan Kashubeck-West, Ph.D.

Elizabeth Bender, Ph.D

Mary Lee Nelson, Ph.D

Matthew Taylor, Ph.D.

Copyright, Lisa Brougham, 2016 


\begin{abstract}
Urban high school students have greater challenges with respect to retention and graduation rates than their non-urban peers (Farrington et al., 2012). Many academic initiatives have attempted to resolve the problems of retention and poor academic performance with little sustained success. For this study, the empirical literature was reviewed to identify a remedy for poor academic performance that may be implemented by school counselors. Focusing on non-cognitive skills, specifically developing a growth mindset, has shown promising results (Aronson, Fried, \& Good, 2002; Blackwell, Trzesniewski, \& Dweck, 2007; Yeager \& Dweck, 2012). The underlying theoretical framework for this study is Dweck's Implicit Theory of Intelligence (Dweck, 1999), which describes how belief in an incremental theory (intelligence can increase over time) results in a growth mindset. The goal of this study was to help students realize their intelligence is not fixed and they can grow their intelligence. The guiding question was, can a growth mindset intervention impact academic performance for students at two urban high schools? Changes in students' academic performance, operationalized as core grade point average (GPA), were assessed before and after a three 45 -minute treatment intervention and compared with wait-list control groups. The impact on mindset beliefs and attendance were also evaluated. Results from a sample of 69 students from two local urban high schools indicated that the intervention did not improve core GPA. A small sample size reduced the available power to detect significant differences. The intervention resulted in increased growth mindset scores in the students; however, no differences in attendance were found between the treatment and control groups.
\end{abstract}


Implications for school counseling practice and recommendations for future research are discussed.

Keywords: academic performance, urban high schools, growth mindset 


\section{DEDICATION}

This dissertation is dedicated to my husband, our sons, my parents, and my UMSL and school district colleagues. This would not have been possible without all of you. I could not have completed this dissertation journey without the support of my husband, Bill, who took on many additional duties and made it possible for me to maintain my high school counseling job and focus on this research, without having to worry about all of the other incidental tasks life requires. You supported me making the leap from the business world to pursue a less lucrative but much more fulfilling career in education, allowing me to pursue my passion of working with younger people to help them get on the right path.

To our sons, Kyle and Lucas, whose unconditional love, philosophical discussions, and words of encouragement kept me motivated to complete this project. Your unique approaches to your own educations provided me with additional insight to help me perform my job and my research better.

To my parents, Jerry Wetzel and Joan Iannotta, whose continued support of whatever I chose to do gave me the confidence to continue my personal growth, especially my father, who listened early many mornings about the latest challenges or accomplishments, with keen attention, even though he himself did not pursue postsecondary education.

To my colleagues at the university, in my school, and in our district central office, I greatly appreciate the work those of you did to help make this research study possible, as well as the words of encouragement many of you provided along the way. Counselor Allison Mallory, Dr. Wilfred Moore, Dr. Charles Shannon, Dr. Crystal Gale, Dr. Elizabeth Bender, Jackie Perry, Karen Jones, and many teachers all had a piece in making 
this study possible. Dr. Lelia Flagg, at UMSL, provided friendship and shared her experiences. And my neighbor, Jean Gardiner, whose friendship, intellectual inquisitiveness, grounded nature, and willingness to read a draft of chapter one really helped. Thank you all. 


\section{ACKNOWLEGEMENTS}

Thank you to Dr. Susan Kashubeck-West for guiding my research study from start to finish, for sharing your expertise in quantitative methodology, and for all you did and do to make the doctoral learning experience so enriching in the College of Education at UMSL. You set high standards despite all the demands on your time, and I greatly appreciate all the attention you gave my study.

Thank you to Dr. Elizabeth Bender whose support on the district level was invaluable in numerous ways including navigating the district hurdles as the clock was ticking to meet the optimum timing in the semester to conduct the study. Your passion for and dedication to student success are inspiring.

Thank you to Dr. Mary Lee Nelson for your dedication the counseling profession. You are the compassionate heart and soul of the department, leading all of us by example in your interactions with students and colleagues alike.

Thank you to Dr. Matthew Taylor for challenging me to look beyond the obvious research questions and explore how a student's a sense of belonging may interact with the growth mindset intervention and academic performance. Your enthusiasm for my study and willingness to enrich it are greatly appreciated.

Thank you to Rachel Herter and Carissa Romero of PERTS, for working with me on the design of the research study, exploring options within the current work the PERTS team was conducting and sharing materials from their past research work. Having the treatment lesson used in prior research helped make my study design credible. 


\section{TABLE OF CONTENTS}

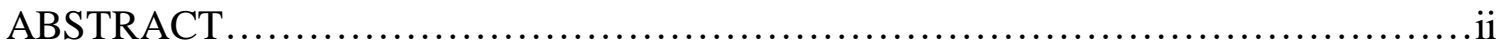

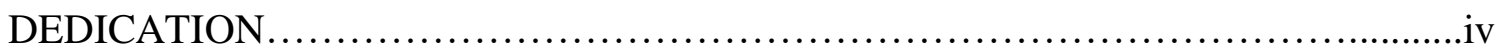

ACKNOWLEDGEMENTS ..................................................vi

TABLE OF CONTENTS .....................................................vii

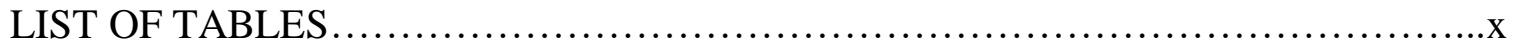

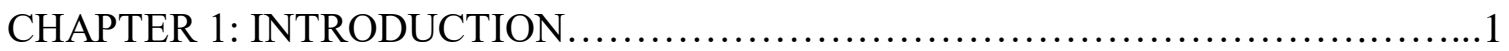

Race, Socioeconomic Status, and Academic Performance....................... 2

Urban High Schools.....................................................4

Educational Initiatives on the National Level..........................5

Educational Initiatives at the District Level............................6 6

Growth Mindset Interventions.............................................

Connectedness........................................................ 10

Research Problem........................................................11

Purpose Statement and Research Questions................................13

Delimitations...................................................... 14

Significance of the Study............................................... 15

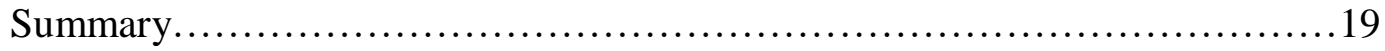

CHAPTER 2: REVIEW OF LITERATURE....................................20

Academic Performance................................................20

Academic improvement initiatives.................................22

Attendance and academic performance.............................28

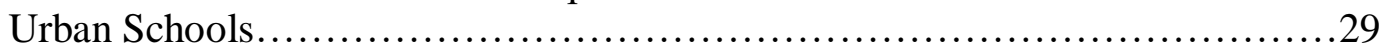

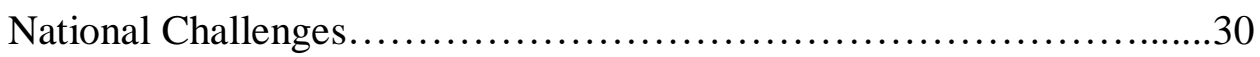

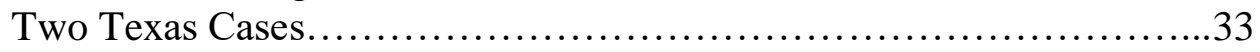

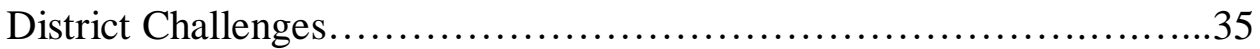

Students Who Are Disadvantaged..................................36

Implicit Theory to Growth Mindset Interventions.............................. 39

Linking Prior Work to the Development of Implicit Theories.............40

Empirical Evidence.............................................40

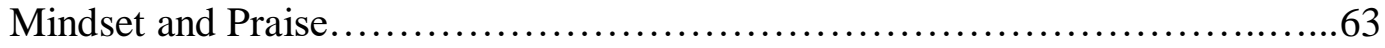

Evidence that Does Not Support Implicit Theory Work.......................64

Summary..........................................................66

Gaps in Research.................................................67

CHAPTER 3: METHODOLOGY ............................................69 


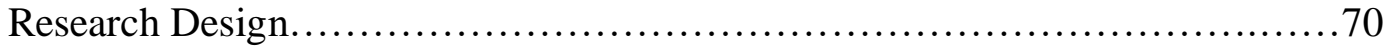

Sample and Population..................................................... 70

Background Information about RMHS ...............................70

Background Information about THS.................................72

Demographic Information about the High Schools.........................74

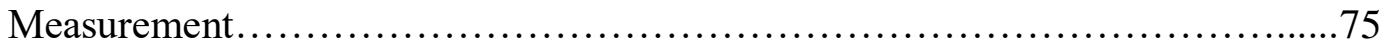

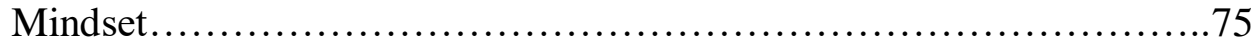

Academic Performance and Attendance................................77

Connectedness...................................................

Practice Sessions.................................................... 78

Data Collection and Procedures............................................... 79

Approval, Consent, and Assent....................................... 80

Recruitment..................................................... 80

Mindset Scale, Ladder Question, and CASSS Administration..............82

Random Assignment and Statistical Significance........................83

Treatment Protocol................................................. 84

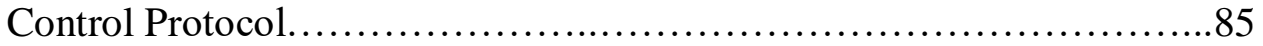

Participant Flow and Data........................................ 87

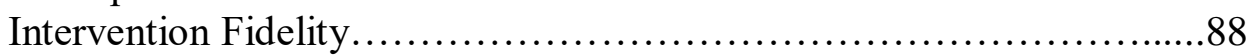

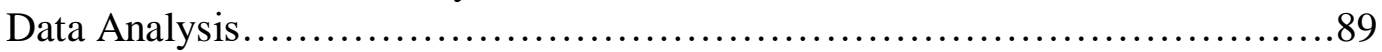

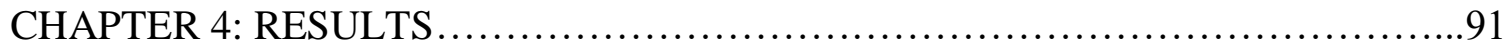

Preliminary Analysis ..................................................... 91

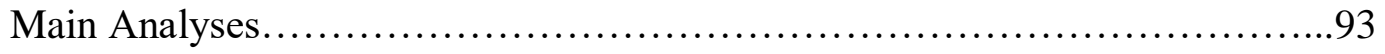

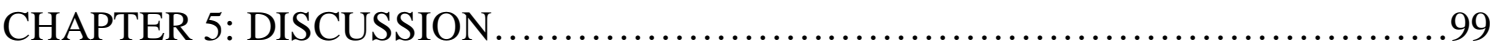

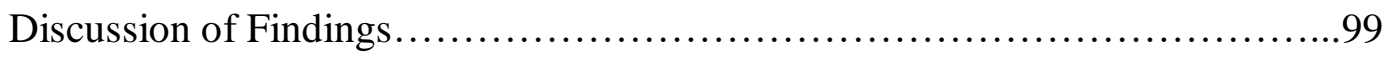

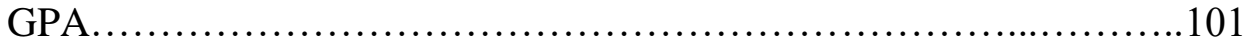

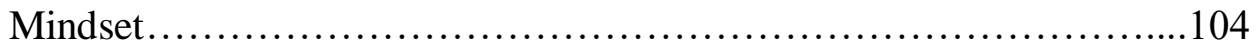

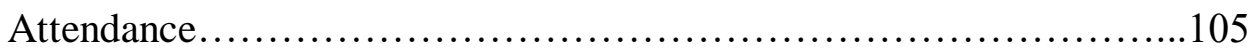

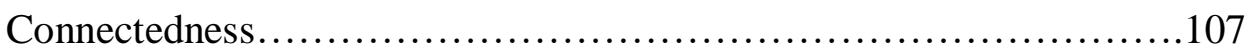

Limitations....................................................

Implications for School Counselors...............................110

Recommendations for Future Research............................112

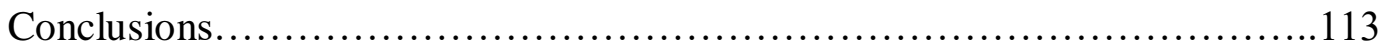

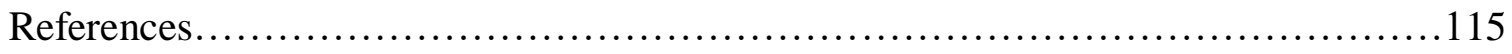

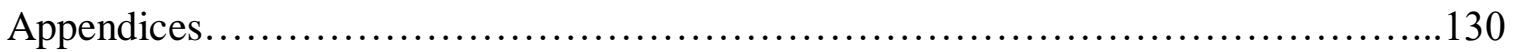

Appendix A1: Treatment Sessions Lesson Plans..............................130

Appendix A2: Treatment Sessions-Lesson I..............................134

Appendix A3: Treatment Sessions-Lesson II..............................140

Appendix B1: Control Sessions Lesson Plans.................................141 
Appendix B2: Control Sessions - Lesson I........................... 145

Appendix B3: Control Sessions-Lesson II...............................151

Appendix C1: Mindset Scale-pre, with SES Ladder........................153

Appendix C2: Mindset Scale-post..................................... 154

Appendix D: CASSS ............................................... 155

Appendix E: Informed Parental Consent Form......................... 157

Appendix F: Student Assent Form.........................................160

Appendix G. Research Study Calendar..................................162

Appendix H: Session Journal Entries, PI, January-February 2016............163 


\section{LIST OF TABLES}

Table 1. Comparison of Incremental and Entity Theories of Intelligence.............166

Table 2. Comparison of Math and Science Scores for Disadvantaged vs National.....167

Table 3. Impact of Charter School Enrollment on Learning Gains..................168

Table 4. Key Metrics and Demographic Data for Schools, 2014....................169

Table 5. Flow of Participants Through a Three Week Intervention.................170

(Table 6. Sense of Connectedness, Disaggregated and Aggregated—In Text ........93)

(Table 7. Core-Subject GPA Change, Disaggregated and Aggregated-In Text......95)

(Table 8. Attendance Change, Disaggregated and Aggregated-In Text.............96)

(Table 9. Group Dynamics Score and Last Session Attendance-In Text............104) 


\section{CHAPTER 1}

\section{INTRODUCTION}

Many urban districts and schools contend with issues of a shrinking tax base, buildings that are aging, poorly qualified teachers, crowded classrooms, high student mobility, and students who are from disadvantaged backgrounds (Yendol-Hoppey, Jacobs, \& Dana, 2009). These problems make the typical challenge of educating students that much greater in urban environments.

This study explores these difficulties as observed in one urban school district in a Midwestern city in the United States. The study compares two schools in this district, an academically rigorous magnet high school (RMHS) and a traditional high school (THS); both struggling with the challenges outlined here. At the esteemed RMHS, if a student earns three Fs in one school year, that student is not eligible to return to RMHS the following school year; because of this, approximately 30-40\% of the students who come in as freshman do not graduate with their RMHS cohort (internal data from RMHS Student Information System database). At the comprehensive Traditional High School (THS) the graduation rate fluctuated between $36 \%$ and $59 \%$ in the last five years, far below the state average of 79.8\% for the 2010-11 school year (Missouri Comprehensive Data System [MCDS], 2015a).

Educators have worked to improve retention at both Midwest Urban Public Schools (MUPS), yet the problem persists. Research finds that increasing retention correlates with improving academic performance (Morrissey, Hutchison, \& Winsler, 2014; Strickland, 1998). Toward this end, some researchers have focused on improving non-cognitive skills and developing a growth mindset rather than targeting specific academic skills, 
with promising results (Blackwell, Trzesniewski, \& Dweck, 2007; Farrington et al., 2012; Yeager \& Dweck, 2012). This study will present the extant research and then implement and evaluate a growth mindset intervention at the two MUPS schools. This chapter will establish the need for this study through a review of the key academic performance variables, urban high school realities, and growth mindset interventions.

\section{Race, Socioeconomic Status, and Academic Performance}

Race and socioeconomic status (SES) are two demographic factors commonly used when studying academic performance. In urban environments, students of color (particularly Black students) and those living in poverty are often identified as disadvantaged when compared to a White, middle class norm reference group (Farrington et al., 2012). This disadvantaged label is applied to students without a deeper examination of the factors that are correlated with poverty, such as school quality, family systems and developmental history (Farrington et al., 2012; Layton, 2015). The number of students living in poverty is greater than it has been in the last 50 years in the U.S. (Layton, 2015). A recent study (Sorhagen, 2012) found that teachers' perceptions of students' academic ability in earlier grades influence students' high school grade point averages (GPAs), and that students from low-income families are more negatively perceived than their higherincome peers. In schools where student populations tend to be low SES and minority, the teachers' and principals' expectations of students tend to be low, and vice versa; this expectation is internalized by students, and the low expectation becomes a self-fulfilling prophecy for all (Reddick, Welton, Alsandor, Denyszyn, \& Platt, 2011). The academic challenge is exacerbated at urban schools with large minority enrollment, where teacher 
attrition rates are more than twice as high as schools with lower minority enrollment (Yendol-Hoppey, Jacobs, \& Dana, 2009).

Students from minority groups have to deflect negative stereotypes at school, in the media, and in the community (Reddick et al., 2011). These challenges affect students at all levels of academic ability at high poverty, high minority schools. Black and Latino students are underrepresented in honors classes, which makes it less likely they will have had the rigor essential to a strong foundation for college (Reddick et al., 2011). Minority students with special needs in high-poverty urban schools are disproportionately segregated from their general-education peers (DeMatthews \& Mawhinney, 2013). The negative impact of combined low SES and high minority populations makes improving academic performance a bigger task at urban schools than it is at non-urban counterparts. These issues impact academic performance and will be covered at greater length in chapter 2 .

The terms academic ability and academic performance are often conflated, yet the distinction between the two is important when thinking about student performance. Academic ability suggests a student's potential to perform, whereas academic performance describes the outcome, or how one has actually performed. When thinking about achievement gaps between advantaged and disadvantaged students, this distinction is particularly important because achievement is often attributed to a student's perceived academic ability without considering the myriad contextual factors at play (e.g., poverty, family systems, school environments). Based on a review of the literature, this study will use the term academic performance when referring to the construct related to academic 
growth. As discussed in this section, race and SES are correlated with academic performance in urban high schools in the United States.

\section{Urban High Schools}

One of the most critical factors in improving student retention is attendance (Farrington et al., 2012). Poor school attendance rates exacerbate poor academic performance in urban settings (Farrington et al., 2012). A review of the literature on attendance and academic performance reveals numerous studies reporting a strong positive correlation between attendance and GPA (Allensworth, Gwynne, Moore, \& de La Torre, 2014; Gump, 2005; Morrisey, Hutchison, \& Winsler, 2014; Strickland, 1998). Urban high schools contend with population stability issues more than the non-urban schools; this is due not just to students transferring out of a district but also to students transferring between charter schools and district schools in the same city (Center for Research on Education Outcomes [CREDO], 2015). Factors affecting students from disadvantaged backgrounds, such as low SES, low parent education levels, and being from a traditional educational minority as well as the difficult ninth grade transition experienced by most students are more negatively experienced in urban schools as compared to non-urban schools (Farrington et al., 2012). Seemingly basic things like getting enough sleep, getting to school, and not being distracted by hunger are often daily challenges for many urban students.

Absences can contribute to gaps in learning and poor course grades due to missed assignments, and they can also be an indicator of other life problems interfering with student learning (Farrington et al., 2012). These academic challenges have been the focus

of initiatives on both the district and national level, as reported in the following sections. 


\section{Educational Initiatives on the National Level}

A report published in 1983, called A Nation at Risk, is often seen as a touchstone for the current wave of educational reform and the dominant narrative concerning urban schools and academic performance (Hughes \& Byers, 2010). This report called for higher standards in public education. Subsequently, then-President Ronald Reagan mandated the use of standardized test scores to analyze school performance and requiring improvements in test scores in order for schools to maintain federal aid eligibility (Hughes \& Byers, 2010). Effort continues to be made to improve the educational outcomes in urban areas, including school choice initiatives (Resseger, 2014; Strauss, 2014), the introduction of the Common Core standards (Strauss, 2014), the School Improvement Grant (SIG) program supported by the U. S. Department of Education (Peck \& Reitzug, 2014; Strott, 2013), and funding from large private sources (Umphrey, 2011). Despite these efforts, key measures like graduation rate continue to be lower for students in urban areas than their non-urban counterparts (NCES, 2015a; Swanson, 2009).

In 2009, school turnaround policy was introduced, providing four strategies targeting the lowest performing schools in the country. The policy provided School Improvement Grants (SIG) to failing schools; these turnaround initiatives "confront urban school practitioners with a series of paradoxes that simultaneously suggest the possible promise and potential pitfalls of the reform (Peck \& Reitzug, 2014, p. 15).” The model was borrowed from the corporate world, where it had limited success; despite this limited success, turnaround proponents expected dramatic and immediate results, which put tremendous pressure on schools. In a study cited by Peck and Reitzug (2014), of 1,098 
schools that attempted improvement, 262 were able to significantly improve within one academic year, but of those, only 12 were able to maintain that improved level for more than one additional academic year. These outcomes are not surprising. Peck and Reitzug write of the need for slow, sustained change, citing evidence that the model for turnaround came from the business world and that successful turnarounds in that environment typically take three to seven years. The researchers advocate that teachers need to be positively motivated rather than punitively demotivated. Additionally, teachers who cause harm to students should be removed so they do not have a negative impact on the already-delicate system (Peck \& Reitzug, 2014).

Educational reform takes time to allow for positive change to occur and commitment to "stick with a plan", whether the initiative is occurring on the federal level or the district level. SIGs provided the funding for sustained change on the district level; remedies addressing the problems of retention and academic performance on the district level are reviewed in the next section.

\section{Educational Initiatives at the District Level}

For the MUPS district examined in this study, enrollment reached an all-time high of 115,543 students in the 1967-1968 school year and has declined since to the current level of 27,000 students, with another 8,100 city students enrolled in public charter schools (Crouch, 2014). In 2007 the MUPS district lost its accreditation due to poor academic performance, financial stability issues, and leadership turmoil (Bock, 2012). The current superintendent has been at the helm since 2008 (Crouch, 2014). And in 2012 MUPS earned provisional accreditation (Bock, 2012). Since then the superintendent and 
the mayor, who supported the opening of 18 charter schools in the city since 2007 , are working together to improve educational outcomes for all city students (Crouch, 2014).

MUPS faces the same challenges as urban school districts throughout the country: poverty, lower test scores, lower graduation rates, and lower rates of matriculation to college than state averages (MCDS, 2015a, b). Increasing competition from charter schools has added to the challenges of improving student performance (O'Neil, 2015) and working to regain state accreditation (Crouch, 2014). A review of the data on the performance of charter schools for school years 2006-2007 to 2011-2012 collected by CREDO (2015) shows that students at charter schools in this city on average score no better than those at the MUPS schools. Despite this data, the proliferation of charter schools continues, further stressing the financial and resource allocations for MUPS schools and students.

Eleven schools in the MUPS district have participated in the SIG restructuring program (Strott, 2012). One of those eleven is a comprehensive high school (CHS) that was to be one of the schools in this growth mindset intervention study. Starting in 2010 school administrators focused on discipline, attendance, leadership training, and data tools, which were areas cited as pivotal to bringing about change (Strott, 2012). One year into the program, CHS had less discipline referrals, improved attendance, and math and reading achievement increases of $15 \%$ (Stott, 2012). That same year, the graduation rate at CHS jumped from 49.8 to $60.6 \%$, but then dropped to $54.0 \%$ in 2012 and $43.6 \%$ in 2013 , which was below the graduation percentage of $47.6 \%$ in 2009 , before the infusion of SIG support (MCDS, 2015b). 
The MUPS state-appointed school board introduced an initiative called Transformation Plan in spring of 2014; Transformation 2.0 was introduced a year later, in spring of 2015 (Lloyd, 2015.) The Transformation Plan created 11 Superintendent Zone schools to receive heightened focus from the superintendent and additional resources for improvement, and Transformation 2.0 added another 16 schools; the combined 27 schools were called Support Schools, and though all were identified as being in need of extra attention, only the Zone schools would receive extra funding and staffing (Lloyd, 2015). Part of the Transformation 2.0 plan is for CHS, which was originally to be the traditional high school included in this study, to transition from a comprehensive high school that accepts all students to an international business and coding magnet school to which students must apply and be accepted (Lloyd, 2015). CHS will not be the focus of this study, but its recent history is illustrative of the effect of SIG on urban schools. MUPS has remained committed to improving the academic landscape across the district by working to address the problems of academic performance and retention at CHS and other schools in the district. Along with more traditional approaches, there may be some value and benefit to including non-cognitive interventions.

\section{Growth Mindset Interventions}

The acute attention of academic leaders on academic scores has caused many schools to focus narrowly on content, trying to reach their Annual Yearly Progress (AYP) test score measures while ignoring non-cognitive social and executive skill development (Farrington et al., 2012; Fullan, 2009; Lemberger \& Clemens, 2012). One of these noncognitive skills, referred to as mindset, has been shown to improve academic performance (Blackwell et al., 2007; Dweck, 2006; Paunesku, 2013). Per mindset theory, 
a person may either possess a fixed mindset or a growth mindset (Dweck, 2006). Mindset theory is grounded in implicit theory, which are beliefs one develops to explain his or her place in the world (Dweck, 1999, 2006). Someone with a growth mindset subscribes to an incremental theory of intelligence and believes he or she can increase his or her knowledge and ability and that traits are malleable. Someone with a fixed mindset subscribes to an entity theory of intelligence and believes traits are permanent, unchangeable, and what one possesses at birth is all one will have for life (Dweck, 1999; Yeager \& Dweck, 2012). According to entity theory, a person with a fixed mindset is performance-oriented, concerned with appearing smart, and focused on grades rather than knowledge. A person with a growth mindset is mastery-oriented, open to difficult challenges, and is focused on effort and process. Table 1 contains a comparison of the incremental and entity theories.

One example of a growth mindset intervention teaches students how the brain learns, describes a student who has had academic struggles and through effort has improved, and then asks students to write a letter of encouragement to a future student, incorporating what they have learned about how the brain grows and how to be academically successful. Based on empirical evidence, growth mindset interventions have been effective in helping college students improve their college GPA .21 units (Aronson, Fried, \& Good, 2002), helping middle school students' improve math achievement by .30 grade points (Blackwell et al., 2007; Yeager \& Dweck, 2012), and in cutting community college students' drop-out rate in half from $20 \%$ to $9 \%$ (Paunesku, Yeager, Romero \& Walton, in Tough, 2014). In another study, students highly at-risk of dropping out, defined as having a 2.0 or lower GPA, showed the greatest benefit from the 
growth mindset intervention than the other participants: overall the probability of graduating improved by an average $0.6 \%$, but for the students with GPAs of 2.0 and lower, the probability of graduating improved by $3.5 \%$ (Paunesku, 2013).

Studies have shown that students praised for their effort (a growth mindset trait) will take on more difficult challenges and have a mastery focus (Dweck, 2007b; Mueller \& Dweck, 1998; Skipper \& Douglas, 2012). Students praised for their intelligence (a fixed mindset approach) have a performance focus and are more concerned about their grades and the appearance of being smart, rather than truly learning (Dweck, 2007b; Mueller \& Dweck, 1998; Skipper \& Douglas, 2012).

Implementing a growth mindset intervention at RMHS and THS may provide a missing skill or mindset to help students succeed. If that proves to be the case, the growth mindset intervention will be taught to other district school counselors so that other students in the district may benefit from this potentially powerful paradigm-shifting tool. The purpose of this research study will be to determine if a growth mindset intervention can improve students' academic performance at these two distinct high schools in the same urban district.

\section{Connectedness}

Academic performance and increased academic skills have been shown to be moderated by or related to connectedness in several studies (Lemberger \& Clemens, 2012; Lohmeier \& Lee, 2011; Malecki \& Demaray, 2006). Connectedness in the school setting can be understood as a student's sense of belonging, or being connected to others; in studies, it has been shown to moderate the negative relationship between SES and GPA (Malecki \& Demaray, 2006). For example, through their participation in the free or 
reduced-price school lunch program, students categorized as low income experienced a stronger relationship in their perception of support and their actual academic performance (Malecki \& Demaray, 2006). Sources of connectedness in schools have been identified by Lohmeier and Lee (2011) as teachers/adults and peers. The perceived relationships with and social support of these significant others can have a positive effect on the academic performance of economically disadvantaged students (Malecki \& Demaray, 2006).

The present study will investigate the potential mediating or moderating effect of connectedness on the impact of a growth mindset intervention on academic performance at students at two urban high schools.

\section{Research Problem}

At RMHS, even though the school has been ranked a top public school in the state and the nation by Newsweek (2013), U.S. News and World Report (2014), and Washington Post (2014) for over a decade, the trend is that approximately $30 \%$ or more of the freshman class does not graduate with its cohort from RMHS. An analysis by the school principal revealed that half of the $30 \%$ left the school due to failing a class, and the other $15 \%$ left due to a combination of concern about being able to pass classes $(7 \%)$ or not liking the academic rigor (4\%), and because the family moved (4\%) (W. Moore, personal communication, April 6, 2015). Students at THS are at risk as well. The dropout rate in 2014 was 51\% while the graduation rate was just 54\% (MCDS, 2015a), significantly below the 2005 national average of $70.6 \%$ for all high schools and the $60.9 \%$ average for urban high schools (Swanson, 2009). A more recent graduation 
percentage for national urban high schools was not available; the THS comparison graduation rate for 2005 was $55.8 \%$ (MCDS, 2015b)

The district has implemented different programs aimed at improving students' academic performance and retention rates: Check \& Connect (drop-out prevention program), Response to Intervention (RTI; levels of tiered support determined by each student's needs), Student Intervention Teams (a district practice in response to the overidentification of students qualifying for Individual Education Plans [IEPs]), and Care Teams (school teams consisting at minimum of the school nurse, social worker, and counselor) to support underperforming students. Interventions are often dropped when improved results are not experienced quickly enough or another new initiative shows more promise (or another administration assumes authority). While these programs have improved the overall district attendance rate from $88.7 \%$ to $93 \%$ and the district graduation rate from $54.8 \%$ to $71 \%$ in the last seven years, they do not seem to have had significant impact on another student performance measure, the average ACT score, which in MUPS the average score has varied from 16.0-16.9 for the last nine years, while the state average hovers at 21 (MCDS, 2015a).

Student engagement is key to active participation in the learning process, according to social psychologists Yeager and Walton (2011). They report interventions work best when students do not feel controlled or forced to take action but rather have the opportunity to experience the discovery on their own. Based on the primary researcher's observation and experience at MUPS since 2006, all the initiatives described in the previous paragraph are adult focused, meaning the main initiator and implementer of the change in behavior is the adult. The locus of control must shift to the student, who should 
be encouraged to play an active role for meaningful change to occur. Growth mindset interventions place the locus of control on the individual student. If students can be helped to understand that their academic performance is not a pre-determined entity and that through effort they can change their learning trajectory, it is predicted that student grades will improve, and that this will positively impact retention at both RMHS and THS.

\section{Purpose Statement and Research Questions}

It was stated previously that year after year, RMHS loses one-third of a cohort to attrition while THS graduates just over half a cohort, despite the implementation of various initiatives to address these problems. These are compelling reasons to examine whether a growth mindset intervention might help students change their mindsets and realize they are capable of incremental learning and academic improvement. The purpose of the study will be to determine if a growth mindset intervention can improve the academic performance of high school students at these two schools.

This research will address several questions:

1. What is the impact of a growth mindset intervention on academic performance of students at an

a. academically low-performing urban high school (THS)?

b. academically high-performing urban high school (RMHS)?

2. Will students' mindset score change, indicating greater belief in a growth mindset, as a result of the growth mindset intervention?

3. Will attendance rates increase, especially at THS, based on the growth mindset intervention? 
4. Will a student's sense of connectedness mediate the effect of the growth mindset intervention on academic performance, mindset, or attendance?

Based on prior research, the hypotheses are:

1. Students in the treatment groups at RMHS and THS will have larger increases in their core GPAs scores than students in the control groups.

2. Students' mindset scores will shift to indicate adoption of a stronger growth mindset belief than they had before the growth mindset intervention.

3. THS is expected to have an increase in attendance as a result of this growth mindset intervention and it is expected to be larger than the attendance increase at RMHS.

\section{Delimitations}

Because this researcher is a counselor at RMHS, the possibility exists that the primary researcher will unintentionally confound the results because of pre-existing relationships with students participating in the study (the primary researcher is the school counselor for every one of them). The lack of an a priori relationship with the participants at THS could have a negative impact on the results as there is not yet a relationship built on trust. Also the primary researcher is White and the majority of the students at THS are Black. The three THS counselors, with whom the primary researcher has good relationships, are Black. One of them will assist with the groups, with the expectation that the THS students will see that the counselors have mutual respect and trust for each other which should help the students develop trust in the researcher as well. 
Another delimitation is there are many community-based agencies and numerous district and school initiatives to assist underperforming students. It is likely at both schools that the students in the treatment and control groups will be exposed to these other initiatives, and while it would be ideal to be able to control for those, that is not realistic.

Finally, these two schools were selected for this study to be able to compare the outcomes of schools at opposite ends of the spectrum, the rationale being if only RMHS participated, the outcome would not be generalizable to all the other high schools in the district, but if THS was included the results had a greater likelihood of applying to all schools in the district.

\section{Significance of the Study}

Poor retention rates are damaging - not just to schools, but to society at large and to individuals as well (OECD, 2014). If this study can yield the incremental academic improvements seen in prior research (Aronson et al., 2002; Blackwell et al., 2007; Paunesku et al. in Tough, 2014; Yeager in Tough, 2014) then growth mindset interventions could produce a meaningful change each student needs to experience in order to develop agency and to have a significant impact on his or her life, on the school, and ultimately on the community.

At RMHS, failing three or more semester classes renders a student ineligible to return the following school year (Student Handbook, 2015). It is perceived as a big accomplishment to be admitted to this top-rated school. Like college, though, "getting in" is not enough; one must work to retain his or her seat. For almost all of the students who are not eligible to return to RMHS, there are negative emotions associated with this 
outcome: disappointing family, disappointing self, questioning one's former status as a "smart" student, leaving friends, and leaving a safe environment. These negative emotions are not limited to just the student and his or her family. Friends and classmates, as well as educators, often have a difficult time dealing with the consequential departure of a student. Depending on the dynamics from year to year, it can impact the school culture as well. Course failures at RMHS are due primarily to one of two reasons: lack of academic preparedness or lack of work ethic (or a combination of the two). Whether it is due to lack of academic preparedness or not being willing to put in the work required to graduate from RMHS, teaching students at-risk of failing that they can grow their intelligence could improve academic performance and retention at RMHS.

Lack of academic preparedness affects retention at THS but, unlike RMHS, the problem of poor academic skills at THS is compounded by combinations of the following, according to a school counselor who has been at THS since 2008: education not being a priority for some THS families, lack of family support, single parent homes, low family income, and teacher turnover (A. Mallory, personal communication, October 9, 2015). In addition to not entering high school prepared, absences due to illness or to teen pregnancy, being in juvenile detention, or moving from one foster family to another all cause students to fall behind in credits and make it almost impossible to graduate on time, which leads some students to drop out (A. Mallory, personal communication, October 9, 2015). Mallory observes that students who experience a connection with school, whether it is social or survival (to eat), utilize the MUPS online credit-recovery program, which allows students to make up credit for failed classes, more than students who do not seem to have a connection. The flexible online credit recovery program has 
helped increase the retention and graduation rates, but there are still students who drop out because they cannot form connections with others, need to work, or do not like school (A. Mallory, personal communication, October 9, 2015). Developing a method to engage these students is critical. Helping them realize that through effort they can grow their intelligence may be part of the solution.

Students earning higher grades should lead to more students passing classes, which should improve the retention and graduation rate at both RMHS and THS. Improved academic performance should allow more MUPS students to attend and be successful in college, qualify for scholarship or grant money, increase their earning potential, improve their chances of being self-sufficient, and reduce the likelihood they will be a burden on society.

The purported power of the growth mindset intervention is that is puts the control in the students' hands. The change happens within them; it is a paradigm shift that causes them to believe in their own ability. The empirical evidence shows that growth mindset interventions work. From the .30 grade point increase of several hundred seventh grade math students in the studies of Blackwell et al. in 2007 to the brief online interventions' $50 \%$ reduction in the dropout rate of developmental math community college students (Paunesku et al. in Tough, 2014), growth mindset interventions have improved students' academic performance. Additionally, results from three studies utilizing growth mindset interventions saw $8 \%$ less course failure in high school students over the control, $13.3 \%$ greater increase in course completion for remedial math community college students than control, and 3\% more concept retention in Khan Academy students than the control (Paunesku, 2013). These outcomes demonstrate compelling reasons to provide a growth 
mindset intervention to RMHS and THS students at risk of failing courses or dropping out of school.

A bonus benefit to participants is this change in mindset is not limited to impacting only intelligence. The implicit theory work has been applied to other domains, such as morality and personality (Dweck, 1999). If a person has an incremental theory of personality and she was introverted as a child, rather than believing she will always be uncomfortable in social situations she will believe that if she tries to be more social by talking with one person at a party and then another at a school event, that with effort, overtime, she will become less introverted.

The significance of this study is that it is comparing two distinctly different high schools from within the same district. THS is a low-performing, highly disadvantaged school and RMHS is a high-performing, advantaged school, both in MUPS. The current body of literature is void of this type of study. Evaluating students' academic performance responses to the growth mindset intervention and the impact on attendance in the two distinct schools under the same district leadership and environmental conditions will provide additional insight not currently available.

Furthermore, the fact that this study is being conducted by a full-time high school counselor fills another void in the research literature. There is no work up to this point conducted by a practitioner actively working in a school as a school counselor. School counselors are expected to help students develop skills to succeed in school and in life (American School Counselor Association, ASCA, 2012). The development of these skills is articulated in the ASCA National Model (social-emotional, academic, and career). The theoretical concepts are being sifted through the eyes of a trained professional who is 
working with students and significant others on a daily basis. The theoretical concepts will be applied to the field and direct counseling practice will be influenced. This new knowledge will enhance the understanding of students' situations and will inform discussions with them, their parents, teachers, and administration as well as counseling colleagues in the MUPS district and beyond.

\section{Summary}

Improving academic performance and increasing the number of students who pass classes and graduate on time is needed on an individual student level, school level, and societal level. The data shows this need at MUPS. This study will focus on utilizing a growth mindset intervention to impact academic performance by changing mindsets of students at two academically and demographically distinct high schools within the same urban district. The goal will be to evaluate whether this brief intervention can improve student grades and retention, and if the outcomes are especially beneficial to students who are disadvantaged and/or from a minority group. 


\section{CHAPTER 2}

\section{REVIEW OF LITERATURE}

Motivation and mindset as they relate to academic performance have been studied for more than three decades. Social psychologist Carol Dweck has been a lead researcher on mindset theory and has collaborated with many others to understand the correlation between mindset and academic performance. The purpose of this literature review is to examine the research related to growth mindset, uncover any gaps, and demonstrate how this study will extend knowledge by applying mindset theory to academic performance in urban high school settings.

The database search for relevant books and articles was conducted through Academic Search Complete, ERIC, and PsychINFO. The keywords "mindset," "growth mindset," "implicit theory," and "theories of intelligence" were all used for the search query to ensure any related study was captured. "Academic performance," "high school," and "grades" were used to focus and qualify the selected literature.

\section{Academic Performance}

A review of the literature reveals multiple ways to evaluate academic performance. The concept of academic performance can be applied to countries (Fullan, 2009; Hughes \& Byers, 2010; Organization for Economic Cooperation and Development, 2014; Strauss, 2012), states (Fullan, 2009; National Center for Education Statistics [NCES], 2015b), districts (Fullan, 2009), schools (Hughes \& Byers, 2010) and individuals (Sorhagen, 2013). A review of the literature reveals differences in operationalization of the construct across and within articles. For example, researcher An (2013) identifies academic performance as a student's first year grade point average 
(GPA). While Sawyer (2013) referred to academic performance in his abstract, he never mentions academic performance in the body of his article, only academic success, which he defined as first-year college GPA and retention through the first year. Sorhagen (2013) did not define or quantify the term "academic performance" and interchanges it with other terms, such as "student achievement," "academic achievement," "school performance," "student ability," and "academic ability." Like Sawyer, researchers Morgan, Leenman, Todd, and Weeden (2013) referred to academic performance minimally, once in the abstract and once in the body, using multiple terms to refer to the same construct. Like Sorhagen (2013), they do not quantify performance in their study.

In a study by the Project for Education Research that Scale group (PERTS), academic performance is defined as GPA for core-four content subjects: mathematics, science, communication arts, and social studies (Paunesku, 2013). The PERTS team focuses on core-subject grades due to the challenging nature of these courses and their importance relative to post-secondary success, which renders these core subjects in crucial need of the purported benefits of mindset interventions (Paunesku, 2013).

In their review of the literature on the impact of non-cognitive factors on teaching adolescents to learn, Farrington et al. (2012) identified multiple methods of measuring academic performance. From their study they concluded that high school GPA is more reliable at predicting high school and college graduation than ACT or SAT scores. They cited numerous studies showing that elementary and middle school grades are much better indicators of high school grades than standardized tests and that high school grades are much better predictors of persistence and graduation from college than class rank, college entrance exams, and family background (Farrington et al., 2012). They stated that 
it is logical that students who attend class and complete the assignments have developed the work habits required of being successful in the future.

In this dissertation, academic performance will be operationalized as it is in the PERTS study: GPA for the core-four content subjects. The use of GPA to quantify this construct is supported by the findings of Farrington et al. (2012). Academic performance captures one's actual accomplishment (or lack thereof) whereas academic ability reflects one's potential, what one is capable of at some point in the future. Based on the inconsistent and sometimes confusing or ambiguous use of the terms to describe the construct of academic performance in the literature, only the term "academic performance" will be used in this dissertation to describe this phenomenon. The term academic performance will focus strictly on what a student has achieved, not the potential of what one could earn.

\section{Academic Improvement Initiatives}

In the United States, state and national governments and organizations have attempted to improve academic performance of students and schools for years, with the bulk of the responsibility for educating citizens belonging to the states rather than to federal government (US DOE, 2005). Although the U.S. education system is

decentralized, in recent years the federal government has become more involved (US DOE, 2005). Just as VanOverbeke (2009) identified the purpose of high school as preparing students for life, so too did educational historian, New York University professor, and former US DOE employee Diane Ravitch (Umphrey, 2011). Ravitch argued a public education should prepare students to be able to make wise decisions for themselves, experience personal development, be good citizens, and make good use of 
their free time, but unfortunately, the focus of high school has narrowed to preparing students for college, whether or not it suits them (Umphrey, 2011).

Regardless of the goal of a high school education, the push continues to improve academic performance of students, with initiatives and policy changes on the national and district level. The next sections provide examples of each.

\section{National level initiatives.}

In 2006, business and governmental leaders focused on the need to improve science, technology, engineering, and mathematics (STEM) education to make the U.S. more globally competitive (Hughes \& Byers, 2010). As a result, the Common Core State Standards Initiative commenced in 2009. Governors and state education commissioners from 48 states worked to prepare all U.S. students for college, career, and life (Hughes \& Byers, 2010; National Governors Association Center/CCSSO, 2010). Accountability on these national initiatives in a decentralized education system becomes more complex when funding is provided by private sources. Because states are responsible for the education of their citizens, by law the Common Core standards cannot be funded at the federal level by the US DOE, giving organizations like the Gates Foundation, which provided \$200 million, leverage to promote their perspective of educational reform (Strauss, 2014). Similarly, Ravitch asserts that the Broad Foundation trained numerous urban district superintendents who seemed to subscribe to the belief that failing public schools should be replaced by privately-managed schools (Umphrey, 2011).

The Obama administration's School Improvement Grant program (SIG; 2009) sharpened the focus on accountability with the requirement that in order to share in SIG 
funds, persistently low-performing schools were required to implement one of four approaches:

- Turnaround model: replacing the principal, at least $50 \%$ of the staff, and implementing a new instructional program;

- Restart model: closing the school and restarting it as a charter school;

- School closure: closing the school and redistributing its students to other more highly achieving schools;

- Transformational model: transforming the school by replacing the principal and implementing comprehensive reforms (Peck \& Reitzug, 2014, p. 10). The concept of turnaround was borrowed from the business world, where the results have been mixed; early indications of the outcomes of the turnaround model in education were no better. According to Peck and Reitzug (2014), numerous empirical studies showed little evidence of large-scale school turnaround initiatives positively impacting students' academic performance. While the promise of school turnaround reform was attractive, too many deeply entrenched societal factors needed to be addressed that were often not part of the reform strategy equation: awareness and understanding of the developmental stages students experience and how these stages impact learning; recognizing the students as unique beings with social-emotional needs rather than as "baseline laborers" (p. 25) creating a product (test scores); the cultural incongruence of the traditional White middle class practices versus the cultural norms of students from low-income backgrounds and students of color; and the lack of inclusion of parents, despite research that showed parents to be essential in school success (Peck \& Reitzug, 2014). 
Race to the Top (RTT) was another initiative of the Obama administration, providing competitive grants to states and districts interested in making comprehensive reforms in one of four areas: standards and assessments, data, teachers and leaders, and school turnaround (National Center for Education Evaluation, 2014). While there has been criticism of both SIG and RTT, the official impact and evaluation report is scheduled to be released in the winter of 2016 (National Center for Education Evaluation, 2014).

\section{School level interventions.}

While our national leaders strive to improve student learning, educators on the school level are doing so as well. The Student Success Skills (SSS) program was developed in 2003 under the humanistic notion that all students have the ability to succeed (Villares, Lemberger, Brigman, \& Webb, 2011). School counselors lead the fivelesson program intended to develop skills in the following areas: cognition, selfmanagement, social functioning, and attitude; there is also a complementary parent component (Villares et al., 2011). The student skills developed are not in specific content areas; however, these skills support learning and growth in academic areas. Empirical evidence from five studies showed the program had a large effect size of .41 for mathematics and a medium effect size of .17 for reading (Villares et al., 2011).

A similar study was conducted of inner-city African-American elementary students to evaluate the impact of the SSS program on sense of connectedness and selfregulation (Lemberger \& Clemens, 2012). Lemberger and Clemens used guidelines developed by Sink and Stroh in 2006 for school counseling research, where .01 equals small, .06 equals medium, and .14 and higher equals a large effect size (2012). 
Metacognitive skills were reported at a higher level for the treatment group than the control group, with a statistically significant large effect size of .19 (Lemberger \& Clemens, 2012). Self-reported feelings of connectedness were reported at a higher level for the treatment group than the control at a statistically significant and small effect size of .04 . The benefit of self-regulatory skills and improved learning skills relative to academic performance was reported in another study of the SSS program, this time with a largely Hispanic sample in a rural district in the southwest (Lemberger, Selig, Powers, \& Rogers, 2015). Controlling for demographic variables and pretest variances, the effect size in math was .66 and in reading was .53 (Lemberger et al., 2015).

To improve student grades, another set of studies addressed self-regulation and homework completion. Zimmerman, Bonner, and Kovach (1996) developed homework logs as part of a program to help middle and high school teachers instruct students in ways that build foundational skills like self-regulation rather than just concentrating on content skills (Zimmerman et al., 1996). These self-regulation skills are reinforced through the use of homework logs in which students recorded details about their homework practice, including goals, estimated time to complete, distractions, and how well they met their goals (Bembenutty \& White, 2012; Zimmerman et al., 1996). Information recorded in the homework logs can provide insight for teachers, allowing them to provide feedback to students about their homework practice strengths and weaknesses (Ramdass \& Zimmerman, 2011). Bembenutty and White's 2012 experimental research on the use of homework logs by college students reinforced Zimmerman et al.'s findings (1996) with high school students that homework logs promote greater awareness of self-regulation. Additionally, Bembenutty and White 
(2012) reported a positive relationship between final course grades and specific

homework attributes reported on the homework logs: homework performance satisfaction $(\mathrm{r}=.33)$, specific goal setting $(\mathrm{r}=.32)$, and distraction avoidance $(\mathrm{r}=.25)$.

Another educational intervention developed to increase retention, specifically by lowering the dropout rate, is Check \& Connect, which assigns a mentor to work with students and their families, conducts regular formal and informal checks of the student's school progress, implements timely interventions if the student's connection is waning, and partners with families (Stout \& Christenson, 2009). Essential to Check \& Connect is relationship building and the consistent monitoring of the student's engagement through the formal checks of attendance, behavior, and academic performance (Stout \& Christenson, 2009; US DOE, 2007). The U.S. Department of Education's What Works Clearinghouse evaluated 11 evidence-based dropout prevention programs; Check \& Connect was the only one to achieve the highest rating level in the domain of "staying in school" and achieved the second highest rating level in the domain of "progressing in school" in the evaluation of two studies of more than 200 Minneapolis high school students at risk of dropping out (US DOE, 2007).

To determine the effects of the Check \& Connect intervention on students' academic performance, attendance, and behavior a randomized block design was used to assign students to the treatment or control condition (Maynard, Kjellstrand, \& Thompson, 2014). In this study of 260 students in grades six to nine, $89 \%$ of who were Hispanic and $74 \%$ of who were economically disadvantaged, a step-wise hierarchical linear model estimation procedure was used to account for differences in the 14 urban Texas middle and high schools (Maynard et al., 2014). The researchers found significant impacts of 
Check \& Connect on academic performance and discipline, but not attendance.

Limitations of this study included a high attrition rate (27.3\%) that made the researchers unable to complete their intent-to-treat analysis. There may be some bias in the results, although they followed What Works Clearinghouse guidelines to minimize threats to internal validity. These guidelines include utilizing consistent measurements of fidelity across sites and implementers of the intervention; recognizing the possibility that certain relational behaviors may impact students' sense of belonging differently; and acknowledging the reduced length of the study, six months instead of the recommended two years for the Check \& Connect program (Maynard et al., 2014).

\section{Attendance and Academic Performance}

One of the goals of the Check \& Connect program is to improve student attendance (Maynard et al., 2014; Stout \& Christenson, 2009; US DOE, 2007). Attendance has been shown to correlate with academic performance (Allensworth, Gwynne, Moore, \& de La Torre, 2014; Gump, 2005; Morrisey, Hutchison, \& Winsler, 2014; Strickland, 1998). In his review of the literature, Strickland (1998) cited five studies in which attendance positively correlated with grades and noted that parents, peers, family dynamics, and community expectations influence students' attendance and grades. In his own study, Strickland (1998) assessed the relationship between attendance and grades in public high school students in Chicago over a two year period. The results from the first year showed a strong significant positive correlation of .82 between days present and GPA. In the second year of the study Strickland (1998) found a moderately significant positive correlation between attendance and GPA of .49. Similar findings were reported by Allensworth and colleagues in their 2014 study, in which they reported 
eighth grade students with chronic absences (18 days or more) and a low GPA (2.0 or lower) had less than a 50-50 chance in ninth grade of being on track to graduate. According to Allensworth et al. (2014), "Absences not only lead students to struggle to pass their classes, but they also prevent students with strong academic skills from earning high grades" (p. 8). In their study about the relationship between low income, attendance and academic performance in 35,000 Florida public school students from kindergarten through fourth grade, Morrisey and colleagues (2014) showed in their regression analysis that as the number of days absent increased there was a growing negative correlation with grades, from -..11 for 2-4 days absent to -.56 for 18 or more days absent for random effects and from - .80 to -.30 for within-child fixed effects. In a study of 300 undergraduates at a large state university in the Midwest, Gump (2005) reported findings of a negative correlation of -.60 between number of absences and final course grade. Gump (2005) cautioned that absences are a contributing factor and not the only variable leading to poor grades. As Morrisey et al. (2014) noted, low income is another factor impacting grades; these factors have a significant presence in urban school settings.

\section{Urban Schools}

"Your search for the average ACT for urban schools is complicated (probably fatally) by the lack of a consensus about what is an urban district" (T. Jones, personal communication, April 4, 2015). This quote from a public administration professor is accurate with respect to attempts to find data on urban districts, as the state's department of higher education, MCDS, Google, the ACT website, and NCES reports did not yield data for the average ACT score for urban schools in the U. S. A researcher at the NCES 
could not provide a single metric but rather links to many data files, to be used once it was decided how "urban district" would be defined.

In their study of urban charter schools the Center for Research on Education Outcomes (CREDO, 2015) researchers wrote about the difficulty to define and then adhere to a consistent definition of what constitutes an "urban school." Their rigorous evaluation considered population stability (low versus high mobility), permeability (allowing for selection from suburban schools versus only other urban schools) and geography (compressed versus dispersed). Their approach to deal with these issues was so specific and complex it was presented in the Technical Appendix (CREDO, 2015). In reporting the data on urban schools in this dissertation, if a definition of the "urban" area under study has been defined that definition will be stated; otherwise, "urban" will denote a densely populated geographic area whose population is typically disadvantaged in the areas of income and race.

\section{National Challenges}

Beyond the challenge of defining the concept of urban school or district is the plethora of challenges these schools face. Many urban schools and districts in the U.S. face a shrinking tax base, high student mobility, students who are disadvantaged, buildings that are aging, overcrowded classrooms, pressure for better test scores, and inexperienced or poorly qualified teachers (Yendol-Hoppey, Jacobs, \& Dana, 2009). Embedded in the U.S. government promise to educate all is the assurance that every student will have access to well-trained staff, appropriately challenging curricula, and sufficient resources (Umphrey, 2011; Webber et al., 2014). However, according to Fullan (2009), "perversely in the [U.S. education] system, incentives work to the effect that the 
least experienced teachers and principals work in the worst schools" (p. 110). The Recovery Act of 2009 addressed this with one of its program requirements that there be: "equitable distribution of teachers and principals...to ensure that students in high-poverty and/or high-minority schools have equitable access to highly effective teachers and principals and are not served by ineffective teachers and principals at higher rates than other students" (Webber et al., 2014, B-12). This is a critical goal, yet teacher attrition at high-minority schools is double the rate of attrition at schools with lower minority enrollment (Yendol-Hoppey, Jacobs, \& Dana, 2009), suggesting there is still much work to be done to provide equitable resources to all.

Related to the issue of effective teachers and principals is the complex issue of the small versus comprehensive school. The issue is complex because small schools have not been proven to outperform comprehensive public schools yet cities like New York, Boston, and Philadelphia continue to promote small schools and charter schools (Resseger, 2014; Strauss, 2014). For example, the Gates Foundation, which had endorsed small schools, acknowledged in 2009 that attending a small school did not significantly improve test scores (Resseger, 2014). The issue is complex because when their neighborhood school closes, students who do not apply to choice schools are transferred to other large schools, and typically these students are low-performing students whose difficulties may include learning disabilities or language barriers; these students ultimately increase the percentage of students with additional needs in the school (Resseger, 2014). Unfortunately, urban schools often fail to appropriately serve their special needs students (DeMatthews \& Mawhinney, 2013), whether by providing inadequately trained teachers or failing to meet Individual Education Plan (IEP) goals and 
accommodations; this is despite the historical federal government practice of providing additional funding to schools and districts serving students living in poverty or struggling with learning disabilities (Umphrey, 2011). Ravitch noted the privatization of schools, enthusiastically supported by politicians and investors alike, had not promoted evidencebased good practice (Strauss, 2014; Umphrey, 2011). Charter schools were touted as the answer to the problem of poor academic performance yet the data did not support this claim and charters were incentivized to be selective about whom they educated, often rejecting the very students they were intended to serve (CREDO, 2015; Umphrey, 2011).

Students in urban districts faced many more obstacles to high school graduation and continuing post-secondary education than their non-urban peers, as the following data demonstrate. The graduation rate for urban high schools in the U.S. for the class of 2005 was 60.9 versus 70.6 for the entire U.S. (Swanson, 2009). For the school year ending in 2010 , the graduation rate for city schools was 71.1 versus 77.8 for the entire U.S. for reporting states (U.S. DOE: NCES, 2011). The online data explorer of National Assessment of Educational Progress (NAEP) contained composite scores; Table 2 captured 2009 scores for disadvantaged and advantaged groups for $12^{\text {th }}$ grade students in the subjects of mathematics and science (NCES, 2015b). For every variable categorized as disadvantaged the scores were significantly lower: students with IEPs, students eligible for Free or Reduced Lunch (FRL), parents with lower educational levels, students from traditional educational racial minorities, and students from cities (NCES, 2015b).

Studies showed that students from low-income, minority, and inner-city backgrounds have more difficulty than their more affluent peers in several tasks, including graduating from high school, scoring high on college admissions tests, 
matriculating to post-secondary school and, if they do, graduating from post-secondary school. In college, these urban students need more remediation, according to a 2001 Midwestern-state Department of Higher Education (MDHE) report on achievement gap elimination, as well as findings by other researchers (Reddick, Welton, Alsandor, Denyszyn, \& Platt, 2011).

Many initiatives exist and much funding has been allocated to close the achievement gap shown by the preceding data. On the national level, large private funding sources like the Walton Family Foundation, the Gates Foundation, and the Broad Foundation have been investing millions of dollars to improve education in the United States (Umphrey, 2011). All three, according to Ravitch, supported merit pay, questionable evaluation schemes, privatization, school choice, and market-based rather than evidence-based policies (Umphrey, 2011). An example of a controversial evaluation scheme was the Common Core standards, which on the surface sounded like an honorable cause but upon closer inspection revealed little transparency and no educator participation. The Common Core standards are not developmentally appropriate for the lower grades, do not avail themselves to teacher input for incorrect items, and require online testing which unfairly biases the results. Specifically the results are biased against the students from low SES homes and requires under-resourced schools to cut already stretched and stressed staff to pay for computers to complete testing (Strauss, 2014).

\section{Two Texas Cases}

A large Houston, Texas school district was scrutinized after a decade of claims that they were the model No Child Left Behind (NCLB) success story, asserting that accountability and high stakes testing supported claims of miraculous improvement 
(Vasquez-Heilig, 2011). Through his in-depth research, Vasquez-Heilig proved what many in the popular media charged: that the "Texas Miracle" was a myth. In this highpressured educational period, student data was misrepresented and some students "disappeared." Rather than the reported 54\% to $75 \%$ increase in the graduation rate from 1997 to 2002, Vasquez-Heilig (2014) found the rate of urban minority cohorts progressing to senior year actually dropped from $43 \%$ to $37 \%$ for this period. This demonstrates the real pressure on urban districts to improve and the lengths some are willing to go to in order to appear they are making the required progress.

Another Texas study assessed high minority, high poverty (HMHP) students who, despite their own success in college, had to contend with lingering negative assumptions about their high school, their urban area, and themselves (Reddick et al., 2011). Negative stereotypes from teachers, parents, classmates and community members plagued these students who had the additional burden of having to prove themselves worthy, which their classmates from more advantaged schools did not have to contend with (Reddick et al., 2011). The HMHP students dealt with issues of stereotype threat, low expectations from and of teachers and even from themselves at times, and tracking and in-school segregation caused by accelerated and advanced placement courses for which they may not have been prepared by middle school (Reddick et al., 2011). On the other hand, many HMHP students have college access programs like Advancement Via Individual Determination (AVID), Project ADVANCE, GEAR UP, as well as parental involvement and support, community support, and role models to provide the positive influences needed to help these students from urban schools succeed in college (Reddick et al., 
2011). This qualitative Texas study shows that despite the societal challenges, there can still be success stories for HMHP students.

\section{District Challenges}

Many of the same challenges that face urban school districts nationally affect the MUPS district. Poverty in the schools and community correlates with lower test scores, lower graduation rates, and lower college attendance than the state averages (MCDS, 2015a, b). Factors observed within MUPS include less state funding/shrinking budgets, higher percentage of students in transition and more mobility, aging buildings, poorly qualified teachers, and frozen wages for the last seven years, all of which create additional burdens on a system that continues to struggle to support its students.

Charter schools have broadened the options for families in this Midwestern city, with the first charter school opening in 2000 (O'Neil, 2015), and complicating the business of MUPS. The promise of charter schools was that they would increase the quality of education, in part because of the freedom from policies that control public education and also because they would present healthy competition to the city public schools. However, a study comparing 41 regions in 22 states conducted by Stanford University for the school years 2006/07-2011/12 shows that most of the charter schools in this city on average are no better than the MUPS schools (CREDO, 2015). See Table 3 for a total and subpopulation comparison of this Midwestern city to all regions. In a comparison of mathematics scores, overall $24 \%$ of the regions were worse, $33 \%$ the same, and $43 \%$ were better with the existence of charter schools; the percentages for this Midwestern city were $42 \%$ worse, $32 \%$ same, and $26 \%$ better (CREDO, 2015). In a comparison of reading scores, overall $16 \%$ of the regions were worse, $46 \%$ the same, and 
$38 \%$ were better with the existence of charter schools; the percentages for the city were $17 \%$ worse, $50 \%$ same and $33 \%$ better (CREDO, 2015). The impact of charter schools is more positive for reading in this region, but overall, the data shows that the positive effect on academic performance in math and reading is negligible.

As discussed in the previous section about National Challenges, the small school issue may be a problem on the district level as well. MUPS itself has changed its school setting approach from large comprehensive neighborhood schools to smaller magnet or choice schools - competing with itself in a similar fashion to the charter schools by offering a focused education for which students must apply. While a smaller school environment encourages a closer community and greater chances of connectedness, the smaller setting uses resources less efficiently and often support staff must be shared (for example, a small school may have a nurse for only two and a half days a week, and a social worker for one day a week), and course offerings are more limited than larger schools. The latest small school additions offer a curriculum that focuses on medicine and bioscience and on international finance and business (Marks, 2015).

\section{Students Who Are Disadvantaged}

As discussed above, the factors more prevalent in urban environments often leave students in urban schools at a disadvantage. It is essential that school reform initiatives meet students where they are, which means reformers, educators, and researchers need to understand the whole problem and not just focus on the test scores. Students' realities are impacted by their families' socioeconomic status, their parents' education level, whether they receive special education services (for needs from learning disabilities to physical disabilities to being gifted), the education system, global competition, career planning (or 
lack thereof), socio-emotional needs (including mental health, racial, and gender issues), self-control (and the related self-discipline, self-regulation, self-efficacy, and selfesteem), developmental maturity, motivation, and, in the last decade, social-media distractions (Farrington et al., 2012; Layton, 2015). While all of these factors warrant attention, the focus here will be on the challenge of low SES as it correlates with student populations in urban high school settings.

In the U.S., the number of students living in poverty is greater than it has been in the last 50 years (Layton, 2015). "Low income" is defined as the financial reality for those students who qualify for the federal free or reduced lunch (FRL) program (Jones \& Palazzolo, 2009). Citing data collected by the NCES, the Southern Education Foundation (2015) found that in 2013, 51\% of students in public schools qualified for the FRL program. Of the just under 55 million students educated pre-kindergarten through $12^{\text {th }}$ grade in the U.S. in the 2011-2012 school year, 10\% were enrolled in private schools (NCES, 2014) leaving $90 \%$ of the nation's students attending public schools, $51 \%$ of whom qualify for FRL. The seeds of the negative impact of poverty can be planted at an early age. In a prospective longitudinal study, first grade teachers' perceptions of students' ability in math, reading, and language skills were shown to influence students' high school GPAs (Sorhagen, 2012). Students from low-income families were shown to be disproportionately impacted at later ages by under- and over-estimations of their math and language skills by lower grade teachers. Another study showed that poverty impacts academic skill level and indicated that poor students have less support at home, less exposure to enriching activities, are more likely to drop out of high school, and are less likely to attend college than their peers from privileged families (Layton, 2015). 
In addition to poverty, being a student from a disadvantaged minority group increases the challenges (Reddick et al., 2011). Graduating from college, enrolling in college, and earning a college degree are all strongly correlated to race and income (Pathways to College Network, 2007). Students of color in high poverty schools have the additional burden of having to defend themselves and their schools against the negative stereotypes reinforced in the media and the community at large (Reddick et al., 2011). Black and Latino students are underrepresented in advanced placement courses; this inadvertent tracking leads to in-school segregation and keeps minority students from taking the courses essential to preparing them for college (Reddick et al., 2011).

The challenges are even greater for minority students with special needs in urban schools with high poverty; a disproportionate number of these students are segregated from their general-education peers, despite evidence of the benefits of inclusion (DeMatthews \& Mawhinney, 2013). This lack of inclusion, which defies federal mandates, has required supervision by the federal courts to bring these urban schools into compliance with practices to educate poor minority students with special needs (DeMatthews \& Mawhinney, 2013).

The state of urban public schools, the discrepancy in academic performance of advantaged and disadvantaged students, and the variability of outcomes in educational initiatives all point to the need to continue the search to find an intervention to help students succeed academically. The focus of this dissertation will be on public urban high school students. The next section will explore the implicit theory of intelligence and related interventions that have proven effective in helping students change their beliefs regarding their academic ability. 


\section{Implicit Theory to Growth Mindset Interventions}

Implicit theories are self-theories, beliefs individuals develop to explain their world (Dweck, 1999). For more than three decades, social psychologists have been refining the implicit theory of intelligence (Dweck, 1999, Dweck, Chiu, \& Hong, 1995; Mueller \& Dweck, 1998; Nicholls, 1984; Yeager \& Dweck, 2012). Their work revealed that a person may possess either an incremental theory of intelligence, also known as a growth mindset, or an entity theory of intelligence, also known as a fixed mindset. Someone with a growth mindset believes he or she can increase his or her knowledge and ability and is intrinsically motivated. Someone with a fixed mindset believes that intellectual abilities are permanent and unchangeable, and is extrinsically motivated, performing an activity for a grade rather than mastery (Dweck, 1999; Yeager \& Dweck, 2012). Studies have shown that students praised for their effort (a growth mindset approach) will take on more difficult challenges and have a mastery focus (Dweck, 2007b; Mueller \& Dweck, 1998; Skipper \& Douglas, 2012). Students praised for their intelligence (a fixed mindset approach) have a performance focus and are more concerned about their grades and the appearance of being smart rather than truly learning (Dweck, 2007b; Mueller \& Dweck, 1998; Skipper \& Douglas, 2012). This is important information for both educators and parents, as researchers caution this is especially a concern for gifted students who may not pursue more difficult activities for fear of failing and losing the gifted label that had identified them (Dweck, 2007b). Table 1 contains comparisons of incremental and entity theories of intelligence as well as comparisons of learning and performance goals to help clearly distinguish between the dichotomies of each dyad. 


\section{Linking Prior Work to the Development of Implicit Theories.}

Work on the malleability of intelligence was being done long before the last few decades. In her books Dweck $(1999,2006)$ cited the work done by Alfred Binet, creator of the intelligence quotient (IQ) test. When Binet developed an IQ test in the early 1900s he had the same goal as current educators have, which was to identify students who were in need of academic assistance. Binet wanted to help students with poor academic performance in the public school system in Paris; he was not trying to determine how smart these students were. Yet the IQ test is perceived by many to be an assessment of how smart one is. Binet did not perceive of students' intelligence as fixed but rather as a trait that could be enhanced through the right educational curricula, which he hoped to develop (Dweck, 1999, 2006, 2007a; Dweck \& Leggett, 1988). One could say Binet perceived intelligence through a growth mindset lens.

\section{Empirical Evidence}

The development of the implicit theory of intelligence started with researchers' desire to understand student motivation and the behavioral or psychological causes that allowed some students to perform at a high level and retarded the growth of others (Diener \& Dweck, 1978). The following section details the evolution of the implicit theory of intelligence interventions, from helpless- and mastery-group sessions to the current iteration of an online growth mindset intervention.

\section{Helpless and mastery orientation.}

Early research related to mindsets started with studies on helpless- and masteryoriented patterns observed in fifth-grade students by Diener and Dweck in a semirural community in 1978. The first study consisted of 67 students (34 male, 33 female); in the 
second study another 60 fifth-graders (30 male, 30 female) were assessed. Based on responses to the Intellectual Achievement Responsibility (IAR) Scale by Crandall, Katkovsky, and Crandall as cited in Diener and Dweck (1978), answers to 34 positive or negative items were used to place students in a helpless or mastery group, depending on their response to items that attribute failure to a lack of effort. The students were equally skilled at developing the solution strategies and being committed to the activity (Diener \& Dweck, 1978). For these two experiments about the effect of feedback on problemsolving strategies, students were trained specifically on how to problem-solve. In Study 1, students' attributions to failure were analyzed; in Study 2, the types of verbalizations a different group made in response to failure were studied. After solving a series of easy problems, the students were asked to state their thoughts and feelings as they then solved more difficult problems.

Chi-square analysis, correlations, and analysis of variance revealed significant differences between the ways mastery and helpless students respond to failure (Diener \& Dweck, 1978). In study 1 the results from the IAR were confirmed: $52 \%$ of the students categorized as helpless-oriented attributed failure to lack of ability whereas none of the students categorized as mastery-oriented did -- despite equal learning, success experiences, and failure feedback during training for both groups in both studies (Diener \& Dweck, 1978). In Study 2, the mastery-oriented students used solution-focused selftalk like, "the harder it gets the harder I need to try" (p. 459), while the helpless-oriented students would dwell on their failure and attributed it to factors seemingly beyond their control, "I was never good at math" (Diener \& Dweck, 1978). While working on facile problems did not reveal any differences in the two groups, once the problems became 
more difficult, differences emerged. The students with the helpless orientation had negative self-thoughts, blamed uncontrollable factors, and displayed no hope of expecting to be able to solve future problems; they also reported being anxious and bored with the problems, despite being engaged in the process just a few problems earlier (Diener \& Dweck, 1978). Two-thirds of the helpless students (and none of those with masteryorientation) brought up irrelevant self-praise to boost their image, such as talking about how skilled they were at unrelated activities (Diener \& Dweck, 1978). The masteryoriented students maintained a positive outlook, effectively self-instructed and selfmonitored, and developed constructive problem-solving strategies (Diener \& Dweck, 1978). One limitation of the study was there were no real consequences of failure; results may have been different if there had been. Within the mastery-oriented group, there may be a sub-group who, like the helpless-oriented students, perceive failure as a negative judgment of their ability and would persist beyond the point of being effective (Diener \& Dweck, 1978). Clearly the orientation the students held initially influenced their behavior, thoughts, and feelings about the task, with a mastery orientation leading to productive growth-orientation and a helpless orientation inhibiting task completion.

\section{Achievement goals.}

Further development of the understanding of helpless and mastery orientations by Dweck and Elliott (1983) led to the conceptualization of performance goals (focused on proving competence) and learning goals (focused on improving competence), achievement goal orientations that framed how students perceived and responded to situations (Dweck \& Leggett, 1988). Concurrent with Dweck's and others' work on achievement goals, Deci and Ryan were developing their theory of motivation, called 
Self-Determination Theory (SDT; 1985). SDT posits that people have three psychological needs that must be fulfilled to experience life satisfaction: needs for autonomy, affiliation, and achievement. The achievement need identified in SDT is a central focus of implicit theory. Achievement is the need to be competent, to learn new skills, and to master tasks (Deci \& Ryan, 1985). Achievement goals manifest as either performance goals or learning goals (Dweck, 1986). Performance goals are those for which one seeks positive perception or attempts to avoid negative judgment from others of his or her ability (Dweck, 1986); performance goals are also known as ego-involving goals, ability goals, or normative goals (Dweck, 1999).

Students who possess performance goals may care only about measuring their skills, have a helpless response, or avoid valuable learning opportunities out of fear of failure rather than developing the skills (Dweck, 1999). On the flip side, learning goals are thought to cause students to attempt to increase their knowledge and improve their skills (Dweck, 1986); learning goals may promote intrinsic motivation and are also called mastery goals or task-goals. Students who possess learning goals care about developing new strategies and learning new information more than establishing their competence (Dweck, 1999).

Teacher feedback about performance influences students; whether that influence encourages them to work harder is dependent on whether the comment is a reflection on intelligence or effort (Blackwell, Trzesniewski, \& Dweck, 2007; Mueller \& Dweck, 1998). For example, in an experimental study of achievement goals, Mueller and Dweck (1998) tasked a group of fifth graders with solving age-appropriate logic problems. The six studies ranged from 46 to 128 participants from a public school in a Midwestern town 
or two schools in a large city in the Northeast. Based on the group to which they were assigned, students received praise for their solutions to these fairly easy problems as they might from a teacher; those in the intelligence group were told, "You're smart," the neutral group was told "That's a high score," and the effort group was told, "You worked hard" (Mueller \& Dweck, 1998). All the students were then given problems that were more difficult, although they were not told of the difficulty level at any phase of the experiment; all three groups scored poorly on these more difficult problems (Mueller \& Dweck, 1998).

In the next phase of the study students were instructed to select an achievement goal, placing their choice in an envelope to be considered later in the study if time permitted (Mueller \& Dweck, 1998). Three of the achievement goals were performance goals ("problems that aren't too hard, so I don't get many wrong," "problems that are pretty easy, so I'll do well," and "problems that I'm pretty good at, so I can show that I'm smart."). The fourth choice was a learning goal, "problems that I'll learn a lot from, even if I won't look so smart," (Mueller \& Dweck, 1998). This true experimental design employed multiple two-way analyses of variance (ANOVAs), one-way ANOVA, and chi-square analysis to determine the outcome.

The final set of problems was of the same difficulty level as the initial set. Those students praised for their intelligence attempted to solve $30 \%$ less problems than they had solved previously; students praised for their effort attempted more problems and scored higher than they had on the first set of problems (Mueller \& Dweck, 1998). The researchers concluded that students with a performance-goal orientation who had been praised for their intelligence interpreted their struggle with challenging problems to mean 
they were not smart and caused them to lose confidence and motivation. Even on the third set when problems got easier, students subscribing to a performance theory still did poorly while students holding a learning-goal theory continued improving throughout the challenge. When asked to report their scores to unfamiliar peers, almost $40 \%$ of the students holding performance goals lied about their scores, while only $10 \%$ of those with a learning goal orientation lied about their scores.

These experiments illuminate the power of teacher-attributed mindset in a school setting. The mindset of each student prior to the experiment was not assessed, but the impact of external delivery of a mindset regardless of one's own propensity for an entity or an incremental theory can affect a student positively or negatively in the academic arena. Praise for the outcome was shown to affect a student's future achievement motivation. Related to that, labeling a student as gifted can have the same long-term negative effect as praising performance.

\section{Implicit theory of intelligence interventions.}

Empirical studies of implicit theory provide an understanding of the role of students' implicit theories in their academic performance. In several studies of implicit theory of intelligence, students respond to question items such as, "You have a certain amount of intelligence, and can't really do much to change it" and "No matter who you are, you can significantly change your intelligence level" (Dweck, 1999, p. 178). Their response pattern classified them as a person who held an entity or fixed theory of intelligence or one who held an incremental or malleable theory of intelligence.

In their landmark implicit theory of intelligence research, Blackwell and colleagues (2007) surveyed students in the first phase and then conducted an intervention 
with another group of students. The research team chose to study achievement, motivation, and resiliency in seventh grade students, as this population traditionally experiences a difficult life transition at this developmental stage (Blackwell et al., 2007; Dweck, 2006). In the first study, 373 seventh graders in four New York City public schools completed six survey instruments. Possessing an incremental theory of intelligence correlated positively with learning goals, failure-response strategies, nonhelpless attributions, positive effort beliefs, and positive strategies, and predicted higher scores in math one year later though they did not correlate with scores on prior-grade math exams (Blackwell et al., 2007). Statistical results were not provided in this research article.

\section{Mindset intervention study.}

In the intervention phase of the Blackwell et al. (2007) study, 91 public school seventh graders in New York City participated in an eight-session incremental theory intervention. Students were randomly assigned to a growth mindset or a control group. Both groups were trained in study skills, memory techniques, and time-management strategies; the intervention group also received incremental theory lessons, learning about the brain and about how effort and learning enhance plasticity (Blackwell et al., 2007). One lesson about the brain included:

Many people think the brain is a mystery. They don't know much about intelligence and how it works. When they do think about what intelligence is, many people believe that a person is born smart, average, or dumb - and stays that way for life. But new research shows that the brain is more like a muscle - it 
changes and gets stronger when you use it. And scientists have been able to show just how the brain grows and gets stronger when you learn (Dweck, 2006, p. 213). Additionally students were taught how practice and learning new concepts makes their brain "grow":

When you learn new things, these tiny connections in the brain actually multiply and get stronger. The more that you challenge your mind to learn, the more your brain cells grow. Then, things that you once found very hard or even impossible like speaking a foreign language or doing algebra - seem to become easy. The result is a stronger, smarter brain (Dweck, 2006, p. 213).

Students discussed the concepts and did activities to learn how to apply this new understanding about how their brain works to their schoolwork. To equalize the amount of treatment, the amount of educational content received by students in the control group consisted of additional study skills training and as much one-on-one attention as the students in the experimental group. The only element the control group did not receive was the growth mindset lessons. Despite all the skills training the control group received, they did not learn how to "think differently about their minds, they were not motivated to put their skills into practice" (Dweck, 2006, p. 215).

Blackwell et al. (2007) conducted an ANOVA to compare learning of study skills (equal in both groups) and endorsement of incremental theory (significantly higher for the experimental group). A 2x2 ANOVA revealed students' views of incremental theory shifted in the experimental group significantly more than the control group (Blackwell et al., 2007). Teachers independently reported improved academic interest in students in the experimental group, not knowing which students were in which groups, or even what the 
groups were. The experimental group's grades showed significant growth in math skills over the two years of the study. The control group's math grades continued to decline over the two-year period.

Despite this being an oft-cited piece of research, the improvements were addressed in words but no numeric evidence was provided to quantify the significance of the results. The first quantified results for this study, a 30 grade point difference between two groups, were reported by Yeager and Dweck in their 2012 article. There seems to be a dearth of hard data supporting academic improvement until more recently with the numerous online interventions reviewed in the next sections.

While academic performance in math was positively impacted when students endorse an incremental theory of intelligence during challenging transitions of their education, limitations to this research include the following:

1. Generalizability, as both studies were conducted in one school;

2. The experimental group received training on anti-stereotyping, which may have influenced the incremental theory message;

3. Effects were only evaluated for a short period and long-term effects need to be assessed;

4. Initial results suggest there are mediators but a more comprehensive study is needed to explore how motivational factors are impacted by teaching students about incremental theory;

5. Teachers and parents were not included in study; and

6. The results reported are based on a small effect size (Blackwell et al., 2007). 
These studies demonstrated the benefit of instilling an understanding of how the brain functions and how intelligence is malleable, showed that this belief can improve student achievement, and provided information about how to talk to students.

\section{Brief online interventions.}

The everyday use of the computer and the Internet has allowed for a proliferation of mindset intervention studies. Several are reviewed here.

\section{Mindset intervention in developmental math for community college students.}

Students at all grade levels are affected by their perception of the meaning of an action; sometimes their interpretation is not the message intended. For example, when students take college placement tests for math and test into the remedial level, entitytheory thinking sends two messages: the obvious one is the individual is not good at math and the unfortunate one is the individual does not belong in college. A study of 288 community college students taking a developmental math class supports this point. The 30-minute intervention consisted of students reading an article describing the brain science behind incremental theory and writing an encouraging letter to future students explaining how the brain changes and grows. The control group read a different article and wrote a summary to future students as well. The 30-minute intervention resulted in the dropout rate being cut in half: only $9 \%$ of the students in the treatment group dropped out while $20 \%$ of the control group dropped out (Tough, 2014; Yeager \& Dweck, 2012).

\section{Mindset intervention and stereotype threat.}

The influence of mindset affects other issues in education as well. An intervention based on theories of intelligence was conducted to combat the effect of racial discrimination. Poverty, culture, and genetic predisposition have been blamed 
for academic underachievement in African Americans (Aronson, Fried, \& Good, 2002). To alter these factors would require significant societal paradigm shifts, and/or investments of time and money, and cannot be changed by a single group; but a psychological factor known as "stereotype threat" was responsive to intervention (Aronson et al., 2002). Stereotype threat occurs any time an opportunity to confirm or dispute a negative group label is assessed; an individual in the stereotyped group has the additional burden of the anxiety about fulfilling the stereotype, adding pressure to the original challenge (Aronson et al., 2002). This has occurred in girls with respect their real and perceived ability to solve math problems and in African Americans with respect to intellectual ability.

To see if stereotype threat could be reduced by subscribing to incremental theory, Aronson et al. conducted a "pen pal" study of 79 male and female Stanford University undergraduate students, 42 of whom were Black and 37 of whom were White (Aronson et al, 2002). The researchers wanted to determine whether they could change attitudes that were suspected to trigger stereotype threat in Black students and may have yielded lower grades than those earned by White students. They hypothesized that if they acknowledged the existence of the stereotype threat and taught the students to perceive their intelligence differently - as malleable rather than fixed - then those students would be able to increase their academic performance (Aronson et al., 2002). They reasoned that stereotypes threatened Black students in the same way an entity theory does: by telling the students that they are not capable of excelling at an intellectual task and have no hope of ever being capable, due to intelligence being a fixed trait (Aronson et al., 2002). The 
intervention group and one of two control groups attended three sessions, during which they were told they were part of a pen pal program. They were exposed to attitude change techniques plus students assigned the malleable trait group received training on incremental theory. Both pen pal groups were also asked to share what they learned in a letter to future students. The pen pal groups were assessed within a week after the last session and again several months later, and the non-pen pal control group was assessed at the same intervals (Aronson et al., 2002).

The experimental-condition group wrote letters to middle school students endorsing the concept that intelligence is malleable; control group wrote to middle school students about multiple intelligences; the other control group did not write letters (Aronson et al, 2002). A 2(race) x 3(condition: malleable focus, multiple intelligence focus, and no letter) ANCOVA (SAT scores = covariate) for short-term and long-term results was conducted on beliefs at both stages and grades in the long-term (Aronson et al. 2002). The researchers reported a .21 increase in GPA was experienced by Black and by White students who endorsed malleability; Black students also reported increased engagement in school (Aronson et al., 2002). As predicted, malleability of intelligence helped Black students seemingly avoid stereotype threat with respect to intelligence as they reported more engagement in college and earned higher grades (Aronson et al., 2002).

\section{Mindset intervention computer program: Brainology.}

The results from these studies were promising with respect to how to help students understand what it takes to perform better and to be more motivated about learning in school. The challenge was how to provide this labor-intensive 
eight-session program to more students. Dweck and her team met with experts from the educational, media, and neuroscience fields to develop a computer program they named "Brainology." Users of Brainology follow two animated seventh grade characters who are struggling academically and learn the brain science that could help them maximize their potential and achieve more in school (Dweck, 2006, 2007a). Brainology is available for purchase through the mindset website http://www.mindsetonline.com/. The program contains four units: Brain Basics, in which students learn that the brain is the control center for the body; Brain Behavior, where they learn the science behind how the brain works, how it relates to emotions and self-regulation; Brain Building, where they learn about neuroplasticity and learning; and Brain Booster, which teaches about memory and study strategies. The units can be completed in five intense weeks or spread over 20 weeks (Mindworks, 2012). The basic school kit costs $\$ 6,000$; there are additional fees for an educator kit(s), and individual student licenses.

In a 2012 study, Brainology was found to have positive mindset results for the intervention group in a post-test of 33 Scottish students age 13-14 (Donohue, Topping, \& Hannah, 2012). This quasi-experimental, mixed-methods study used a six-item mindset scale with three growth and three fixed mindset questions. A 10-minute semi-structured focus group built on the perception of the source of intelligence. Despite the post-test increase, the pre- and three-month follow-up scores showed no statistical significance, $F(1,17)=.38, p=.55$ (Donohue et al., 2012). Moreover, no significant results were seen for mindset at the one-year follow up. In a different study of high school students, Antick 
(2010) found they did not like the animated design of the Brainology program, perceiving it was targeted for students appreciably younger than they were.

\section{Mindset intervention online scaled to the masses: university study.}

Brainology requires five to eight sessions to implement, which necessitates an investment of staff hours and time away from other instruction, in addition to the cost of the program. Due to restricted budgets, many schools do not have the funding to implement a multi-session intervention. Yeager has researched implicit theory, mindset, and brief, single-session interventions (Tough, 2014). Brief, relatively small interventions were scaled for over 8,000 college freshmen in the class of 2016. The purpose of the experiment was to close the graduation gap for disadvantaged students, defined in that study as Black or Latino first-generation students. In the study, the typical welcome emails sent to new students the May before their freshmen year were embedded with an interactive mindset message. Students randomly were assigned to one of four groups and received the associated message: The first group was the "mindset" group, which received an article about brain malleability and how new connections develop with practice, as well as messages from current students who told of initially being concerned they were not smart enough but then discovered by putting in effort and studying they became smarter; the second group was a "belonging" treatment group which received messages from current students who initially felt isolated when they arrived at college but soon realized many others felt lonely too and eventually they felt more relaxed and at home; the third treatment group was a combination of the first two groups and were sent articles that were a blend of the mindset and belonging 
interventions; and the fourth group was the control which received messages about current students' initial reactions to the culture of Austin and its weather, and how they have since acclimated to both. Each group read a dozen webpages and was then requested to write their reflections to help future students (Tough, 2014). The brief intervention took 25-45 minutes, and more than 7,200 students participated.

Despite being the first time a study of this magnitude was undertaken, significant results emerged. One measure for closing the graduation gap was completing 12 credits the first semester, which was an indicator of future success at college. Historically, and again in this intervention, $90 \%$ of all of the advantaged students and $82 \%$ of the disadvantaged students who received the control message completed 12 credits (Tough, 2014). The first semester completion of 12 credits was increased to $86 \%$ by the disadvantaged freshmen, who received the messages about mindset and about belonging, cutting in half the gap between the advantaged and the disadvantaged groups (Tough, 2014). The hope is this will have significant ramifications for closing the graduation gap for U.T.'s class of 2016. (Note: this study was not available in the research literature but is important to include due to the magnitude of the study and the significant results.)

\section{Mindset to the masses: PERTS, high school students and course failure.}

Building on Yeager's study and working with Yeager and Dweck as advisors, Paunesku and Carissa Romero co-founded the Project for Education Research that Scales (PERTS) research center at Stanford University. The PERTS team conducted a study with almost 1,600 high school students from 13 high schools (public, charter, and one private) in the Southwestern and Northeastern regions of the United States 
during spring semester 2012 (Paunesku, 2013). Trained teachers explained to their students that they were participating in a Stanford University study about student learning. Teachers were instructed to not tell the students they were participating in an intervention because research shows that can make participants resistant and closed to the impact of the intervention (Paunesku, 2013). For this high school study, two 45-minute online interventions were administered two weeks apart. Study 1 started with a pre-survey, then students randomly received either the growth mindset intervention or the control treatment (Paunesku, 2013). Two weeks later, students were given the sense of purpose intervention or the control treatment; the Study 2 session ended with a post-survey (Paunesku, 2013). Just like previous mindset intervention studies, the format of these studies consisted of reading a scientific article, reading a hypothetical situation of a student who struggled with the topic and improved, and then writing a letter of encouragement to struggling students providing advice based on the article (Paunesku, 2013). The growth mindset lesson taught that as a result of effortful practice the brain could restructure itself and grow like a muscle, using the example that one cannot lift 100 pounds immediately but starts with 20 pounds and with practice and effort increases to 100 pounds (Paunesku, 2013). The pre- and postsurvey contained two questions assessing growth mindset; "You can learn new things but you can't really change your basic intelligence" and "You have a certain amount of intelligence and you really can't do much to change it."

Manipulation checks were conducted including a linear regression to assess prestudy incremental theory belief and the treatment group was shown to endorse more of a 
growth mindset view than the control, $\mathrm{b}=.17, \mathrm{t}(1009)=2.647, \mathrm{p}=.01$. (Paunesku, 2013). At-risk students were determined to make up $29.3 \%$ of the total sample. A linear regression showed the effect to be significant for students who were at-risk, $b=.15$, $\mathrm{t}(1589)=2.529, \mathrm{p}=.01,($ Paunesku, 2013). The effects for growth mindset interventions and sense of purpose were of similar significance and magnitude so they were reported as one treatment. The treated group had $8 \%$ less course failures than control (Paunesku, 2013). The combined group did not perform any better than either treatment group. With respect to the finding about at-risk students noted above, Paunesku used metrics he developed using the University of Chicago Consortium on School Reform (CCSR; Farrington et al., 2012) database (because they had more longitudinal information than the PERTS database). He found that academically at-risk students have better outcomes with this type of intervention than students not at-risk: the average improvement for the probability of graduating averaged $0.6 \%$ for all participants, but increased to $3.5 \%$ for students with a 2.0 GPA and lower (Paunesku, 2013).

Limitations of this study include Paunesku's (2013) suggestion that the combined method may not have worked well because students facing challenges may not be able to incorporate two separate messages or there was not enough time to digest two separate messages and perhaps an integration of growth mindset and sense of purpose into a single message would have better results. Given the sample size, its diversity, and the online methods used to ensure consistent delivery, the results are robust for at-risk students benefiting from the growth mindset and sense of purpose interventions (Paunesku, 2013). The researcher suggests even more regions and populations conduct similar studies to extend the generalizability as well as the possibility that being at-risk is not a static 
condition and students who receive the intervention who are not at risk at intervention time may well benefit at a future time, when they face a challenging situation, possibly a college course.

\section{Mindset to the masses: PERTS, community college students and remedial}

math.

The PERTS team also conducted research of 884 community college students in remedial math classes from two different regions of the country, Southern California and the Midwest, with similar results; $13.3 \%$ more students in the growth mindset intervention group completed the semester-long math course than students in the control treatment (Paunesku, 2013). In addition to the academic problems community college students taking remedial or developmental math face there are also the psychological problems associated with failure. This study consists of two 45-minute online sessions two and a half weeks apart with three treatments: growth mindset, sense of purpose, or a combination of the two (Paunesku, 2013). Students randomly assigned the single intervention completed that treatment in the first session; in the second they completed the other intervention's control (Paunesku, 2013). The control group completed the growth mindset control first and the sense of purpose control in the second session (Paunesku, 2013). Linear mixed effects models were used to establish GPA measures and analyze GPA performance and satisfactory completion of math courses (Paunesku, 2013). Just as with the previous high school study, the significance and magnitude was similar for both single-treatment groups so the data was collapsed into one code (Paunesku, 2013). 
Results of Paunesku's (2013) study show students in the treated group earned higher grades than the control. The completion rate of treated group was $6.4 \%$ greater vs control. The unsatisfactory course completion number was reduced by $13.3 \%$ (Paunesku, 2013). Results seem to only impact students who have a fixed mindset; those with growth mindset are believed to experience less benefit (Paunesku, 2013). A limitation of the study is that there are likely various reasons students hold a fixed mindset and each of these potential reasons would probably respond differently to the intervention; the current research does not provide insight into why a disengaged student may not get benefit from interventions yet one with weak math skills who wants to do well may (Paunesku, 2013). Still, growth mindset and sense of purpose brief online interventions led to improved grades and completion rates for the treated community college groups. As researchers continue to study the psychological factors that impact students' academic performance, it is expected that the effectiveness of the interventions will increase (Paunesku, 2013).

\section{Mindset to the masses: PERTS and Khan Academy single sentence.}

The PERTS group partnered with Khan Academy, the online math and science tutoring website, to test whether a single sentence could encourage a growth mindset and improve performance (Paunesku, 2013). Over 250,000 Khan Academy users were exposed to growth mindset statements that were posted on treatment Khan Academy website pages (Paunesku, 2013). On fraction practice pages, the standard, noheader Khan Academy default was the control. There were also two control statement headers: science statements ("Did you know: An elephant brain weighs 7/2 as much as a human brain") and standard encouragement ("Some of these problems are hard. Just do your best") and two growth mindset groups: general 
growth mindset encouragers ("If you make a mistake, it's an opportunity to get smarter!") and an encourager plus a hyperlink to learn more about how the brain is malleable (Paunesku, 2013).

To analyze the proficiency results a negative binomial regression model was used (Paunesku, 2013). (Khan Academy does not grade students' work; rather, if a student has $94 \%$ probability of proficiency in the current area they are identified as ready to move on to the next concept.) The two growth mindset header groups had statistically similar results and were reported as one group (Paunesku, 2013). The concepts were mastered 3\% more by those who had growth mindset messages versus the control, default or standard encouragers. Paunesku (2013) identified the following areas for future research: does the appearance of the encourager with every problem create a message-overload situation where students eventually tuned them out and would it be better to program the appearance of the statements when students struggle with a concept? What is the effect of long-term exposure to mindset messages? Are the mindset messages more effective with more challenging than less challenging problems?

The results show that standard encouragers do not provide substance to the general statements to "try harder" whereas the growth mindset statements provide students with information that greater effort will increase their intelligence and make them smarter (Paunesku, 2013). A simple growth mindset sentence had a positive effect on learning outcomes as did the 8-session (Blackwell et al., 2007) and 45-minute and 90-minute interventions (Paunesku, 2013). While a 3\% increase is modest, the application of this intervention extends beyond the Khan Academy 
webpages. Paunesku's (2013) research confirms parents and teachers who provide more concrete encouragement rather than generic positive statements will be enhancing students' potential to learn.

\section{Growth Mindset and grades.}

In a 2014 correlational study of 115 suburban public school students in grades 6-8 by Romero, Master, Paunesku, Dweck and Gross, a 3-item theory of intelligence scale (IV) was used to predict grades (DV) at 4 points in time. The authors claim the study is diverse, but only $2 \%$ of the participants were Black. Romero et al. (2014) addressed the following research questions in their study: do students with a growth mindset earn higher grades? Do they take more challenging courses in math over time? What is impact of SES (operationalized as mother's education level) on enrolling in more challenging courses over time? The analytics used by Romero et al. (2014) are hierarchical linear model, course grade hierarchical linear analysis, and mixed-effect logistic regression models. The researchers observed that higher malleability of intelligence beliefs in 6th grade led to higher grades at all points in time, $\mathrm{t}=3.77, \mathrm{p}<.001$, and enrolling in higher level math courses, $\mathrm{z}=2.16, \mathrm{p}<.03$ (vs. .6 -.72 on chart) (Romero et al., 2014). A secondary analysis showed students are likely to take higher level math if the mother's education level is high, $\mathrm{z}=1.99, \mathrm{p}<.05$.

Limitations of this study are that only one middle school was analyzed, hence the study needs to be replicated at other schools to determine generalizability; surveys were administered at different times during the school year, allowing for the possibility that timing could be a confounding issue; and the correlational design does not support causality, however a prior academic study by Blackwell et al. did prove causality of the 
implicit theory of intelligence in the academic domain (Romero et al., 2014). For sixth graders, possessing the belief that intelligence is malleable predicts higher academic grades.

\section{Mindset work in other cultures.}

As growth mindset status is evaluated in other cultures, sensitivity to and awareness of cultural differences pertaining to the domain being assessed must be considered.

\section{Germany.}

Implicit theory of intelligence has been studied in cultures outside the United States. The three-item implicit theory of intelligence scale created by Dweck (1999) was translated into German by Spinath and Stiensmeier-Pelster (2001) and had a high internal consistency of .94. Six studies were conducted, four of university students, one of mothers, and one of adolescent students. Overall these studies supported the claims made previously about incremental and entity theory, yet there were some key deficiencies that could not be explained (Spinath \& Stiensmeier-Peltser, 2001). Unlike the study of Chinese students discussed below, this study of German students did not reveal any cultural limitations of implicit theory.

\section{Hong Kong.}

In another study, students matriculating to the University of Hong Kong where all instruction was in English were given an opportunity to take an English class to improve their English language skills (Dweck, 2007a). The students were given a scientific article on intelligence to assess their reading skills. One article endorsed entity theory, the other endorsed incremental theory (Dweck, 2007a). They answered some questions and moved 
on to the next phase of study where they solved problems and were given feedback on their performance. They were then offered the opportunity for some training that they were told would help them do better on the next set of problems (Dweck, 2007a). ANOVA revealed the majority of those who were told they did relatively well chose to take the training, regardless of whether they received an incremental or entity mindset. Of those who did poorly, there was a difference between the two mindsets: the majority (73.3\%) of those who were given an incremental mindset chose to receive the training; of those who were given an entity mindset, only $13.3 \%$ chose to receive training (Dweck, 2007a).

Apparently those who endorsed entity theory did not want to risk not looking smart, which they believed taking a remedial English class would do, and ultimately were willing to risk performing poorly in college (Dweck, 2007a). A limitation of this study is generalizability, as only college students in Hong Kong were studied. Concern over performance and looking good in the short-term prohibited these students from investing in themselves for the long-term (Dweck, 2007a). They were not interested in skillimprovement or challenging learning tasks. On a related note, the psychological needs of affiliation and achievement, which were identified earlier in the discussion of SDT, were central in this study and influenced human behavior.

\section{China.}

The extant research on implicit theories of intelligence was expanded to implicit theories of school or academic performance by Wang and $\mathrm{Ng}$ (2012). In Chinese culture, academic success is perceived to be a function of intelligence, effort, and environmental influences, with academic performance being more important than intelligence (Wang \& 
$\mathrm{Ng}, 2012$ ). In the fall 581 tenth graders were surveyed using three instruments, Implicit Theory of Intelligence (consisting Dweck's three-item 1999 scale), Implicit Theory of School Performance (consisting of a three-item scale modeled on the intelligence scale), and Helplessness (modeled after the 12-item scale developed by Blackwell et al., 2007); six months later 361 of those tenth graders responded to those instruments again (Wang $\& \mathrm{Ng}, 2012$ ). Results showed Chinese students hold distinct beliefs about the malleability of intelligence as compared with academic performance. Academic performance is perceived as more malleable than intelligence. The more strongly held a student's belief that intelligence or academic performance is not malleable, the more helpless the student's approach to schoolwork becomes, meaning the attribution of poor grades is to causes outside the student's perceived control, i.e., "I will never be good in this subject" (Wang \& Ng, 2012). The role of intelligence in Western culture is much more central to achievement and learning than it is in Chinese culture.

\section{Mindset and Praise}

Given that teachers' word choice can influence student behavior, Dweck (2007b) suggests educators praise the process. When a student exerts appropriate effort, Dweck suggests a comment like, "1 like the way you tried all kinds of strategies on that math problem until you finally got it" (2007b, p. 37). For those students who master a concept without much effort, Dweck suggests, “That was too easy for you. Let's do something more challenging that you will learn from" (2007b, p.37). For the student who truly tried but did not do well, again the focus is on the process rather than ability: "I liked the effort you put in. Let's work together some more and figure out what you don't understand" (Dweck, 2007b, p. 37). 
The influential power of parents' word choice has been discussed in the popular media. "How Not to Talk to Your Kids: The Inverse Power of Praise" (Bronson, 2007) appeared in New York magazine and told of Blackwell et al.'s study (2007) and how a single line of praise, either "You must be smart at this" or "You must have worked really hard" significantly influenced student behavior.

\section{Evidence that Does Not Support Implicit Theory Work}

While much of the research on the implicit theory of intelligence has been very supportive, there has been some criticism as well. In a longitudinal study of university students in Britain, entity and incremental theory were not found to be related significantly to academic achievement (Furnham, Chamorro-Premuzic, \& McDougall, 2003). Participants in this study were 93 students from the elite University College London where applicants are assessed based on grades, maturity, stability, and motivation and only $8 \%$ of the applications are accepted (Furnham et al., 2003). Seventy of the undergraduates were female; the average age of the participants was 19.3 years (Furnham et al., 2003). Data on academic performance, which was operationalized as exam grades over a two-year period, was collected from the students' grade files. Five personality traits, including introversion and conscientiousness, were assessed by a 240item questionnaire while Beliefs About Intelligence (BAI) were assessed by a 7-item scale modified from Dweck's Theory of Intelligence scale (Furnham et al., 2003). Seminar performance was evaluated by two instructors and cognitive ability was evaluated using the Wonderlic Personnel Test (Furnham et al., 2003).

The quantitative analysis started with ANOVA and then hierarchical regressions were conducted to determine the correlation between academic performance and all the 
factors. Of Furnham and colleagues' multiple hypotheses, the one pertaining to academic performance and beliefs about intelligence is most relevant to this study. They predicted that BAI would strongly correlate with academic performance and incremental beliefs would be positively related while entity beliefs would be negatively related to academic and seminar performance. Beliefs about intelligence were not significantly correlated with academic or seminar performance (Furnham et al., 2003). Results were not generalizable due to the elite status of the school and the related high levels of ability of the students, as well as that the findings are based on the British education system. While personality traits like conscientiousness and introversion were found to be important factors for this school to consider when selecting students, Furnham and colleagues (2003) did not find that the type of implicit theory of intelligence a student possesses influences his or her academic performance.

Entity theory and performance goals were found to not be related in a study by O'Shea, Cleary, and Breen (2010). This study consisted of 182 students (43 male) in math classes taught by the authors at three colleges in Ireland. During a class period, students answered a 20-minute survey with questions relating to theory of intelligence, goal orientation, confidence, and persistence (O'Shea et al., 2010). The researchers used binary analyses and chi-square tests to determine the relationships. Theory of intelligence was not significantly related to goal orientation and entity theory did not correlate with performance goals (O'Shea et al., 2010). The researchers suggested limitations of their study included the self-selecting for academic ability that happens once a student reaches the college level as well as the fact that the self-reporting used to collect the student information may be biased. O'Shea et al. (2010) found the relationship of the theory of 
intelligence and goal orientation to be more complicated than postulated in previous research, with greater variability between genders.

A dissertation study of California high school geometry students was conducted by Antick in 2010. Similar to previous growth mindset studies, this intervention required students to read articles on how the brain grows and autobiographical stories of students not being capable but subscribing to incremental theory and then experiencing growth and success (Antick, 2010). The geometry students used Learning and the Brain Online Program, and wrote and reflected on implementing what they learned. The outcome of the research showed no significant impact on standardized tests, grades, or scores on final exams; however, the typical third quarter grade drop did not occur (Antick, 2010). The impact on retention was inconclusive as there was a change in a counseling program policy that encouraged students who were at risk of failing to drop a course rather than negatively impact their transcript. Students who took Algebra II the subsequent year earned one full letter grade higher than they did the first quarter of geometry (Antick, 2010).

Given that the evidence is inconclusive from prior growth mindset intervention studies, the intention of this study is to determine if a growth mindset intervention can indeed cause the adoption of a growth mindset and if that in turn improves students' grades at two distinctly different urban high schools in the Midwest.

\section{Summary}

Numerous academic initiatives have been implemented on the national, state, and local levels. Challenges to improving students' academic performance and attendance are especially difficult to overcome in urban settings. Overall, the data is convincing that 
mindset interventions can impact students to change their beliefs about their ability to improve their intelligence and can have a positive effect on their academic performance, but it is not conclusive. The intervention approach has evolved from one or a few researchers delivering in-person a growth mindset intervention designed for a specific group of students over the course of multiple sessions to scaling the intervention to an interactive online program that delivers the same intervention consistently to as many students as can access the intervention program on a computer.

\section{Gaps in the Research}

A comprehensive literature review was conducted by the University of Chicago Consortium on School Reform (CCSR; Farrington et al., 2012) and undertaken to identify best practices in school reform and improve student achievement through non-cognitive factors by applying research to practice. Their review found that the mindset evidence supports a moderate 0.2-0.3 improvement in GPA, which is meaningful on the student level as it could mean the difference between passing or failing a course. Additionally, that improvement compounds from one year to the next. The CCSR identified gaps in the mindset research including uncertainty about whether more interventions would be more beneficial, questions about the contextual transferability, teacher intentionality with respect to the use of language, little variance between strategies to cultivate an incremental mindset in students, and the role and benefit of school-wide mindset interventions. The research work of the PERTS team is addressing a number of the gaps cited in the CCSR study.

With respect to contextual transferability, missing from the research is an analysis of a growth mindset interventions with students from the same general community at two 
different schools in the same district, with the growth mindset intervention delivered by their school counselor, who has conducted research on motivation for over five years to address the problem of poor academic performance and student retention. Therefore, this study will address that gap.

This study will also address the impact of a growth mindset intervention on attendance, a variable that has not been specifically evaluated in the prior research. As increases in attendance have been shown to correlate with increases in GPA (Allensworth, Gwynne, Moore, \& de La Torre, 2014; Gump, 2005; Morrisey, Hutchison, \& Winsler, 2014; Strickland, 1998), determining whether the growth mindset intervention has a positive impact on attendance will be meaningful for practitioners seeking to improve attendance as well as academic performance. 


\section{CHAPTER 3}

\section{METHODOLOGY}

This chapter contains the methodology used to study the impact of a growth mindset intervention on the academic performance of students at two distinct high schools in the Midwest Urban Public Schools (MUPS) district. The expectation was that students would learn that their intelligence is not a fixed entity, but rather that it is malleable, and through effort they would improve their academic performance, as has been found in prior research (Aronson et al., 2002; Blackwell et al., 2007; Paunesku et al. in Tough, 2014; Yeager in Tough, 2014). This quantitative study consisted of a 3-session lesson starting with a brief mindset survey administered to freshmen at Traditional High School (THS) and at Rigorous Magnet High School (RMHS). Based on the positive outcomes of related research, it was expected that students would develop a more incremental mindset and a belief that they can increase their intelligence and academic performance, which would be reflected in the outcome stated in hypothesis 1: Students in the treatment groups at RMHS and THS will have larger percentage increases in their core GPAs than students in the control groups. Additional expectations are stated in the following hypotheses:

2. Students' mindset scores will shift to indicate adoption of a stronger growth mindset belief than they had before the growth mindset intervention.

3. THS is expected to have an increase in attendance as a result of this growth mindset intervention and it is expected to be larger than the attendance increase at RMHS.

\section{Research Design}


For this research, a true experimental study was conducted. According to Heppner, Wampold, and Kivlighan (2008), “A true experimental design always includes random assignment of subjects to conditions, manipulation of the independent variable(s), and comparisons between or among groups" (p. 175). These three requirements were met with this study design. A total of 84 freshmen were randomly assigned to the treatment or the control group, a 2x2 design was implemented crossing school (RMHS or THS) with treatment (yes or no). A third factor, race (Black or White) was dropped due to the concern of being able to obtain consent for 160 freshmen, 80 at each school.

The independent variable was the 3-session lessons; students received either the treatment or the wait-list control group (which is referred to from this point forward as "control group" for simplicity). There was one status variable: school. The main dependent variable was academic performance, which was operationalized as core-GPA. The other dependent variables were the Mindset Scale score and attendance.

\section{Sample and Population}

The participants were freshmen from a convenience sample as they attend RMHS where the primary researcher is employed as a school counselor, and freshmen from another high school in the same district, THS.

\section{Background Information about RMHS}

The two high schools selected for this study represent very different segments of the MUPS district. Rigorous Magnet High School (RMHS) is the most academically competitive of all the high schools in the MUPS district. At RMHS students must qualify (by scoring proficient or advanced on the state standardized assessments in seventh grade 
and earning no grade lower than a $\mathrm{C}$ in middle school as well as submitting a letter of recommendation from a teacher or principal) for their names to be entered in the lottery for admission to RMHS. Students are selected using a formula that ensures $50 \%$ are African American based on a desegregation case ruling in the city (W. Moore, personal communication, October 8, 2014).

RMHS was founded in 1972 (Autman, 1996) as an alternative school for students who were not challenged academically and may have had some behavior issues in a traditional school setting (W. Moore, personal communication, October 8, 2014). In the 1980s as part of the desegregation agreement between the city and the surrounding suburbs (Freivogel, 2003), RMHS became a magnet school focused on academic rigor. In 2000, the prestigious International Baccalaureate (IB) program was added to the school curriculum (W. Moore, personal communication, October 8, 2014). RMHS has a "3 F policy": if a student fails three semester classes in one school year, he or she is not eligible to return the following academic year (RMHS Student Handbook, 2015). There are no Ds at RMHS; grades below a $70 \%$ translate to failing a class.

RMHS is perceived by some students and staff as being "two RMHSs"- one that some see as rigorous, welcoming, encouraging, and scholarly, and the other that is seen as overwhelming, elitist, uncaring, and too rigid. Reddick, Welton, Alsandor, Denyszyn, and Platt's quote from a student in their study of an urban Texas community about "two schools within one roof' (2011, p. 606) resonated with this perception of RMHS. A student in the Reddick et al. focus group attributed the divide to regular and advanced classes, the former being comprised predominantly of students of color and the latter being comprised mostly of White students. A similar racial divide in course 
demographics exists at RMHS, with a significantly larger percentage of White students in the advanced classes and a larger percentage of Black students in the regular classes. Approximately $50 \%$ of the students at RMHS had been identified as gifted in elementary or middle school (W. Moore, personal communication, October 8, 2014). The majority of these students are White; historically a high proportion of them are on the advanced track at RMHS. For the last five years, special education services have been required for less than five percent of the population of RMHS students (K. Luebbert, personal communication, July 6, 2015). RMHS has attendance and graduation rates over $90 \%$.

\section{Background Information about THS}

The Traditional High School (THS) was founded in 1925 as a neighborhood school in a predominantly White section of the city; in the 1980s and 1990s the district bussed students from the predominantly Black section of town to THS to increase diversity (Bosenbecker, 2005). From 1985 to 1993, THS housed an international magnet school program and an Air Force JROTC program. THS students have attended school in the original building with the exception of the 1992-1993 school year, when renovations were made to the building (Bosenbecker, 2005). In the 1990s and 2000s, this comprehensive neighborhood high school experienced increasing discipline, enrollment, and drop-out problems; threats of violence caused the 2006 homecoming dance to be canceled; dozens of gangs were reported to be dominating the school (Giegerich, 2006). For the last five years, the drop-out rate has ranged from a low of $23.5 \%$ in 2013 to a high of $51 \%$ in 2014 . During the same period, the graduation rate fluctuated from $59 \%$ in 2012 to $35.7 \%$ in 2014 (MCDS, 2015b). THS's special education population has averaged 25\% of the total enrollment for the last five years (K. Luebbert, personal communication, July 
6 , 2015). The attendance rate at THS hovered between 75\%-77\% from 2005-2008; since 2009 it has been a full 10 percentage points higher (MCDS, 2015a). This increase coincides with the district's introduction of initiatives to improve attendance, including the employment of attendance monitors.

THS is no longer classified as a neighborhood school. As a result of the MUPS district creating more, smaller schools and encouraging families to enroll students in a school whose mission matches students' interests, only two schools remain that were formerly classified as neighborhood and are still called comprehensive schools. THS is one of the two comprehensive high schools in the MUPS district. Students from the north and west sides of town are enrolled in THS, which once only enrolled students from the south side (A. Mallory, personal communication, October 9, 2015). Students are not required to apply to THS and will be admitted simply by enrolling. Parent involvement in their students' education and in the Parent-Teacher Organization is low; the attitude Mallory often perceives is "he's in high school now, he can make it on his own" (A. Mallory, personal communication, October 9, 2015).

While parent involvement is low at THS, community organizations overwhelm the THS principal and support staff with programs to help THS students (A. Mallory, personal communication, October 9, 2015). In response to the abundance of support resources attempting to work with THS, in 2015 counselor Mallory established a teen outreach program in which community organizations (including Kingdom House, SLU TRIO, Education TRIO, Boys' and Girls' Club, and Urban Futures) were paired with a teacher to deliver their curriculum to the freshmen students the last class period of the 
day (personal communication, October 9, 2015). The impact of this innovative approach is not yet known.

Another dynamic impacting the THS educational environment is that immigrant students who are not proficient in English do not attend THS during their freshman year but instead they attend the district school for English Language Learners (ELL; A. Mallory, personal communication, October 9, 2015). ELL students transfer to THS their sophomore year when they have gained sufficient English-speaking skills; this transition adds to the complexity of social interactions and academic needs of students at THS. Additional factors are that the majority of the THS students read on the fourth grade level; $25-30 \%$ of the students have IEPs; and, while it may not be obvious to all educators, gang activity occurs (A. Mallory, personal communication, October 9, 2015). All this creates a challenging urban environment within which to educate students.

\section{Demographic Information about the High Schools}

Demographic data and key educational measures appear in Table 4 in the Appendix. This data is from the school report cards presented on the State Department of Elementary and Secondary Education's (DESE) Comprehensive Data System website. THS has the larger enrollment of the two schools, more than double RMHS. RMHS is more diverse than THS. Since students are qualified based on test scores and grades, and RMHS attracts students looking for academic rigor, it follows that RMHS would have higher achievement scores on the ACT exam than THS. The closest measure to socioeconomic status (SES) on the DESE website is the Free and Reduced Price Lunch (FRL) category. Family income relative to the number of members of the family qualifies a student for free or reduced price lunch. Given the negative correlation between 
academic performance and SES (Layton, 2015; Pathways to College Network, 2007;

Reddick et al., 2011; Sorhagen, 2012) one would expect that RMHS students would come from families with higher SES than THS; the FRL percentages of $42 \%$ at RMHS and 86\% at THS, confirm this (MCDS, 2015a, b). Starting with the 2014-2015 school year, FRL percentages are not available as the district no longer collects that data on an individual basis; since over $40 \%$ of the students are homeless, migrant, in foster care, or living in households receiving food stamps, the district qualifies for community eligibility and all students receive free breakfast and lunch (Food Research and Action Center, 2013).

Ten percent of the students at RMHS are from the suburbs; $100 \%$ of the students at THS reside in the city. THS has a significantly larger number of discipline issues as well as the larger percentage of students qualifying for special education services and a higher drop-out rate.

\section{Measurement}

There were three dependent variables in this study: mindset label, academic performance (core-GPA), and attendance. They are described below.

\section{Mindset}

A mindset scale was used to gauge whether a student possessed a fixed mindset or a growth mindset pre- and post-intervention. The 3-item Theories of Intelligence Scale (Dweck, Chiu, \& Hong, 1995) uses a 6-point response scale ranging from 1 (strongly agree) to 6 (strongly disagree). The items are as follows (Dweck et al., 1995, p. 271):

1. You have a certain amount of intelligence, and you can't really do much to change it. 
2. Your intelligence is something about you that you can't change very much.

3. You can learn new things, but you can't really change your basic intelligence.

This 3-item scale has been shown to have high internal reliability in six studies by Dweck et al. (1995), where alphas ranged from .94-.98; participants were not described in this article. With respect to validity, a factor analysis of the three types of implicit theory constructs (intelligence, morality, and world) was conducted to verify there was no influence of an acquiescence set. Their study revealed three clearly distinct factors with respect to implicit theories about human attributes, with factor loading scores for implicit theory of intelligence ranging from .91-.96 (Dweck et al., 1995). Analysis of their data showed that measures of implicit theory of intelligence were independent of sex, age, political affiliation, and religion (Dweck et al., 1995). Five studies conducted in Germany by Spinath and Stiensmeier-Pelster (2001) of three groups of university students and one group of mothers indicated a high internal consistency of .88-.91; their study of $5^{\text {th }}-8^{\text {th }}$ grade students revealed a lower reliability coefficient of .62 . While validity was not assessed in this study, Spinath and Stiensmeier-Pelster reported that students in younger grades defined the construct of intelligence differently than the older students (the former defining it as the amount of knowledge a person possesses and the latter defining it as an ability to solve problems) and questioned the validity of the concept of implicit theory of intelligence, given the variance in perception of the construct.

Research conducted in China on 581 tenth-grade students by Wang and Ng (2012) showed an internal consistency rating of the scale of .72 at Time 1 and .80 at Time 2. Exploratory factor analysis was conducted to assess the distinction of the theories of 
intelligence and school performance constructs. The data clearly indicated distinct constructs. There is an eight-item Theories of Intelligence Scale, but Dweck et al. (1995) reported a social desirability phenomenon revealing bias in the incremental theory questions which led them to utilize the three entity theory questions rather than the full scale. The 3-item version was used in this study as that has become the standard for evaluating mindset (Spinath \& Stiensmeier-Pelster, 2001).

\section{Academic Performance and Attendance}

The two other dependent variables are academic performance and attendance. Academic performance was operationalized by cumulative GPA. GPA reflects the semester grade point average for the four core subjects: communication arts, mathematics, science, and social studies. This data was obtained from the district's Student Information System (SIS) database. Attendance was operationalized as the time a student spends in school. This data was obtained from SIS and is calculated based on the percentage of hours present in school.

\section{Connectedness}

The influence of a student's sense of belonging, or connectedness, within a school environment was measured using the 60-item Child and Adolescent Social Support Scale (CASSS; Malecki \& Demaray, 2006). The CASSS contains five 12-item subscales: Teachers, Classmates, People in My School, Parents, and Close Friends. Strong internal consistency scores for the subscales ranged from .92-.96 (Malecki \& Demaray, 2006). Test-retest reliability evidence was established 8-10 weeks later $(r=.78)$.

In the present study, two subscales were used: Teachers and Classmates, due to session time constraints and per Malecki's recommendation (personal communication, 
November 5, 2016). All responses were assessed on a 6-point Likert scale ranging from 1 (never) to 6 (always), for how often a student has that particular perception. The importance of that perception was rated on a 3-point Likert scale ranging from 1 (not important) to 3 (very important). Internal consistency for the two subscales used in this study was demonstrated by coefficient alphas of .92 for both the Teacher and Classmates subscales (Malecki \& Demaray, 2006). Questions on the Teacher subscale included "My Teacher(s)...treats me fairly" and "My Teacher(s)...spends time with me when I need help." Questions on the Classmates subscale included "My Classmates...pay attention to me" and "My Classmates...ask me to join activities."

\section{Practice Sessions}

Two practice sessions were implemented to ensure the materials were appropriate, the timing and activities were realistic, and the delivery was connecting with the students. No data was collected. To avoid exposure to possible study subjects, only juniors and seniors were asked to participate in the practice sessions. They were told the materials were being considered for a study about learning, and that practice sessions were seeking to ensure that the materials were appropriate. In both classes the Mindset Scale was administered first and students were asked what they knew about learning and what they would want to research about intelligence. They read about how the brain learns (Mindset Works, Inc., 2002-2013) and discussed their reaction to the article.

In the first practice period they quietly read a testimonial from a hypothetical student who had struggled academically and learned that with effort he could increase his ability. Based on what they learned they wrote a letter of encouragement to a future student who was struggling. In the second practice period, students were asked to 
illustrate and briefly summarize the six highlighted concepts in the three-page article about how the brain works and discussed what they learned from the article.

Both groups found the article engaging and demonstrated that they learned from the article. The mostly-seniors class was very serious when they wrote the letter of encouragement. Students wanted to share what they wrote; five letters were read with each followed by a warm response from their classmates. The mostly-juniors class did not seem as committed overall, yet their illustrations demonstrated learning from the article (although some commented afterward that they had been exposed to some of the terms in the psychology class they took that period). There were no comments from either group that conveyed the materials were inappropriate for $9^{\text {th }}$ graders.

\section{Data Collection and Procedures}

To determine if the 3-session growth mindset intervention improved academic performance of students at two urban high schools in the same district, data was collected pertaining to GPA. Data for the four core subjects was collected from each school's SIS database by subject, exported into an Excel spreadsheet, and calculated to establish each student's core GPA for the first semester and the second semester. Similarly, attendance data was collected for the first and the second semester. Demographic data regarding gender, race and IEP status was collected from SIS. Self-reported SES level was captured utilizing the MacArthur Scale of Subjective Social Status ladder (Adler, Epel, Castellazzo, \& Ickovics, 2000); students were asked to identify which rung they perceived themselves to be on. 


\section{Approval, Consent, and Assent}

Application for approval from the Internal Review Board at the University of Missouri - St. Louis and from the MUPS school district was received before the study was conducted. Initial recruitment began in November 2015, with parental consent being sought at a THS event. Recruitment was conducted in earnest starting mid-January 2016, first at THS and a week later at RMHS, by the primary investigator (PI) visiting designated classrooms to inform freshmen about the subject and encourage interested students to have the form signed by their parent or guardian, and submitted to their teacher or to the PI in subsequent visits. Additional details of the recruitment process can be found in the section below.

Signed paper consent forms were collected by teachers at both schools initially, and then by the PI when she visited the designated classrooms. Signed, scanned forms emailed to the PI by RMHS parents and guardians were also accepted. The day before the first sessions began at each school, freshmen with active parental consent were randomly assigned to the treatment or control group at their school on the day their class met. These students were called to the library at THS and to the gym at RMHS the first day of their assigned group meeting. Students at both schools were reminded of the purpose of the study, that participation was voluntary, and that they could discontinue their participation at any time. The freshmen signed an assent form at the start of this first session in February.

\section{Recruitment}

The PI attended the Day of Thanks event at THS in November to obtain signed consent forms. That event had a history of high attendance by parents and guardians. 
Unfortunately, family participation for the 2015 Day of Thanks was low and only three parents were available to sign consent forms for students in the THS freshmen class. Because of semester finals, winter break, and the intense focus by the PI at RMHS and the counselors at THS to be sure students were in the correct classes at the start of the second semester, recruitment began in earnest January 11, 2016 at THS. The counselor at THS had introduced the PI via email before winter break to two teachers of non-core content classes and recruitment sessions were scheduled. The PI realized achieving statistical power would not be possible with just two classes so two more Career Development and two more Teen Outreach classes were added to the pool of classes whose students could be selected for the study period 4 and period 8 , respectively. Ten visits to THS, half of those days recruiting from the three Career Development class and the other half recruiting from the three Teen Outreach classes, did not yield enough participants, even with the counselor calling some THS students in the evening per their request to remind them to have the form signed. To obtain more signed consent forms, the PI and the THS counselor went to the homes of THS students the Friday before the study was to begin and the PI went to more THS student homes that Saturday. Students were put into groups using random number generation later that day. Three students returned their signed consent form the week the study began. They were added to the group the day their form was returned to maintain the integrity of the random assignment; one on Monday and two on Thursday. Appendix G contains the calendar of recruitment attempts for the study for both schools.

Recruitment began at RMHS, where the PI works, one week later than THS, with a total of six visits to classrooms, three to Intro to Art classes and three to Intro to 
Business classes. An email describing the study and containing the consent form was sent to parents and guardians of students in those classes to increase the likelihood of obtaining signed forms. (This method was not utilized at THS because there were few email addresses available for THS families.) Two physical education classes were also visited to have one more chance to remind freshmen to return the forms if they were interested in participating. A few RMHS students who had requested the assistance were called in the evening to remind them to have the consent form signed.

At both schools, the PI's initial contact with the class consisted of trying to pique the students' interest in the study without telling them specifically what the study was about, sharing that there was a possibility of helping themselves and/or other students academically, and reviewing the content of the parent consent form. Questions were encouraged and answered. Chocolate kisses were given to students with the PI telling them this was to help them associate a good-night kiss with the reminder that they needed to have their consent form signed. Subsequent visits sought to maintain positive rapport and to encourage the freshmen to participate in the study. At all visits, the PI mentioned that snacks and drinks would be provided at each session and that one freshman in each class session would win a VISA gift card. Only students for whom a signed parent consent form was received were allowed to participate in the study.

\section{Mindset Scale, Ladder Question, and CASSS Administration}

The Mindset Scale was administered on paper in the first session and again three weeks later at the end of the third session. Students at both schools were told the study was about the brain and the data would be used for a doctoral study. The three questions were read aloud to all participants to ameliorate any concerns about reading level. In the 
first administration, the MacArthur Scale of Subjective Social Status ladder question appeared below the Mindset Scale and students were instructed to place an "X" on the rung they believed pertained to their family's SES. The scales were collected early in the first session. Scores were manually tallied and entered onto a spreadsheet after the intervention was completed.

The CASSS was administered using paper and pencil. The 24 questions were read aloud to increases comprehension and avoid concerns about participants' reading skill level, although some students went ahead without waiting for questions to be read. The CASSS responses were collected. The scores were tallied manually after the intervention was completed; the scores were entered onto a spreadsheet.

\section{Random Assignment and Statistical Significance}

Random assignment was used to assign students from each school to either the treatment or control group. Assuming a statistically significant beneficial outcome, the wait-list control group would receive the treatment the semester after this study was conducted so as to avoid the ethical concern of denying treatment (Heppner et al., 2008). This delay avoided confounding or biasing the results which could have happened if the treatment was delivered to the control group during the same semester.

There were two experimental and two control groups at each school, with the goal of a minimum of 12 students in each, for a total of 96 students. To ensure the results were statistically significant and generalizable, concerns about statistical power and Type I and Type II errors were addressed. According to Whitley and Kite (2013), avoiding Type I and Type II errors is critical. They describe a Type I error as claiming the results are statistically significant when they are not (a false positive); a Type II error occurs when 
the result is significant but missed (a false negative) and indicates inadequate statistical power, typically due to the sample size being too small. Based on evaluating for two independent variables (school and treatment vs. control) and utilizing the gold-standard of 20 participants per cell for this 2 x 2 study, 80 participants were needed for this study. $\mathrm{G}^{*}$ power calculations were run to confirm this using an accepted standard statistical power of .80, a medium effect size, and an alpha of .05 (Heppner et al., 2008). The G*power results for analysis of variance (ANOVA) and linear regressions indicated 80 students should ensure this study would not be underpowered.

\section{Treatment Protocol}

Appendix G contains the Research Study Calendar used to guide the study. The intervention consisted of three 45-minute group sessions about how the brain learns and application of that knowledge. In every session the goal was to make the students feel

welcome and comfortable. Snacks, Sunny D drink, juice, and bottled water were provided at each session. In the first session the students read about how the brain learns (Mindset Works, Inc., 2002-2013). Six points were highlighted in the three-page article and participants were asked to illustrate and briefly summarize each concept. The group then discussed what they learned from the article and how it might apply to their academic lives. Students were encouraged to be aware of this knowledge as they went through their week and to share in the next session what they experienced differently as a result of this learning. Their illustrated responses were collected at the end of the session.

The collected responses were returned to the participants at the start of the second session to remind them of the prior week's lesson. In the second session, some students shared with the group how they applied what they learned from the first session to their 
life. Then the students read a testimonial from a hypothetical student who had struggled academically and learned how with effort he could increase his ability and how he learned from his mistakes. The participants discussed how they would apply the concepts to their daily life. Again they were encouraged to be prepared to share any new experiences as a result of this learning in the following session.

In the third session, the main brain science concepts were reviewed again and a few students shared with the group experiences they had in the prior week that related to the learning experiences they had read about. The participants were asked to write a letter to a future student who may be struggling and to encourage the student based on what the participant had learned in the three sessions. Before the session ended the students completed the Mindset Scale for a second time and then celebrated their group time together. The students who participated in all three sessions were entered into a drawing to receive $\$ 25$ (The VISA gift card option did not pan out, so in lieu of the preferred gift card, cash was awarded). The names of eligible students were put on a small card and shuffled until the students said, "Stop", and then the top card was selected to reveal the winner. The last treatment group at THS, which only had five eligible freshmen, did not like the idea that one person would win and the other four would not so they decided to split the attendance prize so that each of them received $\$ 5$.

\section{Control Protocol}

The control-group sessions were modeled after the treatment sessions. As such they consisted of three 45-minute group sessions, but these sessions focused on the anatomy of the brain and they learned about Phineas Gage and his improbable survival after a serious brain injury. The goal was for the students to feel comfortable; snacks and 
beverages were provided. In the first session the students read about the lobes of the brain and their functions (Chudler, 2014) as well as about Phineas Gage and his infamous traumatic brain injury (Swarmer, 2012). Participants were asked to illustrate and briefly summarize six facts about the brain. The group discussed what they learned from the article and any application it may have to their lives. Students' illustrated worksheets were collected at the end of the session.

The worksheets were returned to the students at the start of the second session to remind them of the prior week's lesson. In the second session the students were asked to share any experiences or thoughts they had that related to the first session's reading or discussions. They read a testimonial from a hypothetical student who struggled academically due to a brain injury and how she coped. The participants discussed how they would adapt to a situation like that, and adaptations that may be required due to injury.

In the third session, the key brain function facts were reviewed and the students shared thoughts or experiences. The participants wrote a letter to a future student who may be faced with an unexpected trauma and encouraged the student based on what they had learned in the three sessions. The Mindset Scale was administered. The group celebrated their time together. In each group there was a drawing in which the names of students who participated in all three sessions were shuffled and student whose name was on the top card received $\$ 25$. Five freshmen were eligible in the last control group at THS to win the prize; when they began to discuss their odds, the PI told them of the prior group's decision to split the prize. After a thorough discussion, this group also decided to split the $\$ 25$. 


\section{Participant Flow and Data}

Signed parent/guardian consent was ultimately received for a total of 92 students.

Two students were no longer in attendance at THS when the study rosters were created: one moved to Mississippi and the other withdrew from school. Rosters were created using a random number generator with 46 students in the control groups and 46 students in the treatment groups. Two students from RMHS had promised on Friday to bring in their consent forms on Monday, but they did not, and they had each been assigned to a different treatment group. Their lack of parental consent brought the initial roster count down to 46 control and 44 in the treatment groups. Of the 90 students placed in a treatment or control group at each school, all participated in the first session at RMHS, 10 did not participate at THS. Reasons for not participating included: five were absent, two were assigned to In School Suspension (ISS), two were missing - they never made it from their classroom to the library meeting room where the groups were held - and one student declined participation, as she did not want to miss her Teen Outreach class.

Participation for the second session dropped to 74 students: 39 in the control condition and 35 in the treatment condition. Because the content in the second session was the least consequential to the overall study, when one RMHS student in the control session and one in the treatment condition, and two THS students in a control session showed up for the third session, the PI caught them up on the missed material so they could participate in the third session. Despite this addition of four students to the third session pool of participants which would have made 78 in the last sessions, the number of participants dropped to 69 for the third sessions. Reasons for lack of participation included absences and field trips (fortunately, several students were pulled from ISS at 
THS and allowed to participate in the last sessions). Usable data was collected for the 69 participants. See Table 5 for the flow of students through the study.

Demographic details for the final sample of participants follow, starting with gender: 43 (62\%) of the 69 participants were categorized as female. With respect to race, $45(65 \%)$ of the participants were categorized as Black, 18 (26\%) were White, $5(7 \%)$ were Asian, and $1(1 \%)$ was Hispanic. Twenty-three (33\%) attended THS; 11 were in the treatment group. Forty-six (67\%) of the participants attended RMHS; 23 were in the treatment group.

\section{Intervention Fidelity}

Fidelity for the intervention was maintained through consistent administration of the treatment and control sessions. From color-coded folders for each school to same session at each school per day, the focus on fidelity was paramount during the planning and execution of this study. One fidelity requirement was that no additional interaction related to the growth mindset intervention was made by the PI with the participants. This was maintained $100 \%$ with students at THS, and practically all of the students at RMHS, where the PI works as a school counselor, other than with RC21.

With respect to lack of contact or additional support, the PI had contact with every freshman at RMHS and provided support through the academic planning process. Throughout these discussions, the PI's goal was to avoid growth-mindset language and concepts and to avoid additional academic encouragement. While the study goal was that only the treatment content be what influenced grades, RC21 struggled academically the second semester and the PI felt compelled to provide additional academic counseling to her during the student's academic planning meeting. The PI was careful to not state 
specific suggestions from the treatment content, but offered encouragement and suggestions for how to work with each teacher. RC21 had a .5 increase in her GPA semester 2 as compared with semester 1.

\section{Data Analysis}

SPSS 23.0 was used to calculate the statistics in this study. All the data was cleaned following the procedures in Tabatchnik and Fidell (2012). Means, standard deviations, and ranges were calculated for all variables in this study. Each hypothesis was tested as noted below:

1. Students in the treatment groups at RMHS and THS will have larger percentage increases in their core GPAs than those in the control groups.

Analysis of variance (ANOVA) was used to compare the GPA change of semester 1 from semester 2 of students who received the GMI with the GPA of students in the control group. The dependent variable was GPA. The independent variable was GMI treatment (yes vs. no).

2. Students' mindset scores will shift to indicate adoption of a stronger growth mindset belief than they had before the growth mindset intervention.

ANOVA was used to compare pre- and post-intervention the Mindset

Scale score change of students who received the GMI with the Mindset Scale score of students in the control group. The dependent variable was Mindset Scale score. The independent variable was GMI treatment (yes vs. no). 
3. THS is expected to have an increase in attendance as a result of this growth mindset intervention and it is expected to be larger than the attendance increase at RMHS.

ANOVA will be used to test this hypothesis comparing the attendance rate change from semester 1 to semester 2 of students who received the GMI with the attendance change of students in the control group. The dependent variable was attendance rate. The independent variable was the GMI treatment (yes vs. no).

There was a fourth research question for which a hypothesis was not generated, as there was no prior research uncovered on this topic to predict the results. The fourth question concerned whether a student's sense of connectedness would mediate the effect of the growth mindset intervention on academic performance, mindset, or attendance. To determine if the effect of the treatment on any of the three variables was mediated by students' sense of connectedness with teachers and peers, a special PROCESS add-on for SPSS developed by Andrew F. Hayes (http://www.afhayes.com) was run for each of the dependent variables, GPA, mindset score, and attendance. In each case, the independent variable was the GMI treatment (yes or no); the mediator was the student support scale. 


\section{CHAPTER 4}

\section{RESULTS}

The purpose of this applied research study was to determine if a growth mindset intervention (GMI), administered at two distinct high schools in an urban district, improved academic performance of students at each school. In addition to testing for improvement in grade point average (GPA), this study also assessed for a change in mindset beliefs and attendance as well as tested whether students' sense of connectedness mediated the relationship between the independent and dependent variables.

\section{Preliminary Analysis}

The data in this study were reviewed for accuracy and cleaned at numerous stages. After the data file was transferred to SPSS 23 from an Excel spreadsheet by the primary investigator PI, a team of hired data proofers compared the data in the SPSS printout for each school to the original sources of all the data: a) reports generated for each school from the district's Student Information System (SIS) which contained demographic, grade, and attendance data; b) the Mindset Scale pre- and post-intervention responses, and c) the CASSS connectedness-scale responses.

There were no missing responses for the initial mindset score or the post-session mindset score. For data missing from the CASSS, participant mean substitution was used to fill in the missing responses (about 1\%). Missing data were left blank for the one missing value from each of the following variables: SES rung, GPA semester 1, GPA semester 2, and attendance semester 1 .

All variables were checked for violations of assumptions. All were within normal limits for normality and linearity but one, kurtosis for attendance semester 1 . The 
decision was made to not transform one of the two variables being used to create a composite variable, since kurtosis was within normal range for semester 2 attendance.

Two-tailed Pearson correlations were run to determine if there was a relationship between the demographic variables of perceived SES, race (dummy coded to create the discrete variables: Asian, Black, Hispanic, and White), and gender with sense of connectedness and the dependent variables, GPA change, mindset score change, and attendance change. No significant correlations were reported for any of the demographic variables with any of the dependent variables or sense of connectedness. Therefore, no covariates were used in the main analyses.

Participants' sense of connectedness was measured only at the beginning of the first session. Before running the main analyses, a one-way analysis of variance (ANOVA) by treatment status using sense of connectedness as the dependent variable was conducted to check for differences prior to the start of the study. This ANOVA was not significant, $F(1,68)=1.32, p=.255$, partial $\eta^{2}=.02$, indicating no differences in connectedness between the intervention and control groups. Disaggregating the groups by school to examine the between-school comparison indicated by the first research question, a two (school) by two (condition) ANOVA indicated that the school by condition effect was not significant, $F(1,63)=1.03, p=.31$, partial $\eta^{2}=.02$. Although the observed power was quite low for both analyses, the effect sizes were small, suggesting no meaningful differences. Table 6 shows the means for each school by treatment condition as well as the condition total. 
Table 6

Sense of Connectedness, Disaggregated and Aggregated

\begin{tabular}{clcc}
\hline Condition & School & $\mathrm{n}$ & $M(S D)$ \\
\hline Treatment & RMHS & 23 & $102.91(17.38)$ \\
& THS & 11 & $94.23(21.15)$ \\
\cline { 2 - 4 } & Total & 34 & $100.10(18.81)$
\end{tabular}

Control RMHS $23 \quad 91.57(19.64)$

\begin{tabular}{lll} 
THS & 12 & $93.54(26.56)$ \\
\hline Total & 35 & $92.24(21.88)$
\end{tabular}

Total $\quad$ RMHS $\quad 46 \quad 97.24(19.22)$

\begin{tabular}{lll} 
THS & 23 & $93.87(23.58)$ \\
\hline Total
\end{tabular}

$69 \quad 96.12(20.66)$

\section{Main Analyses}

The results for this experimental study on the impact of a growth mindset intervention on academic performance are discussed in this section. When effect size is discussed, the SPSS variable Partial Eta Squared was used. Cohen's effect size determinations, as defined by Richardson (2011), were used to evaluate the degree of association between the independent and dependent variables. An effect size of .01 was classified as small, an effect size of .06 was classified as medium, and an effect size of .14 was classified as large (Richardson, 2011).

Hypothesis 1, GPA: The hypothesis for the first research question is: Students in the treatment groups at RMHS and THS will have larger increases in their core GPAs than students in the control groups. The hypothesis addresses the total group, stating that students at both schools will experience increases in their GPA. Upon further reflection, embedded in the research question is the question of the difference in impact at one 
school versus the other, requiring disaggregation of the data. Therefore, after examining change in GPA for the whole group, data on change by school is presented.

The ANOVA using change in GPA as the dependent variable for the whole group was significant, $F(1,65)=7.65, p<.01$, partial $\eta^{2}=.11$. This is a medium effect size. Examination of group means indicated that the change in grade point average over time for the treatment group was slightly negative $(M=-.05, S D=.63)$ while the GPA change for the control group was positive $(M=.32, S D=.45)$. Thus, hypothesis one was not supported.

Disaggregating the groups by school to examine the between-school comparison indicated by the first research question, a two (school) by two (condition) ANOVA indicated that the school by condition effect was not significant, $F(1,63)=2.69, p=.11$, partial $\eta^{2}=.04$. Although not significant, the observed power was low, .37, suggesting a lack of power to detect the effect. Examination of the means suggests the intervention was neutral to positive at RMHS and negative at THS. Table 7 shows the means for each school by treatment condition as well as the condition total. 
Table 7

Core-Subject GPA Change, Disaggregated and Aggregated

\begin{tabular}{llll}
\hline Condition & School & $\mathrm{n}$ & $M(S D)$ \\
\hline \multirow{4}{*}{ Treatment } & RMHS & 23 & $.09(.47)$ \\
& THS & 10 & $-.35(.84)$ \\
\cline { 2 - 4 } Control & Total & 33 & $-.05(.63)$ \\
& RMHS & 23 & $.32(.38)$ \\
& THS & 11 & $.34(.59)$ \\
\cline { 2 - 4 } Total & Total & 34 & $.32(.44)$ \\
& RMHS & 46 & $.20(.44)$ \\
& THS & 21 & $.01(.79)$ \\
\cline { 2 - 4 } & Total & 67 & $.14(.57)$
\end{tabular}

Hypothesis 2, mindset score: The hypothesis for question 2 is: Students' mindset scores will shift to indicate adoption of a stronger growth mindset belief than they had before the growth mindset intervention.

Results of a one-way ANOVA showed that the treatment and control groups differed on mindset change, $F(1,67)=10.45, p=.002$, partial $\eta^{2}=.13$. This effect size is medium. The treatment condition produced significant improvement to the students' mindset scores $(M=1.79, S D=3.17)$, while the control experienced a decline $(M=-.54$, $S D=2.95)$. Thus, hypothesis two was supported.

Hypothesis 3, attendance: The hypothesis for question 3 is: THS is expected to have an increase in attendance as a result of the growth mindset intervention and it is expected to be larger than the attendance increase at RMHS. The findings of a one-way ANOVA for the aggregated sample with respect to attendance change indicated no difference in attendance change between treatment and control groups, $F(1,66)=.53, p$ $=.47$, partial $\eta^{2}=.008$. While participants in both groups saw a decline in attendance 
from the first to the second semester, the decline appeared to be less in the treatment group $(M=-.44, S D=4.16)$ than for those in the control group, $(M=-1.09, S D=3.09)$. Observed power for the treatment versus control analysis was very low, .11, indicating a lack of power to detect this difference.

Disaggregating the groups by school to evaluate the between-school comparison of the attendance change shows the attendance results by school mirror the relationship for the total group. A two (school) by two (condition) ANOVA indicated that the school by condition effect was not significant, $F(1,64)=.006, p=.94$, partial $\eta^{2}=.000$.

Although not significant, the means suggest less of a decline in attendance at RMHS than THS. Hypothesis 3, suggesting a greater effect on attendance at THS than at RMHS, was not supported. Table 8 contains means data for each school for each condition and the totals for each condition.

Table 8

Attendance Change, Disaggregated and Aggregated

\begin{tabular}{llll}
\hline Condition & School & $\mathrm{n}$ & $\mathrm{M}(\mathrm{SD})$ \\
\hline Treatment & RMHS & 23 & $-.22(1.98)$ \\
& THS & 11 & $-.91(6.93)$ \\
\cline { 2 - 4 } Control & Total & 34 & $-.44(4.16)$ \\
& RMHS & 23 & $-.91(1.59)$ \\
& THS & 11 & $-1.45(5.07)$ \\
\cline { 2 - 4 } Total & Total & 34 & $-1.09(3.09)$ \\
& & & \\
& RMHS & 46 & $-.57(1.81)$ \\
& THS & 22 & $-1.18(5.93)$ \\
\hline & Total & 68 & $-.76(3.65)$
\end{tabular}


Research question 4, connectedness: Will student sense of connectedness

mediate the effect of the growth mindset intervention on academic performance, mindset, or attendance? There are no hypotheses for research question 4 as no prior research was found on the relationship of students' sense of connectedness to the dependent variables.

The four steps required to note the significance and confirm a mediating variable follow, starting with the dependent variable GPA. In Step 1, the regression of students' changes in GPA by GMI treatment condition, independent of students' sense of connectedness (mediator), was significant, $b=.37, t(65)=2.77, p=.007$. Step 2 , the relationship between the GMI treatment and students' sense of connectedness was not significant, nor was their sense of connectedness a predictor of GPA, $b=-7.06, t(65)=-$ $1.40, p=.17$. Students' sense of connectedness (mediator), controlling for GMI treatment, was not a significant predictor of GPA, $b=.01, t(64)=1.79, p=.08($ Step 3), yet GMI treatment was a significant predictor of GPA, controlling for sense of connectedness, $b=.41, t(64)=3.08, p=.003$ (Step 4). However, significance was not reached in all steps, and no significance was found for mediation in the Sobel test model, $(z=-1.01, p=.31)$, run at a $95 \%$ confidence level. Therefore, connectedness did not mediate the relationship between the GMI treatment and changes in GPA.

GMI treatment predicted changes in students' mindset belief scores, $b=-2.34$, $t(67)=-3.17, p=.002$ (Step 1). Significance was not achieved in the next two steps for mindset score, $b=-7.86, t(67)=-1.60, p=.12($ Step 2$), b=-.02, t(66)=-.84, p=.41$ (Step 3). GMI treatment was a significant predictor of mindset beliefs, controlling for sense of connectedness, $b=-2.46, t(66)=-3.26, p=.002$ (Step 4), however, no significance was found for mediation in the Sobel test model $(z=.65, p=.52)$, run at a 
95\% confidence level. Therefore, connectedness did not mediate the relationship between the GMI treatment and changes in mindset score.

For the third dependent variable, attendance, none of the steps in the test for attendance achieved significance, $b=-.65, t(66)=-.73, p=.47$ (Step 1), $b=-7.68, t(66)$ $=-1.54, p=.13($ Step 2$), b=-.02, t(65)=-.92, p=.37($ Step 3), and $b=-.80, t(65)=$ $-.80, p=.38$ (Step 4). Additionally, no significance was found for mediation in the Sobel test model $(z=.69, p=.49)$, run at a 95\% confidence level. As with the other two dependent variables, the case cannot be made for connectedness mediating the relationship between the GMI treatment and attendance changes. 


\section{CHAPTER 5}

\section{DISCUSSION}

Improving academic performance is important to multiple constituents at schools across the United States. Extant research showing that a growth mindset intervention (GMI) led to positive outcomes germinated the idea for a study that a GMI could be the key to improving academic performance at the two urban high schools. This research included GMIs that cut in half the drop-out rate for a community college math class (Tough, 2014), provided better outcomes for at-risk students (Paunesku, 2013), increased engagement in school for Black students (Aronson, Fried, \& Good, 2002), and improved grade point average (GPA) for college students and fifth graders, respectively (Aronson et al., 2002; Blackwell, Trzesniewski, \& Dweck, 2007). The research evidence supported providing students with neuroscientific proof that their brains can grow and that it is within their locus of control to make these improvements, leading to better academic outcomes.

\section{Discussion of Findings}

The design of this experimental study replicated previous studies in which students learned about how the brain grows, learned how a struggling student employed growth mindset beliefs and with effort improved his or her academic standing, and then wrote letters based on what they had learned in the sessions to encourage a future student. It was hypothesized that the GMI would have a positive impact on GPA, mindset beliefs, and attendance. In addition, the possibility that a student's sense of connectedness could mediate those results was evaluated. A discussion of the results pertaining to the three dependent variables and the considered mediator follows, after these contextual notes. 
A contextual factor that may have impacted all dependent variables, especially GPA, is the differences between the two schools. The PI is a school counselor at RMHS, and was familiar to all the freshmen participants since they matriculated to RMHS the prior semester. RMHS is more racially diverse than THS, with almost half the students having the same racial identity as the PI. The PI became familiar to the THS students as she visited their classrooms numerous times to recruit, went to some homes after school hours, and called students who requested it to remind them to bring in signed forms. Additionally, the PI called advisory classrooms to remind THS students of sessions later that day. The PI endeavored to build a positive rapport with the THS students, but her length of exposure to THS students was a semester less than the RMHS students. Only a couple of the students at THS identify as the same race as the PI; the vast majority identify as Black.

In addition to the dynamics related to the PI at each school, the schools themselves had distinct realities that may have impacted the outcome. Some are noted here. At THS, there were attendance initiatives to reduce absences, a plethora of community outreach programs attempting to improve the academic outcomes for THS students, and a freshman Teen Outreach class with a curriculum from a few of the community partners in which many of the study participants were enrolled. At RMHS, students are qualified to enroll based on prior academic success, so students are more likely to be committed to learning than their peers at other schools. It should be noted, however, that many students at RMHS are not used to studying. They did well previously based on innate skills, so a significant portion of RMHS freshmen struggle until they 
learn how to study, and until they realize that they too must do homework, that their intellect alone is not going to earn them passing grades.

\section{GPA}

The main purpose of this study was to determine if the growth mindset intervention led to improvement in core GPA. The current research findings did not support the hypothesized improvement; the change in GPA from the first semester to the second was $(M=-.05, S D=.63)$. Thus, the growth mindset intervention did not lead to any improvement in core GPA, a very unexpected finding. In contrast to the findings of this study, four research studies employing the read-scientific-article, read-testimonialfrom-struggling-student, and write-letter-of-encouragement-summarizing-learning GMI approach that the current study was modeled after showed favorable results. They were: a 3-session GMI with a .21 GPA increase (Aronson et al., 2002); an 8-session GMI with a reported .30 grade point difference in treatment versus control (Blackwell et al., 2007); two 45-minute online sessions in which the treated group had $8 \%$ less course failures than the control group (Paunesku, 2013); and one online session in which the brief online growth mindset intervention led to improved grades and $6.4 \%$ higher completion rate for math classes for the treated groups vs control groups (Paunesku, 2013). Additionally, a large study of 250,000 Khan Academy students used a single sentence encouraging a growth mindset on-screen, which resulted in improved performance; $3 \%$ more concepts were mastered by those who saw GM messages versus the control, the default, or the standard encouragers (Paunesku, 2013). Thus, a body of empirical evidence supported the idea that a GMI could improve GPA. 
However, two prior studies did not support a correlational or causal relationship between growth mindset and academic performance. The first was a survey of students at an elite college in London; the type of implicit theory of intelligence a student possessed did not seem to influence his or her academic performance (Furnham, ChamorroPremuzic, \& McDougall, 2003). The second was an action research study of an online GMI for three high school geometry classes from which no significant impact on standardized tests, grades, or scores on final exams were reported; however, the typical third quarter grade drop did not occur (Antick, 2010).

In the current research study, the control outcome was a positive shift in GPA ( $M$ $=.32, S D=.45$ ), with a medium effect size, partial $\eta^{2}=.11$. Given that the session designs were identical, perhaps placebo effect benefits that are known to occur in therapeutic relationships (Wall \& Wheeler, 1996) occurred in this instance. However, the effect of the simple benefit of being in a supportive relationship should have occurred in both the control and treatment groups, thus decreasing placebo effects as a good explanation.

The GPA outcome discrepancy could be due to the lack of some common content in both groups. Study skills were taught in both the treatment and control groups in the study by Blackwell and colleagues (2007), with the treatment group receiving the neuroscientific lessons about the brain and the control group receiving additional study skills content to balance out the time spent on the lessons. But other GMI experiments did not include a study skills component and had positive results (Aronson et al., 2002; Paunesku, 2013). Inclusion of a third group, a true control group that did not receive the GMI or parallel-design control in the study design, could have helped to clarify these 
results. The true-control group design was incorporated by Aronson and colleagues (2002) in their study.

The study fidelity requirement to not allow reinforcement of the mindset message by the PI in other settings does not reflect current pedagogy and best practices to reinforce important messages in multiple settings. With these two samples, it appears the intervention alone was not sufficient to influence students to translate the effort message into growing their grades.

Group dynamics may have impacted the effectiveness of the lessons. The PI maintained a session journal during the three weeks of the study. Information about the dynamics of the sessions and group reactions to the awarding of the gift card/ $\$ 25$ incentive in the third sessions appears in Appendix H. Four months after the last sessions, the PI used the journal entries to rate the group dynamics. Table 9 contains the PI's rating of the dynamic of each group. The number of participants in the last session of each group is also noted. A score of 3 reflects a positive group atmosphere, a 2 represents a neutral atmosphere, and a 1 reflects a negative group atmosphere. The lower ratings happened more in the treatment groups than the control groups. This dynamic could have influenced the learning of the participants, especially in the smaller groups. This smaller group size was more prevalent at Traditional High School (THS); it was the THS treatment condition that had the most negative GPA impact, relative to the treatment condition. The mean GPA change for THS treatment group was - .35 versus .34 for THS control. The mean GPA change for the Rigorous Magnet High School (RMHS) treatment group was .09 versus .31 for the RMHS control. There appears to be a relationship between the group dynamic and the impact of the treatment lessons on GPA. Inadequate 
power may have factored into the results as the disaggregated means suggest possible differences in the effect of the intervention at the two schools.

Table 9

Group Dynamics Score and Last Session Attendance

\begin{tabular}{|c|c|c|c|c|c|}
\hline \multirow[b]{3}{*}{$\begin{array}{c}\text { Control } \\
\text { Sessions }\end{array}$} & \multicolumn{3}{|c|}{ Last } & \multicolumn{2}{|r|}{ Last } \\
\hline & Group & Session & & Group & Session \\
\hline & $\begin{array}{c}\text { Dynamic } \\
\text { Score }\end{array}$ & $\begin{array}{c}\text { Attend- } \\
\text { ance }\end{array}$ & $\begin{array}{l}\text { Treatmt } \\
\text { Sessions }\end{array}$ & $\begin{array}{c}\text { Dynamic } \\
\text { Score }\end{array}$ & $\begin{array}{c}\text { Attend- } \\
\text { ance }\end{array}$ \\
\hline RCp4 & 3 & 9 & RTp4 & 2 & 10 \\
\hline RCp5 & 3 & 14 & RTp5 & 1 & 13 \\
\hline TCp4 & 3 & 5 & TTp4 & 2 & 5 \\
\hline TCp8 & 3 & 7 & TTp8 & 1 & 6 \\
\hline
\end{tabular}

Note: $\mathrm{RC}=\mathrm{RMHS}$ Control Group, RT $=$ RMHS Treatment Group, $\mathrm{TC}=$ THS Control Group, $\mathrm{TT}=$ THS Treatment Group; $\mathrm{p}=$ period .

\section{Mindset}

The second purpose of this study was to determine if a 3-session intervention improved the mindset beliefs of ninth grade students at two urban high schools. Results from this current study indicated the hypothesis was supported. The intervention produced significant improvement to the students' mindset scores in the treatment groups, at a medium effect size.

The general sense from the literature was that increasing one's growth mindset, also known as possessing a mastery orientation, subscription to an incremental theory of intelligence, and pursuit of learning goals, increases the likelihood of academic success (Blackwell et al., 2007; Dweck, 1999; Dweck, 2007a, 2007b; Farrington et al., 2012; Mueller \& Dweck, 1998; Paunesku, 2013; Tough, 2014). However, the number of empirical studies on the GMI increasing one's mindset score is limited. Correlational findings in a study with middle school students showed that higher malleability of intelligence beliefs in 6th grade was associated with higher grades at all future points 
(Romero, Master, Paunesku, Dweck \& Gross, 2014). Another study did not support the premise that a GMI can increase one's mindset score as students' theory of intelligence was not significantly related to a mastery goal orientation (O’Shea, Cleary, \& Breen, 2010). Similarly, subscribing to an entity theory did not correlate with performance goals (O’Shea et al., 2010).

Unlike GPA, which is determined based on many complex interactions (including doing homework, finding time to do homework despite what is going on in one's home, learning a wide range of skills about disparate topics, one's relationship with the teacher and classmates, and prior exposure to content), perhaps the adoption of a growth mindset is a simpler task, within the students' locus of control. Despite the small sample size, the improvement in mindset change was found to be significant in this current study. This is especially noteworthy given prior research that shows a correlation between the adoption of a growth mindset and improvement in academic performance. While this study did not show a direct impact of the GMI on GPA, a correlation between the GMI and adoption of a growth mindset was found, providing hope that there is a correlation between growth mindset and GPA; a larger sample size may have shown that relationship.

\section{Attendance}

The third purpose of this study was to determine if a GMI could improve attendance. While attendance rates did not increase, those in the treatment condition appeared to have less of a decline in attendance from semester 1 to semester 2 than did those in the control condition; however, no impact on attendance can be claimed because significance was not achieved. The small sample size, confirmed by the observed power of .11, limited this study's claim about the impact of the GMI on attendance. A 
correlation between attendance and academic performance has been shown in numerous studies (Allensworth, Gwynne, Moore, \& de La Torre, 2014; Gump, 2005; Morrisey, Hutchison, \& Winsler, 2014; Strickland, 1998). Also, a 30-minute GMI positively impacted a phenomenon related to attendance: dropping out (Tough, 2014). The drop-out rate from a remedial math class was cut in half; $20 \%$ of the control group dropped out, while only $9 \%$ those in the treatment group dropped out (Tough, 2014). Thus, it was reasonable to think the GMI would have a positive impact on attendance.

With respect to the expectation that THS would experience a better attendance outcome than RMHS, the data did not support that. It was expected that THS would outperform RMHS with respect to attendance improvement due to research that showed that academically at-risk students have better outcomes with this type of intervention than students who are not at-risk. In a study by Paunesku (2013), the average improvement for the probability of graduating averaged $0.6 \%$ for all participants, but increased to $3.5 \%$ for students with a 2.0 GPA and lower. Students at THS are more academically at risk than students at RMHS. Similarly, another study showed that Black students also reported increased engagement in school while White students did not (Aronson et al., 2002). THS has a larger percentage of Black students than RMHS. Both claims led to the hypothesis that the attendance of students at THS would fare better than the students at RMHS.

Students at THS may not have had better attendance outcomes than students at RMHS in the current study because attendance may relate less to the concept of drop-out than originally speculated. A large factor in dropping out may be the sense of being academically inferior, which is within a student's locus of control, and which a GMI could remedy. Another factor could be that the studies of Paunesku (2013) and Aaronson 
et al. (2002) involved college students, not high school freshmen, and individual maturity and valuing of education may not be as developed in high school freshmen as in college students.

Poor attendance can be caused by a multitude of factors, many of which are not within a student's locus of control. Factors that have been known to impact attendance of students at THS and/or RMHS include having to care for an ill relative, not having transportation to school, having a medical or court appointment and missing the entire day of school due to time waiting at the clinic, teen pregnancy, out of school suspension (although the goal of the MUPS district is to keep this to a minimum), having to translate for a parent at a legal meeting or with a landlord, having to babysit siblings or cousins, and having to work to so the family can eat or pay bills. The positive correlations of attendance and academic performance cited in numerous studies show a direct relationship between the two variables, with the focus assuming a positive attendance factor. In the current study, attendance declined at both schools from semester 1 to semester 2. None of the studies reported herein showed an indirect relationship between attendance and academics being mediated by a GMI.

\section{Connectedness}

The fourth purpose of this study was to determine if students' sense of connectedness mediated the effect of the GMI on GPA, mindset beliefs, or attendance. The mediation analyses did not indicate that a student's sense of connectedness mediated the effect of the independent variable on the dependent variables. While there was no prior research regarding the mediation of students' sense of connectedness with GPA, mindset beliefs, or attendance, there was speculation that a greater sense of 
connectedness would predict a higher level of GPA, better attendance, or a stronger growth mindset belief for the treatment group. The mediation effect of sense of connectedness may not have been detected because the sample size was so small. Another reason there may not have been a mediator effect for GPA or attendance could have been because there was no correlation between the intervention and improvement in GPA or attendance.

In summary, the intervention was successful with respect to positively affecting mindset beliefs. While it was not successful regarding the direct impact of a GMI on GPA and attendance and there appeared to be no mediation between a sense of connectedness and GPA, mindset, or attendance, the protocol was followed with fidelity. Thus, it will be important to conduct more studies with a focus on GPA to understand when GMIs work and when they do not.

\section{Limitations}

As an applied research experimental study, this project had several limitations. A primary limitation was the small sample size which caused this study to not have enough power to detect the effect of the GMI treatment. Active parental consent, required by the school district, resulted in less participation than desired. Thus, internal validity is at risk. Additionally, the active consent form requirement could have affected participation, in that despite the many attempts at support, forgetful students may not have brought the forms home. Finally, participation was reduced when students for whom consent was received moved, dropped out, or enrolled in Virtual School or a treatment facility, all of which happened. 
With respect to external validity and generalizability, the results of this study are applicable to urban public high schools in the Midwestern region of the United States. They are not generalizable to rural or suburban contexts, or elementary schools, middle schools, or private schools. As a result of the sample coming from a rigorous magnet school and a traditional high school with diverse populations, the outcome covers a wide range of urban public high school experiences. However, the potential lack of internal validity places the external validity at risk too.

With respect to measuring students' sense of connectedness, the version of the Child and Adolescent Social Support Scale (Malecki \& Demaray; 2002) used in this study (see Appendix D) may have benefited from more space between items. Scoring the scale revealed a few students had trouble aligning the answer on the right side of the page with the correct statement on the left-side, despite there being alternating gray and white bars to distinguish one question from the next.

This intervention consisted of three 45 -minute sessions, based on previous research studies with significant results, as well as the logistics required to conduct sessions concurrently at both schools at an optimum time in the semester. Given the prior research, it would appear the duration and timing of the sessions was not a factor impacting the results of this study. However, since the long-term impact on academic performance was not studied, it could be that the real benefit of this study is not fully manifested for a few years.

Finally, the incentive to induce participation, a raffle for a $\$ 25$ gift card, may have served as a distraction to the GMI message or may have been the primary reason some 
students participated. Perhaps they were not focused on the content, but were just going through the motions to get to the reward.

\section{Implications for School Counselors}

A goal of this study was to help school counselors remediate poor academic performance. This applied research study showed a growth mindset intervention resulted in an adoption of more growth mindset thinking in two public urban high schools. Growth mindset has been correlated with improved grades (Aronson et al., 2002; Blackwell et al., 2007; Paunesku, 2013). There are a number of implications for school counselors that could help them impact their students' academic performance. The first is for the training of school counselors. Graduate programs could adjust their curriculum to include an introduction to the growth mindset concepts and the benefits for students and schools as well as recommendations for how to incorporate growth mindset interventions and lessons into the counseling curriculum in the kindergarten through twelfth grade programs. Suggestions for how to involve other school staff and parents should be included. In addition, the American School Counselor Association (ASCA, 2012) could incorporate growth mindset language and concepts in their "ASCA Mindsets \& Behaviors for Student Success: K-12 College- and Career-Readiness for Every Student" program standards for school counselors nationwide.

A related implication is for working school counselors to educate themselves on growth mindset. They should learn what a growth mindset is versus a fixed mindset, and how developing a growth mindset benefits students as well as how to incorporate a growth mindset intervention into their school counseling program. Modeling for their 
peers how to use growth mindset language and how to promote growth mindset thinking in students is well within a counselors' realm of responsibilities.

School counselors can advocate for teaching colleagues to adopt a growth mindset focus, from praising a student's effort rather than praising intelligence when she or he did well on a test (Dweck, 2007a, 2007b) to promoting and reinforcing that one can learn from his or her mistakes (Dweck, 2010; Paunesku, 2013). School counselors can work to change their school culture by encouraging their building and/or their district leadership to adopt a growth mindset approach. School counselors can promote a book club reading among faculty, advocating for honest discussion around Dweck's most recent book, "Mindset: The New Psychology of Success" (2006) and school practice and outcomes. This reading could be supplemented by a number of more recent articles written by Dweck (2007a, 2007b), or colleagues (Romero, Masters, Paunesku, Dweck, \& Gross, 2014; Yeager \& Dweck, 2012), or popular media articles (Bronson, 2007; Tough, 2014). Still another way to supplement knowledge on growth mindset is to visit the mindsetworks.com website and to sign up for their bi-monthly newsletter. Another online tool that can help supplement the integration of growth mindset work is the website of the applied research center at Stanford University, Project for Education Research That Scales (PERTS.net). Free educational resources are available on the PERTS website, such as The Mindset Kit, Mindset Meter, and the PERTS blog to help school counselors and other educators either work from a growth mindset framework or establish a growth mindset culture at their school.

In addition to introducing colleagues to the growth mindset way of educating students, school counselors can also educate parents. If parents understand how their 
students' mindset can impact their academic performance, they may be more inclined to use the same language at home that is spoken at school, reinforcing the important message and helping their students who need to make a paradigm shift: changing their fixed mindset to a growth mindset.

\section{Recommendations for Future Research}

As a result of this study, there are several recommendations for future research. The first is to replicate this study with many more participants to eliminate the lack of power limitation. A larger sample would provide the adequate power required to know definitively that GPA and attendance can be impacted by a GMI. Another recommendation for research is based on generalizability. Since this study was conducted in two urban public high schools, replicating this study in suburban or rural communities would increase generalizability. Conducting this study in elementary or middle schools, or private schools at any grade level also would increase generalizability.

Another recommendation is for a longitudinal study, replicating the design of the current research but with a longer timeframe. Rather than evaluating results from one semester to the next, evaluate results one, two, and three years after the intervention to determine the real gains of the GMI over time. A related recommendation of a larger magnitude is to assess the impact of the GMI on attendance and mindset beliefs and the impact of these two constructs on long-term academic performance, retention and graduation rate.

While allowing a longer period of time for the growth mindset thinking to change behavior is one avenue for future research, another is for the GMI to be conducted in tandem with changes in pedagogy that align with growth mindset beliefs. Having 
empirical evidence that participating in a growth mindset intervention while subsequently having teachers practice from a growth mindset framework will provide much credibility to support those who promote using growth mindset practice to improve academic performance and school culture.

With respect to mediation, while this study did not show that a student's sense of connectedness mediated the relationship between the intervention and GPA, attendance, or mindset improvements, this study could be replicated utilizing a different scale to measure connectedness. Much attention has been given in the literature regarding a student's sense of belonging and school performance, with either a direct relationship between the two or a mediating or moderating influence (Malecki \& Demaray, 2006; Rice, Barth, Guadagno, Smith, \& McCallum, 2013), and it seems worthwhile to pursue what role a sense of connectedness plays in the relationship of a GMI and academic performance, if any.

The PERTS and Mindset Works groups continue to generate much current research and strategies regarding growth mindset and how to incorporate this concept into the education setting. Future researchers should consult these websites to generate ideas for research.

\section{Conclusions}

The purpose of this applied research study was to determine if a growth mindset intervention at two urban public high schools by a working school counselor could impact core academic performance. The findings of this study demonstrated that a 3session GMI improved mindset beliefs. While the current research findings did not support improvement in core GPA or attendance rates as a result of participating in a 
growth mindset intervention, mindset beliefs have been shown to correlate with better grades (Aronson et al., 2002; Blackwell et al., 2007; Paunesku, 2013). 


\section{References}

Adler, N. E., Epel, E. S., Castellazzo, G., Ickovics, J. R. (2000). Relationship of subjective and objective social status with psychological and physiological functioning: preliminary data in healthy white women. Health Psychol 19: 586592. doi: 10.1037/0278-6133.19.6.586

Allensworth, E. M., Gwynne, J. A., Moore, P., \& de La Torre, M. (2014). 4 key findings for high schools from "Looking Forward to High School and College." University of Chicago Consortium on Chicago School Research.

American School Counselor Association (2012). ASCA national model. Retrieved from http://www.schoolcounselor.org/asca/media/asca/ASCA\%20National\%20Model \%20Templates/ANMExecSumm.pdf

An, B.P. (2013). The influence of dual enrollment on academic performance and college readiness: Differences by socioeconomic status. Research in Higher Education, 54, 407-432 DOI 10.1007/s11162-012-9278-z.

Antick, S. B. L. (2010). Geometry success, brain theory, and community building. UMI ProQuest, Ann Arbor, MI.

Aronson, Fried, \& Good, (2002). Reducing the effects of stereotype threat on African American college students by shaping theories of intelligence. Journal of Experimental Social Psychology 38, 113-125. DOI:10.1006/jesp.2001.1491.

Autman, S. (1996, October 22). Gym dandy at Metro high-Students, teachers give new building an A. St. Louis Post-Dispatch, p. 1B.

Bembenutty, H. \& White, M. C. (2012). Academic performance and satisfaction with homework completion among college students. Learning and Individual 
Differences, 24, 83-88.

Blackwell, L., Trzesniewski, K. H., \& Dweck, C. S. (2007). Implicit theories of intelligence predict achievement across an adolescent transition: A longitudinal study and an intervention. Child Development, 78, 246-263.

Bock, J. (2012, October 16). State education board grants St. Louis Schools provisional accreditation. Retrieved from http://www.stltoday.com/news/local/education/state-education-board-grants-stlouis-schools-provisional-accreditation/article_259d84db-ab24-5f2a-883801be312b2a7e.html

Bosenbecker, R. (2005). So, where did you go to high school? St. Louis, Missouri: Virginia Publishing, 112.

Bronson, P. (2007, August 3). How not to talk to your kids: The inverse power of praise. New York Magazine, http://nymag.com/news/features/27840/index4.html. Also, print version cover story 2007, February 19, 40(6), 24-31.

Center for Research on Education Outcomes (2015). "Urban Charter School Report on 41 Regions 2015," retrieved from http://urbancharters.stanford.edu/download/Urban\%20Charter\%20School\%20Stu dy\%20Report\%20on\%2041\%20Regions.pdf

Chudler, E. H. (2015). Neuroscience for kids: Lobes of the brain. Retrieved from https://faculty.washington.edu/chudler/lobe.html

Crouch, E. (2014, June 27). Enrollment, performance up in St. Louis district and charter schools. Retrieved from 
http://www.stltoday.com/news/local/education/enrollment-performance-up-in-stlouis-district-and-charter-schools/article_dffa1459-5d16-566b-921b8ca9e3609114.html

Deci, E. L., \& Ryan, R. M. (1985). Intrinsic motivation and self-determination in human behavior. New York: Plenum.

DeMatthews, D. E., \& Mawhinney, H. (2013). Addressing the inclusion imperative: An urban school district's responses. Education Policy Analysis Archives, 21 (61) Retrieved from http://epaa.asu.edu/ojs/article/view/1283

Diener, C. I., \& Dweck, C. S. (1978). An analysis of learned helplessness: Continuous changes in performance, strategy, and achievement cognitions following failure. Journal of Personality and Social Psychology, 36(5), 451-62.

Donohue, C., Topping, K., \& Hannah, E. (2012). The impact of an online intervention (Brainology) on the mindset and resiliency of secondary school pupils: a preliminary mixed methods study. Educational Psychology, 32(5), 641-655.

Dweck, C. S. (1986). Motivational processes affecting learning, American Psychologist, 4l(10), 1040-1048.

Dweck, C. S. (1999). Self-theories: Their role in motivation, personality and development. Philadelphia: Taylor and Francis/Psychology Press.

Dweck, C. S. (2006). Mindset: The new psychology of success. New York: Random House.

Dweck, C. S. (2007a). Boosting achievement with messages that motivate. Education Canada, 47(2), 6-10.

Dweck, C. S. (2007b). The perils and promise of praise. Education Leadership, 65(2), 34- 
39.

Dweck, C. S., Chiu, C., \& Hong, Y. (1995). Implicit theories and their role in judgments and reactions: A world from two perspectives. Psychological Inquiry, 6(4), 267285.

Dweck, C. S., \& Elliott, E. S. (1983). Achievement motivation. In P. Mussen and E. M. Hetherington (Eds.), Handbook of Child Psychology (pp. 643-692). New York: Wiley.

Dweck, C. S., \& Leggett, E. (1988). A social-cognitive approach to motivation and personality. Psychological Review, 95, 256-273.

Farrington, C.A., Roderick, M., Allensworth, E., Nagaoka, J., Keyes, T.S., Johnson, D.W., \& Beechum, N.O. (2012). Teaching adolescents to become learners. The role of noncognitive factors in shaping school performance: A critical literature review.Chicago: University of Chicago Consortium on Chicago School Research.

Food Research and Action Center. (2013, June). Community eligibility helps low income students and schools. Retrieved from http://frac.org/pdf/community_eligibility_helps_low_income_students_schools.pd $\underline{\mathrm{f}}$

Freivogel, W. (2003, December 14) Desegregation program began with a mother's concern for her son. St. Louis Post Dispatch. Retrieved from http://www.stltoday.com/news/local/education/desegregation-program-beganwith-a-mother-s-concern-for-her/article_dbcflec8-152f-11e1-9f6c0019bb30f31a.html

Fullan, M. (2009). Large scale reform comes of age. Journal of Educational Change, 10, 
101-113. DOI 10.1007/s10833-009-9108-z.

Furnham, A., Chamorro-Premuzic, T., \& McDougall, F. (2003). Personality, cognitive ability, and beliefs about intelligence as predictors of academic performance. Learning and Individual Differences, 14, 47-64.

Giegerich, S. (2006, November 1). "Gangs Plague Troubled School". St. Louis PostDispatch. p. B1.

Gump, S. E. (2005). The Cost of Cutting Class: Attendance as a Predictor of Student Success. College Teaching, 53(1), 21.

Heppner, P. P., Wampold, B. E., \& Kivlighan, D. M. (2008). Research Design in Counseling, $3^{\text {rd }}$ ed., Thomson, Brooks/Cole, Belmont, CA.

Honken, N. B., \& Ralston, P. A. S. (2013). High-achieving high school students and not so high-achieving college students: A look at lack of self-control, academic ability, and performance in college, Journal of Advanced Academics, 24(2), 108124. DOI: $10.1177 / 1932202 X 13482466$.

Hughes, K. H. \& Byers, E. A. (2010). From the classroom to Washington: Einsteins on education reform. The Woodrow Wilson International Center for Scholars, Washington, D. C.

Johnson, S. (2010). United States No Longer the World Leader of Secondary Education of Teen Students - Graduate Rankings Have Fallen. http://www.learningandfinance.com/2010/06/23/united-states-no-longer-theworld-leader-in-education-of-secondary-teen-students-graduate-rankings-havefallen/

Jones, E. T., \& Palazzolo, C. J. (July, 2009). College Access Pipeline Report. White 
paper.

Lastra-Anadon, C. X., \& Peterson, P. E. (2012). Education Next, 12(1), $52-59$.

Layton, L. (January 15, 2015). Majority of public school kids in poverty. Washington Post. Retrieved from http://www.washingtonpost.com/local/education/majorityof-us-public-school-students-are-in-poverty/2015/01/15/df7171d0-9ce9-11e4$\underline{\text { a7ee-526210d665b4_story.html }}$

Lemberger, M. E., \& Clemens, E. V. (2012). Connectedness and self-regulation as constructs of the Student Success Skills program in inner-city African American elementary school students. Journal of Counseling \& Development, 90(4), 450458. doi:10.1002/j.1556-6676.2012.00056.x.

Lemberger, M. E., Selig, J. P., Bowers, H., \& Rogers, J. E. (2015). Effects of the Student Success Skills program on executive functioning skills, feelings of connectedness, and academic achievement in a predominantly Hispanic, low-income middle school district. Journal of Counseling \& Development, 93(1), 25-37. doi:10.1002/j.1556-6676.2015.00178.x.

Lloyd, T. (March 10, 2015). St. Louis Public Schools reconsider discipline policy, move forward with discipline plan. STL Public Radio. Retrieved from http://news.stlpublicradio.org/post/st-louis-public-schools-reconsider-disciplinepolicy-move-forward-turnaround-plan\#stream/0

Lohmeier, J. H., \& Lee, S. W. (2011). A school connectedness scale for use with adolescents. Educational Research and Evaluation, 17(2), 85-95. doi:10.1080/13803611.2011.597108

Malecki, C. K., \& Demaray, M. K. (2002). Measuring perceived social support: 
Development of the child and adolescent social support scale (CASSS). Psychology in the Schools, 39(1), 1.

Malecki, C. K., \& Demaray, M. K. (2006). Social support as a buffer in the relationship between socioeconomic status and academic performance. School Psychology Quarterly, 21(4), 375-395. doi:10.1037/h0084129

Marks, C. (March 4, 2015). Transforming Vashon high school. The St. Louis American. Retrieved from http://www.stlamerican.com/news/columnists/guest_columnists/article_bf177388c2e3-11e4-af6a-37f178ed7682.html

Maynard, B. R., Kjellstrand, E. K., \& Thompson, A. M. (2014). Effect of Check and Connect on attendance, behavior, and academics: A randomized effectiveness trial, Research on Social Work Practice, 24(3), 296-309.

Mindset Works Inc. (2012). Test Your Mindset. Retrieved from http://www.mindsetworks.com

Missouri Comprehensive Data System. (2015a). Missouri Department of Elementary and Secondary Education, District and Building ACT, Attendance, Discipline, Special Education, Graduation and Dropout Rates. Retrieved from http://mcds.dese.mo.gov/quickfacts/SitePages/DistrictInfo.aspx?ID = bk8100130 $\underline{013005300130013005300}$

Missouri Comprehensive Data System. (2015b). Free and Reduced Lunch Percentage by Building 2014. Retrieved from https://mcds.dese.mo.gov/quickfacts/pages/district-and-schoolinformation.aspx ?RootFolder $=\% 2$ Fquickfacts $\% 2$ FSchool $\% 20$ Finance $\% 20$ Data $\%$ 
20and\%20Reports\%2FFree\%20and\%20Reduced\%20Lunch\%20Percentage $\% 20 \mathrm{~b}$ y\%20Building\&FolderCTID=0x012000B3EF86959C3A824680BF44E0680ED1 $\underline{F 4 \& V i e w=\{0 E 813976-3 B D 6-4 D 9 B-9112-5 D 0 C 54 B 515 E 8\}}$

Missouri Department of Higher Education. (2001). Achievement gap elimination report: Report of the Missouri k16 task force. Retrieved from http://dhe.mo.gov/data/achievementgapreport.php

Morgan, S. L., Leenman, T.S., Todd, J.J., \& Weeden, K. A. (2013). Stutter-step models of performance in schools, Social Forces, 91(4), 1451-1474. doi: $10.1093 / \mathrm{sf} / \mathrm{sot} 037$.

Morrissey, T. W., Hutchison, L., \& Winsler, A. (2014). Family income, school attendance, and academic achievement in elementary school. Developmental Psychology, 50(3), 741-753.

Mueller, C. M., \& Dweck, C. S. (1998). Intelligence praise can undermine motivation and performance. Journal of Personality and Social Psychology, 75, 33-52.

National Center for Education Evaluation and Regional Assistance. (2014).

Implementation and impact evaluation of Race to the Top and School Improvement Grants. U.S. Department of Education. Washington, DC. Retrieved from http://ies.ed.gov/ncee/projects/evaluation/other racetotop.asp

National Center for Education Statistics. (January 2014). The Condition of Education. U.S. Department of Education. Washington, DC. Retrieved from http://nces.ed.gov/programs/coe/indicator_cgc.asp

National Center for Education Statistics. (2015a). Public high school 4-year adjusted 
cohort graduation rate (ACGR) for the United States, the 50 states and the District of Columbia: School years 2010-11 to 2012-13 [data file]. U.S. Department of Education. Washington, DC. Retrieved from http://nces.ed.gov/ccd/tables/ACGR 2010-11 to 2012-13.asp

National Center for Education Statistics. (2015b). NAEP data explorer. U.S. Department of Education. Washington, DC Retrieved from http://nces.ed.gov/nationsreportcard/lttdata/

National Governors Association Center for Best Practices and Council of Chief State School Officers. (2010). Common Core State Standards Initiative. Retrieved from http://www.corestandards.org/

Newsweek. (2013). America's best high schools. Newsweek. Retrieved from http://www.newsweek.com/2013/05/06/america-s-best-high-schools.html

Nicholls, J. G. (1984). Achievement motivation: Conceptions of ability, subjective experience, task choice, and performance. Psychological Review, 91(3), 328-346.

O’Neil, T. (2015, January 4). Desegregation: Thousands moved by bus across the citycounty line in saga that cost state nearly $\$ 2$ billion. St. Louis Post-Dispatch, p. B3. Organization for Economic Cooperation and Development. (2014). PISA 2012 results in focus: What 15-year-olds know and what they can do with what they know. http://www.ncsl.org/Portals/1/Documents/magazine/articles/2014/PISA\%20OVE RVIEW.pdf

O'Shea, A., Cleary, J., \& Breen, S. (2010). Exploring the role of confidence, theory of intelligence and goal orientation in determining a student's persistence on mathematical tasks. In M. Joubert \& P. Andrews (Eds.), Proceedings of the 
British Congress for Mathematics Education (pp. 151-158). Manchester: BSRLM.

Pathways to College Network. (2007). The facts: Postsecondary access and success. Retrieved from http://www.pathwaystocollege.net/pdf/FactSheet.pdf

Paunesku, D. (2013). Scaled-up social psychology: Intervening wisely and broadly in education (Doctoral dissertation). Retrieved from https://web.stanford.edu/ paunesku/paunesku_2013.pdf

Peck, C., \& Reitzug, U. C. (2014). School turnaround fever: The paradoxes of a historical practice promoted as a new reform. Urban Education, 49(1), 8-38. DOI: $10.1177 / 0042085912472511$.

Ramdass, D., \& Zimmerman, B. J. (2011). Developing self-regulation skills: The important role of homework. Journal of Advanced Academics, 22, 194-218.

Reddick,R. J., Welton, A. D., Alsandor, D. J., Denyszyn, J. L., \& Platt, C. S. (2011). Stories of success: High minority, high poverty public school graduate narratives on accessing higher education. Journal of Advanced Academics, 22(4), 594-618.

Resseger, J. (2014, December 1). Debate continues: Small high schools vs. comprehensive high schools [online blog]. Retrieved from https://janresseger.wordpress.com/2014/12/01/debate-continues-small-highschools-vs-comprehensive-high-schools/

Rice, L., Barth, J. M., Guadagno, R. E., Smith, G. P. A., \& McCallum, D. M. (2013). The role of social support in students' perceived abilities and attitudes towards math and science. Journal of Youth and Adolescence, 42(7), 1028-1040.

Romero, C., Master, A., Paunesku, D., Dweck, C. S., \& Gross, J. J. (2014). Academic 
and emotional functioning in middle school: The role of implicit theories.

Emotion, 14(2), 227-234. DOI: 10.1037/a0035490

Sawyer, R. (2013). Beyond correlations: Usefulness of high school GPA and test scores in making college admissions decisions, Applied Measurement in Education, 26, 89-112, DOI: 10.1080/08957347.2013.765433.

Skipper, Y., \& Douglas, K. (2012). Is no praise good praise? Effects of positive feedback on children's and university students' responses to subsequent failures. British Journal of Educational Psychology, 82, 327-339.

Sorhagen, N. S. (2013). Early teacher expectations disproportionately affect poor children's high school performance, Journal of Educational Psychology, 105(2), 465-477. DOI: 10.1037/a0031754.

Southern Education Foundation. (2015). A new majority research bulletin: Low income students now a majority in nation's public schools. Retrieved February 21, 2015 from http://www.southerneducation.org/Our-Strategies/Research-andPublications/New-Majority-Diverse-Majority-Report-Series/A-New-Majority2015-Update-Low-Income-Students-Now.aspx

Spinath, B., \& Stiensmeier-Pelster, J. (2001). Implicit theories about the malleability of intelligence and ability, Psychologische Beitrage 43(1), 53-76.

Storek, J., \& Furnham, A. (2013). Gender, 'g', and fixed versus growth intelligence mindsets as predictors of self-estimated Domain Masculine Intelligence (DMIQ). Learning and Individual Differences, 25, 93-98.

Stout, K. E., \& Christenson, S. L. (2009). Staying on track for high school graduation: Promoting student engagement, The Prevention Researcher, 16(3), 17-20. 
Strauss, V. (2012). Why U.S. can’t get back to head of the class (because it was never there). Retrieved from http://www.washingtonpost.com/blogs/answersheet/post/the-myth-of-americashistorical-educational-supremacy/2012/07/02/gJQAwpgAHW blog.html

Strickland, V. P. (1998). Attendance and Grade Point Average: A Study. ERIC.

Strott, A. (2012). Duncan kicks off “let's read! let’s move!”. Ed.Gov Blog. Retrieved from http://www.ed.gov/blog/2012/06/duncan-kicks-off-lets-read-lets-move/.

Student Handbook. (2014). Metro Academic and Classical High School. St. Louis, MO.

Swanson, C. B. (2009). Cities in crisis: Closing the graduation gap, Editorial Projects in Education, Inc. Retrieved from http://www.edweek.org/media/cities_in_crisis_2009.pdf

Swarmer, C. (2012). Into the depths of the human mind: The brain, cognitive function, and Phineas Gage. Retrieved from http://www.intothedepthsofthehumanmind.blogspot.com/2012/10/the-brain$\underline{\text { cognitive-function-and.html. }}$

Symonds, W. C. (2012). Pathways to prosperity: When we insist all students go to a fourcollege, too many get lost along the way, Educational Leadership, 69(7), 35-39.

Tabatchnik, B. G. , \& Fidell, L. S. (2012). Using multivariate statistics, $6^{\text {th }}$ ed. Boston, Pearson.

Tough, P. (2014, May 18). Who gets to graduate: Am I supposed to be here? Am I good enough? The New York Times Magazine. 26-31, 41-42, 54.

Umphrey, J. (2011, March). A time for resolve: A conversation with Diane Ravitch. Principal Leadership, 11(7), 34-36. 
U.S. Department of Education. (2005). 10 Facts About K-12 Education Funding, Washington, D.C. Retrieved from http://www2.ed.gov/about/overview/fed/10facts/index.html

U.S. Department of Education. (2007). Dropout prevention, What Works Clearinghouse Topic Report, 1-18. Retrieved from http://ies.ed.gov/ncee/wWc/interventionreport.aspx?sid=78

U.S. Department of Education. (2011). National Center for Education Statistics, Common core of data, local education agency universe survey dropout and completion restricted-use data file: School year 2009-10 (version 2a) (NCES 2011-314). Retrieved from http://nces.ed.gov/surveys/ruraled/tables/b.3.a.-1.asp

U.S. News and World Reports. (2014). Best high schools: Rankings 2014. Retrieved from http://www.usnews.com/education/best-high-schools/missouri/districts/stlouis-public-schools/metro-academic-and-classical-high-school-11941

VanOverbeke, M. (2009). Aligning secondary and postsecondary education lessons from the past. WISCAPE Policy Brief. University of Wisconsin.

Vasquez Heilig, J. (2011). As good as advertised? Tracking urban student progress through high school in an environment of accountability. American Secondary Education, 39(3), 17-41.

Villares, E., Lemberger, M., Brigman, G., \& Webb, L. (2011). Student success skills: An evidence-based school counseling program grounded in holistic theory. Journal of Humanistic Counseling, 50. 42-55.

Wall, M., \& Wheeler, S. (1996). Benefits of the placebo effect in the therapeutic relationship. Complementary Therapies in Nursing \& Midwifery, 2(6), 160. 
Wang, Q., \& Ng, F. F.-Y. (2012). Chinese students' implicit theories of intelligence and school performance: Implications for their approach to schoolwork. Personality and Individual Differences, 52, 930-935.

Washington Post. (2014). America's most challenging high schools. The Washington Post. Retrieved from http://apps.washingtonpost.com/local/highschoolchallenge/schools/2014/list/natio $\underline{\text { nal/metro-academic-and-classical-st-louis-mo/ }}$

Webber, A., Troppe, P., Milanowski, A., Gutmann, G., Reisner, E. \& Goertz, M. (2014). State implementation of reforms promoted under the recovery act (NCEE 20144011). Washington, DC: National Center for Education Evaluation and Regional Assistance, Institute of Education Sciences, U.S. Department of Education.

Whitley, Jr., B. E., \& Kite, M. E. (2013). Principles of research in behavioral science $\left(3^{\text {rd }}\right.$ ed.). New York: Routledge.

Wikipedia. (2014). [Traditional] high school. Retrieved from https://en.wikipedia.org/wiki/Roosevelt_High_School_\%28St._Louis\%29

Yeager, D. S., \& Dweck, C. S. (2012). Mindsets that promote resilience: When students believe that personal characteristics can be developed. Educational Psychologist, 47(4), 302-314. DOI: 10.1080/00461520.2012.722805.

Yeager, D. S., \& Walton, G. M. (2011). Social-psychological interventions in education: They're not magic, Review of Educational Research, 8(12), 267-301. DOI: 10.3102/0034654311405999.

Yendol-Hoppey, D., Jacobs, J., \& Dana, N. F. (2009). Critical concepts of mentoring in an urban context, New Educator, 5(1), 25-44. 
Zimmerman, B. J., Bonner, S., \& Kovach, R. (1996). Developing self-regulated learners: Beyond achievement to self-efficacy. American Psychological Association, Washington, DC. http://dx.doi.org/10.1037/10213-000 


\section{Appendix A1: Treatment Sessions Lesson Plans}

\section{Growing Your Mind-GM}

\section{Session I}

Materials:

Internet, Smart Board/Laptop

GM Session I Article \& Activity packets

Sharpened pencils

Snacks: Fruit Snacks, Choc Chip Chewy Granola bars, Flaming Hot Chips, and

Bottled Water

Warm-up: Brain Teaser:

https://www.khanacademy.org/math/recreational-math/puzzles/brainteasers/v/finding-heavier-ball

Ice Breaker-tell us your name and what you know about the brain and intelligence. Who would like to start?

Group norms/rules-respect, wait for other person to finish talking, stay on topic

Read brain science article and do activity.

Watch the videos and answer these questions:

https://www.youtube.com/watch? $v=W t K J r B 5 r O K s \quad$ brain grows like muscle

- How do people become more intelligent?

- How does the diagram of the neurons "At birth vs. At age 6" demonstrate this?

- How does the second diagram of the nerves of the animal living in a cage vs. an animal living with other animals and toys demonstrate this?

- How are our brains like muscles?

Closing: Thank you for your interest and participation! Let's take a moment to clean up. Were the snacks ok?

Think about what you learned today and see if it applies to anything in your life this next week. 


\title{
Session II
}

\author{
Materials: \\ Internet, Smart Board/Laptop \\ GM Session II story \\ Sharpened pencils
}

Warm up: review. Who remembers what we learned last week?

Anyone have any related experiences they'd like to share?

\section{https://www.youtube.com/watch?v=ELpfYCZa87g}

\author{
neuroplasticity-changing wiring
}

-When do our brains grow the most?

-What is neuroplasticity?

\section{Read the following story:}

When I was in middle school, I remember struggling with adding negative numbers. I had a hard time figuring out what a 'negative' even meant when talking about a number - how can you have less than nothing? I ended up going through many practice problems and continuing to get many of them wrong. I was a very shy kid, so I didn't ask my teacher many questions. My thought was that I had reached 'the peak' of my math talent, and it was all downhill from here. I eventually asked my mom about this topic and she explained to me the basic concept of negative numbers. This helped me understand it a little, but it was still fuzzy to me. I then researched online for some reallife contexts to show what these mysterious numbers represented outside of some abstract universe. Some of them made sense, and others didn't. I still didn't entirely get it and I was so frustrated that I wanted to just give up (or continue hoping that neg ative numbers were not going to appear in math class ever again). I started to dislike math simply because I couldn't understand it anymore. Instead of entirely giving up on my academic career, I eventually mustered up the courage to ask my teacher for help as well. She explained it in a few different ways, and gave me new strategies to try out. After some practice with these new strategies, I started to solidify my understanding of negatives which allowed me to quickly pick up basic algebra afterwards. While it was a lot of work and I wanted to give up at many points during my journey, I eventually was able to 'rewire' my brain so that negative numbers actually made sense to me.

Do you have any questions about the story?

Talk with a partner about this story. Have you ever had an experience like that? What do you make of it? How can you apply to your life? 


\section{GROUP DISCUSSION}

Share a story about a time that you made your brain smarter by working hard, or taking on challenges, and finding the right strategy.

Closing: Thank you again for your interest and participation! Let's take a moment to clean up.

Think about what you learned today and see if it applies to anything in your life this next week.

\section{Session III}

Materials:

Lined paper

Sharpened pencils

Warm up: review. Who remembers what we learned last week? Anyone have any experience related to putting in effort they'd like to share?

\section{LETTER TO A FUTURE STUDENT}

Take a few minutes to think of a time when you overcame a struggle to learn something. It could be anything - from adding negative numbers to learning a technique in baseball to writing an introduction for a difficult essay. Reflect on the times when you failed at first but through persevering your brain created new neural connections and you eventually became better at the task at hand. [Marathon growth]

Write a letter to a future student of your class about this struggle. In at least five sentences, tell this student your story and give them advice on what they should do next time they encounter an obstacle when learning something new. l'll read you an example. Feel free to be as creative as you would like. 
Dear Future Student,

When learning my multiplication tables I found it really hard to memorize the 7's table. With 5 and 10 there's a pattern to their products, but 7 really gets complicated.

I got kind of down for a while, but then I remembered how I learned to make free throws in basketball. It took try after try to get them in. I had to start from two feet from the basket and keep practicing my form. Only after a long time could I make them in with some consistency. With that in mind, I stuck with it and learned all the way from $7 \times 1$ to $7 \times 12$. Even though it took me a little longer than other students at that time, I am now able to recall them very easily. Stick with what you're working on. The struggle means you're getting close.

Sincerely,

Charlie

Closing: Thank you SO MUCH for your interest and participation! Let's take a moment to clean up. What did you learn? How do you think it will change your behavior? Can you apply it to anything in your life? How? 


\section{Appendix A2: Treatment Sessions_Lesson I}

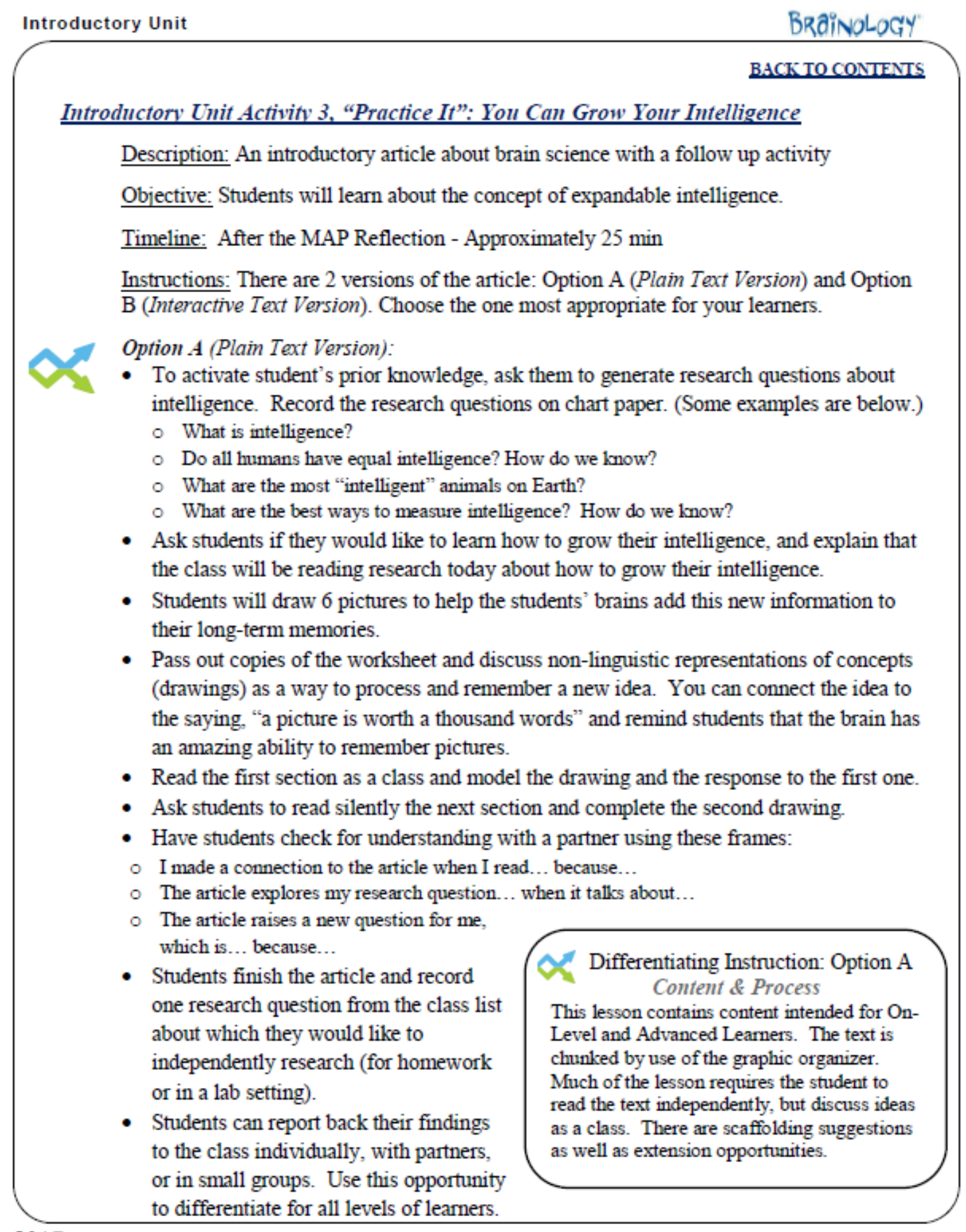

13 | P a g e Copyright \& 2008-2013 Mindset Works, Inc. All rights reserved.

www.mindsetworks.com 


\title{
You Can Grow Your Intelligence
}

\author{
New Research Shows the Brain Can Be Developed Like a Muscle
}

Many people think of the brain as a mystery. They don't know much about intelligence and how it works. When they do think about what intelligence is, many people believe that a person is born either smart, average, or dumb-and stays that way for life.

But new research shows that the brain is more like a muscle-it changes and gets stronger when you use it. And scientists have been able to show just how the brain grows and gets stronger when you learn.

Everyone knows that when you lift weights, your muscles get bigger and you get stronger. A person who can't lift 20 pounds when they start exercising can get strong enough to lift 100 pounds after working out for a long time. That's because the muscles become larger and stronger with exercise. And when you stop exercising, the muscles shrink and you get weaker. That's why people say "Use it or lose it!"

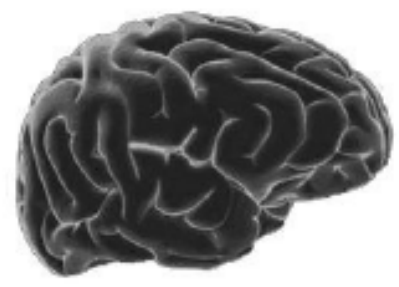

(2) 2010 Mindset Works

But most people don't know that when they practice and learn new things, parts of their brain change and get larger a lot like muscles do when they exercise.

HEALTH \& SCIENCE News You Can Use Page 1 of 3

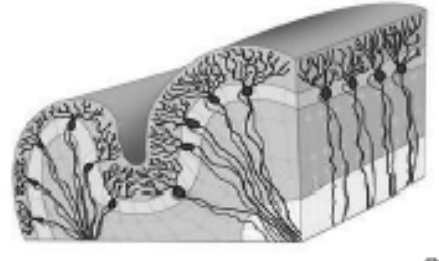

o Fotosearch

A section of the cerebral cortex

Inside the cortex of the brain are billions of tiny nerve cells, called neurons. The nerve cells have branches connecting them to other cells in a complicated network. Communication between these brain cells is what allows us to think and solve problems.

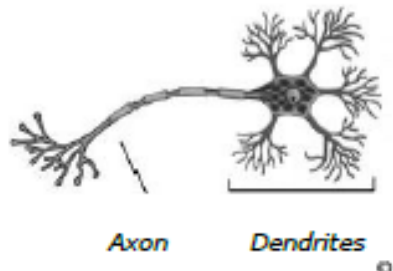

\section{A typical nerve cell}

When you learn new things, these tiny connections in the brain actually multiply and get stronger. The more that you challenge your mind to learn, the more your brain cells grow. Then, things that you once found very hard or even impossible to do-like speaking a foreign language or doing algebra-seem to become easy. The result is a stronger, smarter brain. 
How Do We Know the Brain Can Grow Stronger?

Scientists started thinking that the human brain could develop and change when they studied animals' brains. They found out that animals who lived in a challenging environment, with other animals and toys to play with, were different from animals who lived alone in bare cages.

While the animals who lived alone just ate and slept all the time, the ones who lived with different toys and other animals were always active. They spent a lot of time figuring out how to use the toys and how to get along with the other animals.

Effect of an Enriched Environment

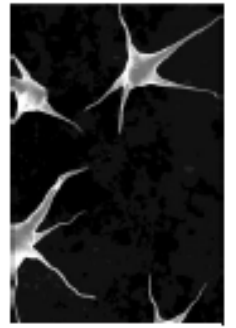

Nerves in brain of animal living in bare cage

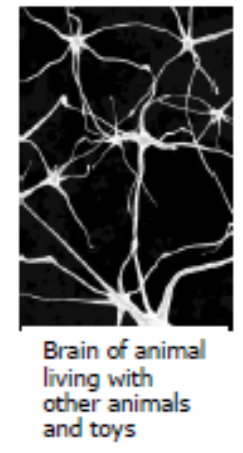

(2) 2010 Mindset Works
These animals had more connections between the nerve cells in their brains. The connections were bigger and stronger, too. In fact, their whole brains were about $10 \%$ heavier than the brains of the animals who lived alone without toys.

The animals who were exercising their brains by playing with toys and each other were also "smarter"-they were better at solving problems and learning new things.

HEALTH \& SCIENCE News You Can Use Page 2 of 3
Even old animals got smarter and developed more connections in their brains when they got the chance to play with new toys and other animals. When scientists put very old animals in the cage with younger animals and new toys to explore, their brains also grew by about $10 \%$ !

\section{Children's Brain Growth}

Another thing that got scientists thinking about the brain growing and changing was babies. Everyone knows that babies are born without being able to talk or understand language. But somehow, almost all babies learn to speak their parents' language in the first few years of life. How do they do this?

\section{The Key to Growing the Brain: Practice!}

From the first day they are born, babies are hearing people around them talk-all day, every day, to the baby and to each other. They have to try to make sense of these strange sounds and figure out what they mean. In a way, babies are exercising their brains by listening hard.

Later, when they need to tell their parents what they want, they start practicing talking themselves. At first, they just make goo-goo sounds. Then, words start coming. And by the time they are three years old, most can say whole sentences almost perfectly.

Once children learn a language, they don't forget it. The child's brain has changed-it has actually gotten smarter.

This can happen because learning causes permanent changes in the brain. The babies' brain cells get larger and grow new connections between them. These new, stronger connections make the child's brain stronger and smarter, just like a weightlifter's big muscles make them strong. 
Growth of neuron connections in a child from birth to 6 years old

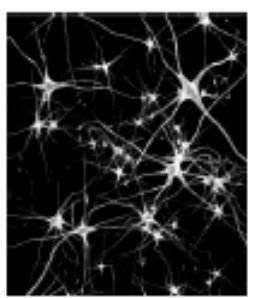

At birth

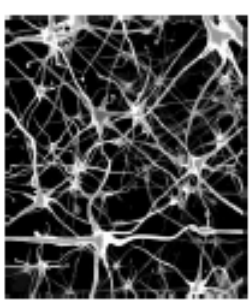

At age 6

(9) 2010 Mindset Works

\section{The Real Truth About "Smart" and}

"Dumb"

No one thinks babies are stupid because they can't talk. They just haven't learned how to yet. But some people will call a person dumb if they can't solve math problems, or spell a word right, or read fast-even though all these things are learned with practice.

At first, no one can read or solve equations. But with practice, they can learn to do it. And the more a person learns, the easier it gets to learn new things-because their brain "muscles" have gotten stronger!

The students everyone thinks as the "smartest" may not have been born any different from anyone else. But before they started school, they may have started to practice reading. They had already started to build up their "reading muscles." Then, in the classroom, everyone said, "That's the smartest student in the class."
They don't realize that any of the other students could learn to do as well if they exercised and practiced reading as much. Remember, all of those other students learned to speak at least one whole language already-something that grownups find very hard to do. They just need to build up their "reading muscles" too.

\section{5}

\section{What Can You Do to Get Smarter?}

Just like a weightlifter or a basketball player, to be a brain athlete, you have to exercise and practice. By practicing, you make your brain stronger. You also learn skills that let you use your brain in a smarter way-just like a basketball player learns new moves.

But many people miss out on the chance to grow a stronger brain because they think they can't do it, or that it's too hard. It does take work, just like becoming stronger physically or becoming a better ball player does. Sometimes it even hurts! But when you feel yourself get better and stronger, all the work is worth it!

E-mail questions or comments to: Growrourbrain@aol.com.

HEALTH \& SCIENCE News You Can Use Page 3 of 3 
Brainology ${ }^{8}$ Intro Unit Activity 3, "Practice It": Plain Text Version Option A

\section{"You Can Grow Your Intelligence"}

Directions: (1)Read each numbered section. (2) Draw a picture that represents the main ideas in that part of the article. (3)Fill in the sentence frames to explain how your picture represents the idea.

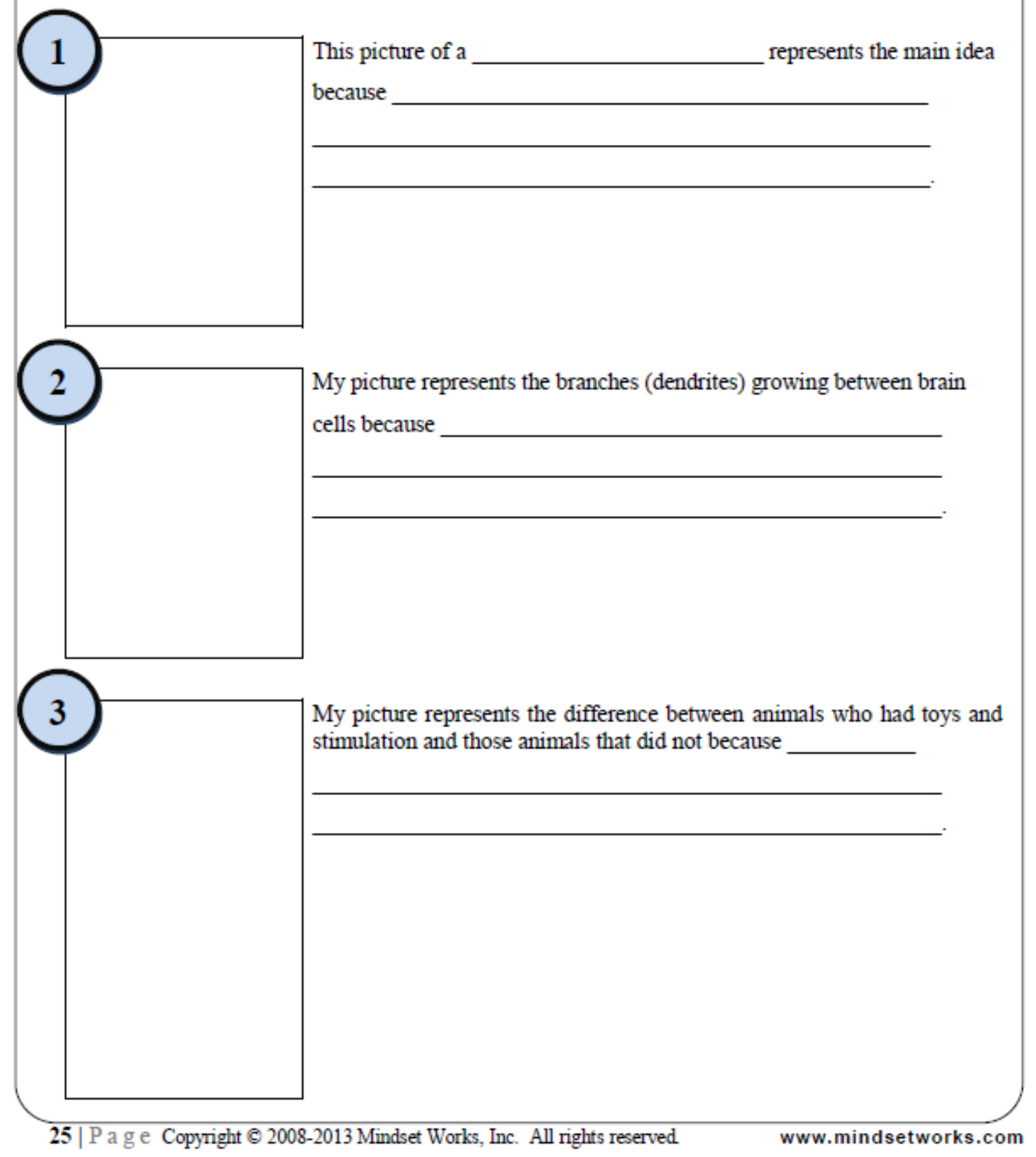




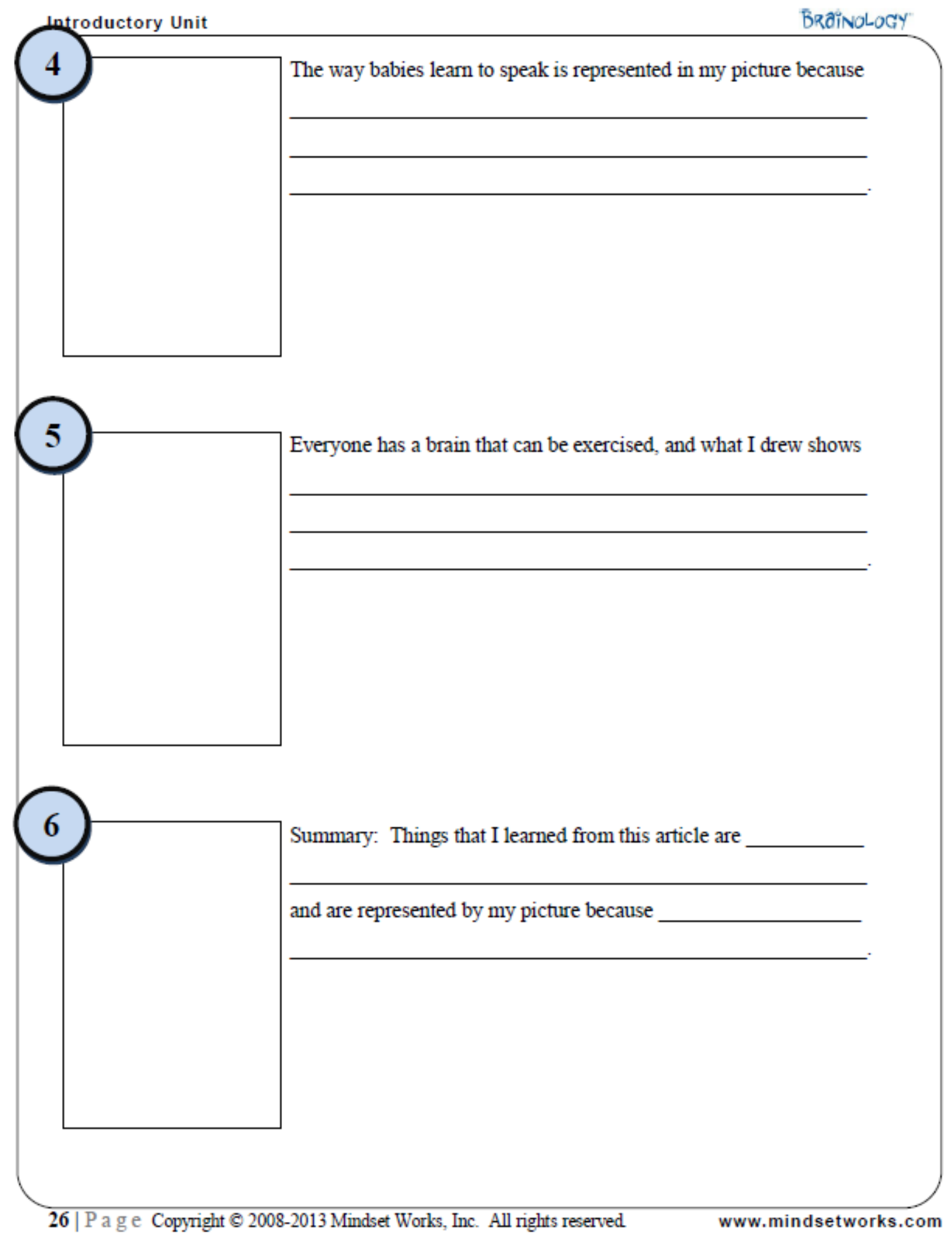




\section{Appendix A3: Treatment Sessions_-Lesson II}

\section{Read the following story:}

When I was in middle school, I remember struggling with adding negative numbers. I had a hard time figuring out what a 'negative' even meant when talking about a number - how can you have less than nothing? I ended up going through many practice problems and continuing to get many of them wrong. I was a very shy kid, so I didn't ask my teacher many questions. My thought was that I had reached 'the peak' of my math talent, and it was all downhill from here. I eventually asked my mom about this topic and she explained to me the basic concept of negative numbers. This helped me understand it a little, but it was still fuzzy to me. I then researched online for some reallife contexts to show what these mysterious numbers represented outside of some abstract universe. Some of them made sense, and others didn't. I still didn't entirely get it and I was so frustrated that I wanted to just give up (or continue hoping that negative numbers were not going to appear in math class ever again). I started to dislike math simply because I couldn't understand it anymore. Instead of entirely giving up on my academic career, I eventually mustered up the courage to ask my teacher for help as well. She explained it in a few different ways, and gave me new strategies to try out. After some practice with these new strategies, I started to solidify my understanding of negatives which allowed me to quickly pick up basic algebra afterwards. While it was a lot of work and I wanted to give up at many points during my journey, I eventually was able to 'rewire' my brain so that negative numbers actually made sense to me. 


\section{Growing Your Mind-C June 15, 2015}

\section{Session I}

Materials:

Internet, Smart Board/Laptop

Blackboard \& Chalk or Whiteboard and Marker

C Session I Article \& Activity packets

Sharpened pencils

Snacks: Fruit Snacks, Choc Chip Chewy Granola bars, Flaming Hot Chips, and Bottled Water

Warm-up: Ice Breaker--tell us your name and what you know about the brain. Who would like to start?

Group norms/rules-respect, wait for other person to finish talking, stay on topic

Read brain science article and do activity.

Watch the video and answer these questions:

https://www.youtube.com/watch?v=1sCh6blHuVw 2-minute musical parts of brain, play twice: 1 to listen, 2 to read

What of the following activities would be hard to do if a person had an injured cerebellum?

1) Running in a race or marathon.

2) Talking and listening to a friend.

3) Playing baseball in the park.

4) Swimming or diving in a pool.

5) Singing a song out loud.

Answers: 1.This task would be difficult, 2 . This task would not be affected by an injured cerebellum, 3 . This task would be difficult, 4 . This task would be difficult, 5. This task would not be affected by an injured cerebellum

Closing: Thank you for your interest and participation! Let's take a moment to clean up.

Think about what we talked about today and see if it applies to anything in your life this next week. 


\author{
Session II \\ Materials: \\ Internet, Smart Board/Laptop \\ C Session II story \\ Sharpened pencils
}

Warm up: review. Who remembers what we talked about last week? Anyone have any related experiences they'd like to share?

https://www.youtube.com/watch?v=3teflb1QNN4 8-minute No-Brainer

-What kind of activities does our brain control?

-Who remembers the Phineas Gage story we read about last week?

Read the following story:

Each part of the brain has a special role. The Phineas Gage injury is one case researchers study to learn more about how the brain works.

\title{
Phineas Gage Accident
}

On September 13, 1848 Phineas Gage suffered a traumatic brain injury. While working as a foreman for the Rutland and Burlington railroad, he suffered the penetrating head injury. A four foot long iron rod went through his skull. It has been reported that the left frontal lobe was the primarily affected area. There are several functions of the frontal lobes. One function is the choosing between good and bad actions. Other functions include suppressing inappropriate social responses, understanding future consequences resulting from current actions and retaining long term memories. The Phineas Gage injury offered researchers much insight into the brain as related to cognitive function.

What was Learned about the Brain and Cognitive Function

Traumatic brain injuries (TBl's) cause several changes in a person. These changes include behavioral, social, and emotional. Before the accident, Gage was hard - working and cautious. After the accident, he became irresponsible, drank heavily, and drifted from one wild scheme to another. Researchers believe this is due to injury to the association areas. The association areas are a major region of the cerebral cortex and the site of higher mental processes. The association areas control functions such as executive, planning, goal setting, judgment, and impulse control. There are personality changes after a type of injury like Gage's. These changes include careless attitudes, taking risks, changes in sociability, unusual sexual habits as well as others. People with these types of injuries have difficulties with functions like memory, information processing speed and executive functions. These personality changes affect a person's ability to make moral judgments. However, the person can still be able to reason logically. 
The frontal lobe is present in all mammals but is much larger in humans than any other animal which is why humans are able to speak to each other and to develop advanced civilization and why bears are not. This also tells us why Gage lived: because the developed frontal lobes of humans are not necessary for basic survival, like mammals.

By Crystal Swarmer: http://www.intothedepthsofthehumanmind.blogspot.com/2012/10/the-braincognitive-function-and.html.

Do you have any questions about the story?

Talk with a partner about this story. Have you ever heard of an experience like that? What do you make of it? How can you apply to your life?

\section{GROUP DISCUSSION}

Discuss what you learned about the brain. How does it impact your life?

Closing: Thank you again for your interest and participation! Let's take a moment to clean up. Think about what we talked about today and see if it applies to anything in your life this next week.

\section{Session III}

Materials:

Internet, Smart Board/Laptop

Lined paper

Sharpened pencils

Warm up: review. Who remembers what we talked about last week? Anyone have any related experiences they'd like to share?

\section{LETTER TO A FUTURE PATIENT}

Take a few minutes to think of a time when you had an injury or had surgery. It could be anything - from having migraine headaches to having a serious illness. Reflect on what you and the people around you did to help you recover/heal.

Write a letter to a future patient about how you coped. In at least five sentences, tell this patient your story and tell them how what you learned about the brain helped you. I'll read you an example. Feel free to be as creative as you would like. 
Dear Future Patient,

When I was a freshman in college I had a car accident in which I had a head injury. I had total amnesia for 4 days and partial for 2 weeks. I was in a hurry to get back to school so I went back late to college 1000 miles from my home.

My roommate picked me up at the airport. I didn't recognize the other students in my classes, but these were new classes so maybe I hadn't met these students before. I was kind of in a fog. My roommate took me to a mall. I got really upset because I didn't recognize it. She was really kind and tried to help me, told me I had only been there once before. But I was in over my head, so I returned home to give my brain time to recuperate. I reevaluated my plans and transferred to Boston University, where I graduated Magna Cum Laude.

Even though my frontal lobe had been messed up in the accident it eventually healed. The body is an amazing machine! Sincerely, Carla

Closing: Thank you SO MUCH for your interest and participation! Let's take a moment to clean up. What did we talk about? What are you going to do with that information? 


\section{Appendix B2: Control Sessions-Lesson I}

\section{The Brain Made Simple Fall 2015}

The brain is the center of all thought and life. It is the center of the nervous system in most animals. It is a substance whose anatomy is complex, yet it can be broken down to simple concepts that are easy to understand. Learn about your brain and unlock the key to understanding yourself!

The nervous system transmits and processes information about the world to the brain, causing the appropriate reactions in the body. In humans, most information is routed through the central nervous system.

The central nervous system consists of the spinal cord and the brain. The brain is where information is processed and stored, and it is responsible for controlling bodily functions and thought. Neuroscience is the science that studies the central nervous system, including the brain.

In adult humans, the brain weighs approximately three pounds. The brain itself is soft tissue that is generally white or pink in color. It is made up of several parts and sections, and each section has a different purpose. The brain, or cerebrum, can be divided down the middle and split into two main sections called hemispheres. The hemispheres are divided into four different lobes.

\section{Cerebral Cortex -1}

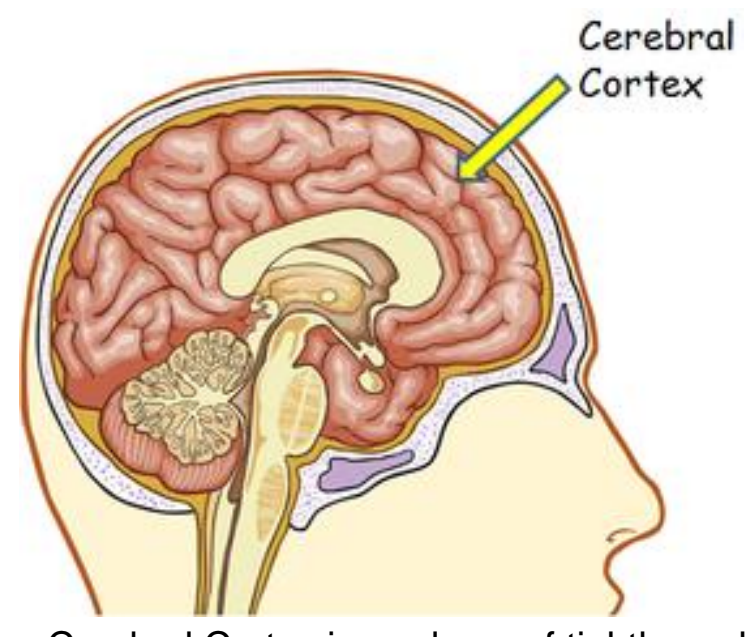

The Quick Facts

Location: Outermost layer of the brain

Function: Responsible for thinking and processing information from the five senses

The Cerebral Cortex is made up of tightly packed neurons and is the wrinkly, outermost layer that surrounds the brain. It is also responsible for higher thought processes including speech and decision making. The cortex is divided into four different lobes, the frontal, parietal, temporal, and occipital, which are each responsible for processing different types of sensory information. 


\section{Fun Fact}

Over time, the human cortex undergoes a process of corticalization, or wrinkling of the cortex. This process is due to the vast knowledge that the human brain accumulates over time. Therefore, the more wrinkly your brain, the smarter and more intelligent you are!

\section{Frontal Lobe-2}

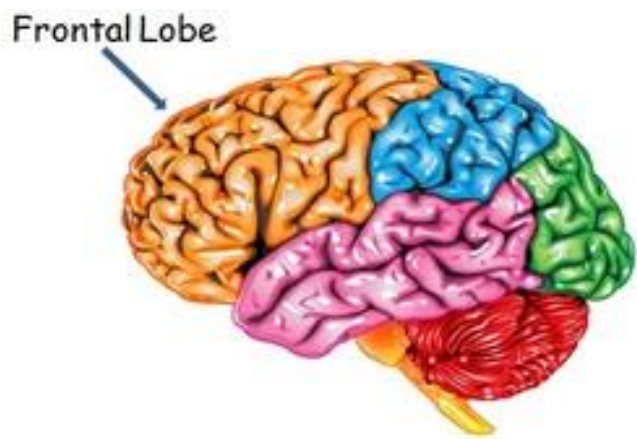

The Quick Facts

Location: Frontal and upper area of the cortex

Function: Carries out higher mental processes such as thinking, decision making, and planning

You use your frontal lobe nearly every day. You use it to make decisions, such as what to eat or drink for breakfast in the morning, as well as for thinking or studying for a test. The frontal lobe is also where our personality is formed and where we can carry out higher mental processes such as planning. In addition, the frontal lobe is necessary to being able to speak fluently (without fault) and meaningfully.

\section{Fun Fact}

In the mid-1800s, Phineas Gage, a railroad worker, miraculously survived an accident where a large iron pole was said to have been driven into his head, specifically into the frontal lobe. After the incident, Gage's personality was said to have changed drastically, or a lot. His friends claimed that the once kind and hard-working Gage had changed after the accident to a lazy and rude man until he died years later. However, this incident did allow doctors and psychologists (doctors who study the mind) to analyze the brain and learn about the frontal lobe. 


\section{Parietal Lobe-3}

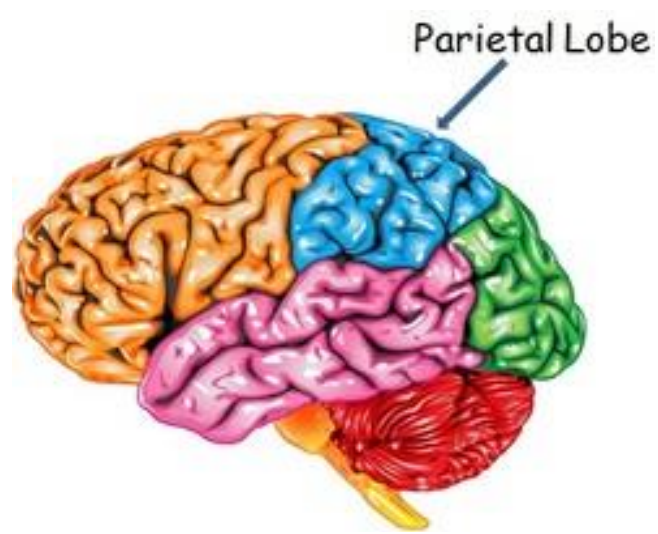

The Quick Facts

Location: Upper, back part of the cortex Function: Processes sensory information that had to do with taste, temperature, and touch

The parietal lobe carries out some very specific functions. As a part of the cortex, it has a lot of responsibilities and has to be able to process sensory information within seconds. The parietal lobe is where information such as taste, temperature and touch are integrated, or processed. We would not be able to feel sensations of touch, if the parietal lobe was damaged.

[http://brainmadesimple.com/index.html June 14, 2015]

\section{Temporal Lobe-4}

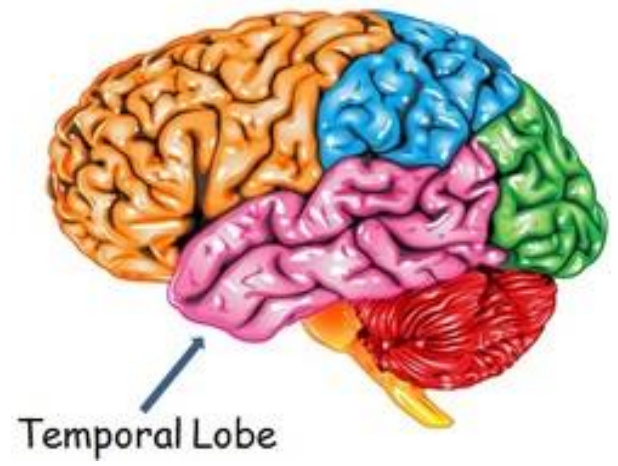

The Quick Facts

Location: Bottom middle part of cortex, right behind the temples Function: Responsible for processing auditory information from the ears (hearing)

The Temporal Lobe mainly revolves around hearing and selective listening. It receives sensory information such as sounds and speech from the ears. It is also key to being able to comprehend, or understand meaningful speech. In fact, we would not be able to understand someone talking to us, if it wasn't for the temporal lobe. This lobe is special because it makes sense of the all the different sounds and pitches (different types of sound) being transmitted from the sensor receptors of the ears.

\section{Occipital Lobe}

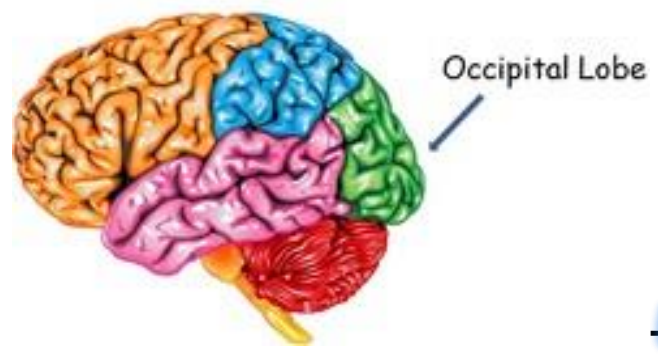

\section{The Quick Facts}

Location: Bottom, back part of the cortex Function: Responsible for processing visual information from the eyes 
The occipital lobe is important to being able to correctly understand what your eyes are seeing. These lobes have to be very fast to process the rapid information that our eyes are sending. Similar to how the temporal lobe makes sense of auditory information, the occipital lobe makes sense of visual information so that we are able to understand it. If our occipital lobe was impaired, or injured we would not be able to correctly process visual signals, thus visual confusion would result.

\section{Cerebellum}

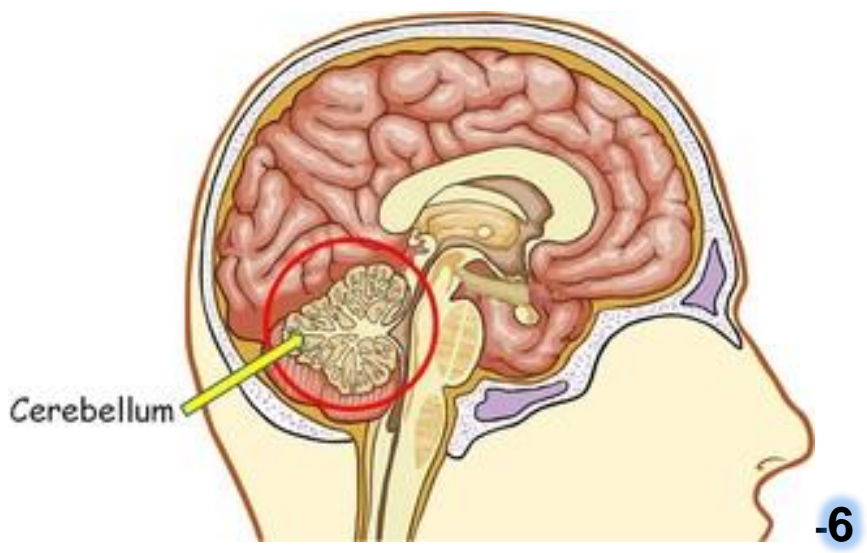

\section{The Quick Facts}

Location: Lower area of the brain, below the pons Function: Responsible for balance and coordination of muscles and the body

The cerebellum is one of the most identifiable parts of the brain due to its unique shape and location. It is extremely important for being able to perform everyday voluntary (done with purpose and intent) tasks such as walking and writing. It is also essential to being able to stay balanced and upright. Patients who have suffered from damaged cerebellums often struggle with keeping their balance and maintaining proper muscle coordination. 
Directions: (1) Read each numbered section. (2)Draw a picture that represents the main ideas in that part of the article. (3)Fill in the sentence frames to explain how your picture represents the idea.

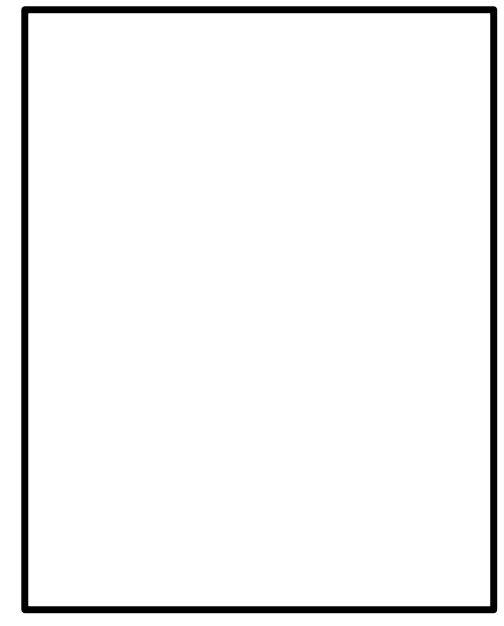

1 The is

the outer layer of the brain. The more

it is the you are.

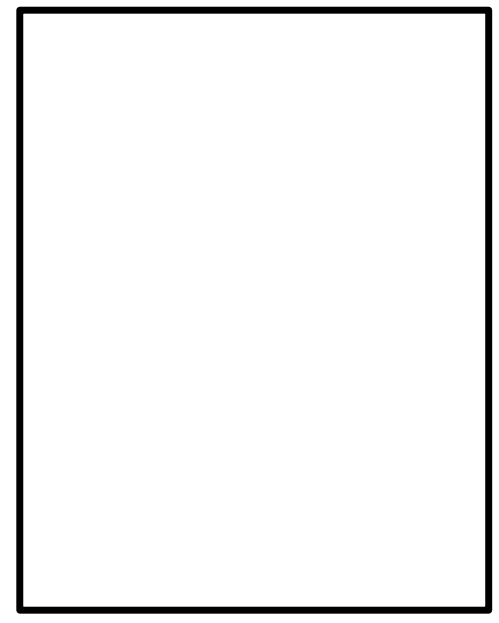

2 The lobe of the brain is

important for

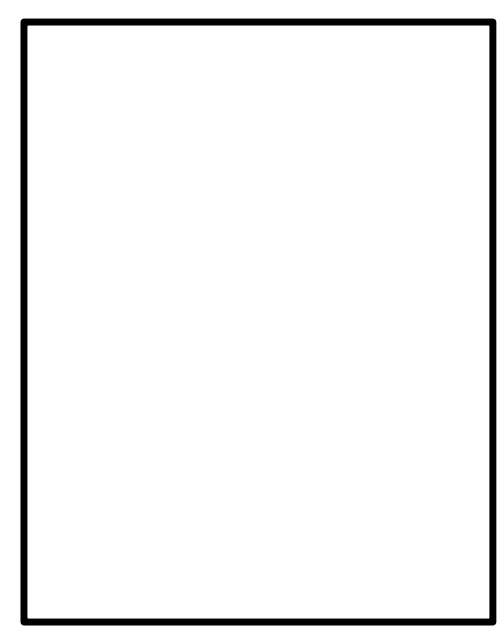

3 The lobe of the brain is important for 


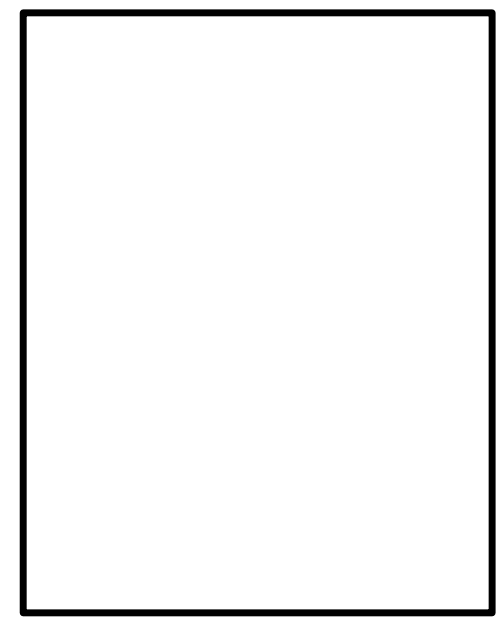

4 The lobe of the brain is important for

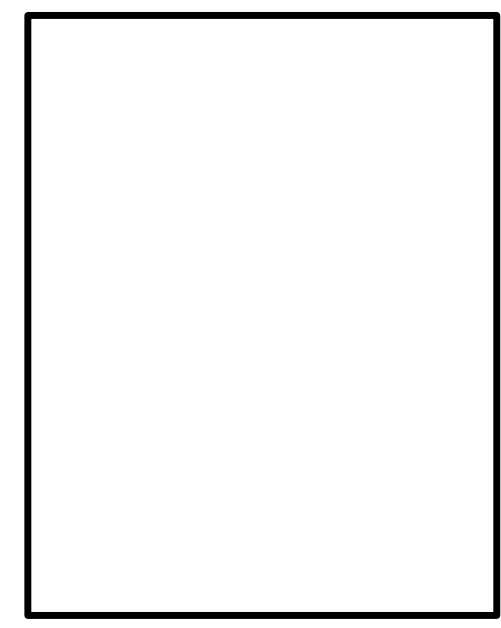

5 The lobe of the brain is important for

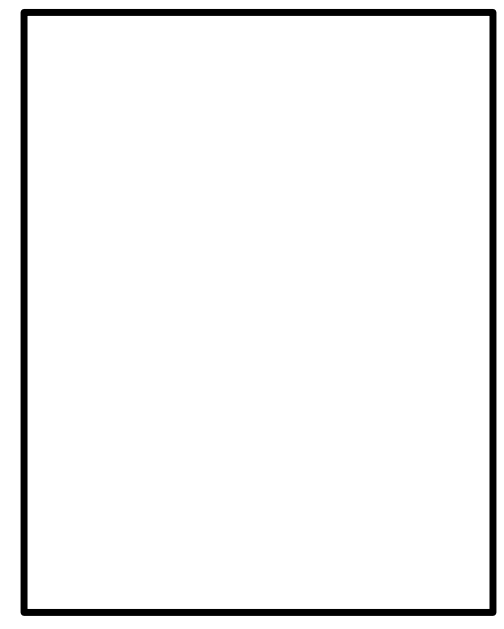

6 The is located at the

and helps us perform tasks. 


\section{Appendix B3: Control Sessions-Lesson II}

\section{Lobes of the Brain Fall 2015}

Each part of the brain has a special role. The Phineas Gage injury is one case researchers study to learn more about how the brain works.

\section{Phineas Gage Accident}

On September 13, 1848 Phineas Gage suffered a traumatic brain injury. While working as a foreman for the Rutland and Burlington railroad, he suffered the penetrating head injury. A four foot long iron rod went through his skull. It has been reported that the left frontal lobe was the primarily affected area. There are several functions of the frontal lobes. One function is the choosing between good and bad actions. Other functions include suppressing inappropriate social responses, understanding future consequences resulting from current actions and retaining long term memories. The Phineas Gage injury offered researchers much insight into the brain as related to cognitive function.

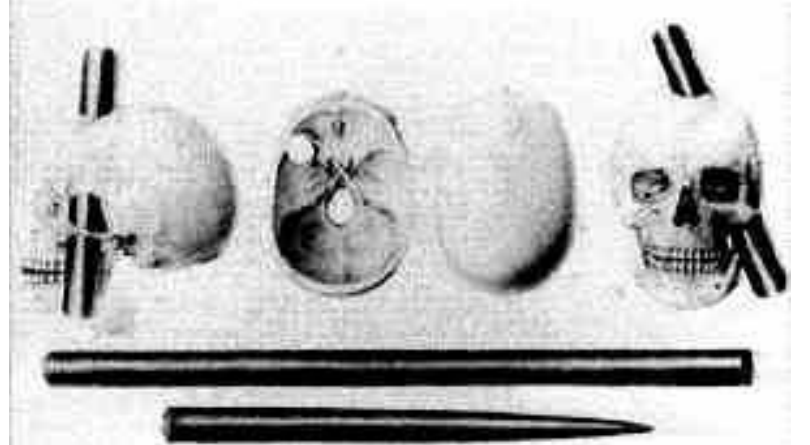

The skull of Phineas Gage. From https://faculty.washington.edu/chudler/lobe.html

What was Learned about the Brain and Cognitive Function Traumatic brain injuries (TBI's) cause several changes in a person. These changes include behavioral, social, and emotional. Before the accident, Gage was hard - working and cautious. After the accident, he became irresponsible, drank heavily, and drifted from one wild scheme to another. Researchers believe this is due to injury to the association areas. The association areas are a major region of the cerebral cortex and the site of higher mental processes. The association areas control functions such as executive, planning, goal setting, judgment, and impulse control. There are personality changes after a type of injury like Gage's. These changes include careless attitudes, taking risks, changes in sociability, unusual sexual habits as well as others. People with these types of injuries have difficulties with functions like memory, information processing speed and executive functions. These personality changes affect a 
person's ability to make moral judgments. However, the person can still be able to reason logically.

The frontal lobe is present in all mammals but is much larger in humans than any other animal which is why humans are able to speak to each other and to develop advanced civilization and why bears are not. This also tells us why Gage lived: because the developed frontal lobes of humans are not necessary for basic survival, like mammals.

By Crystal Swarmer: http://www.intothedepthsofthehumanmind.blogspot.com/2012/10/the-braincognitive-function-and.html.

Approximately Locations: Lobes of the Brain

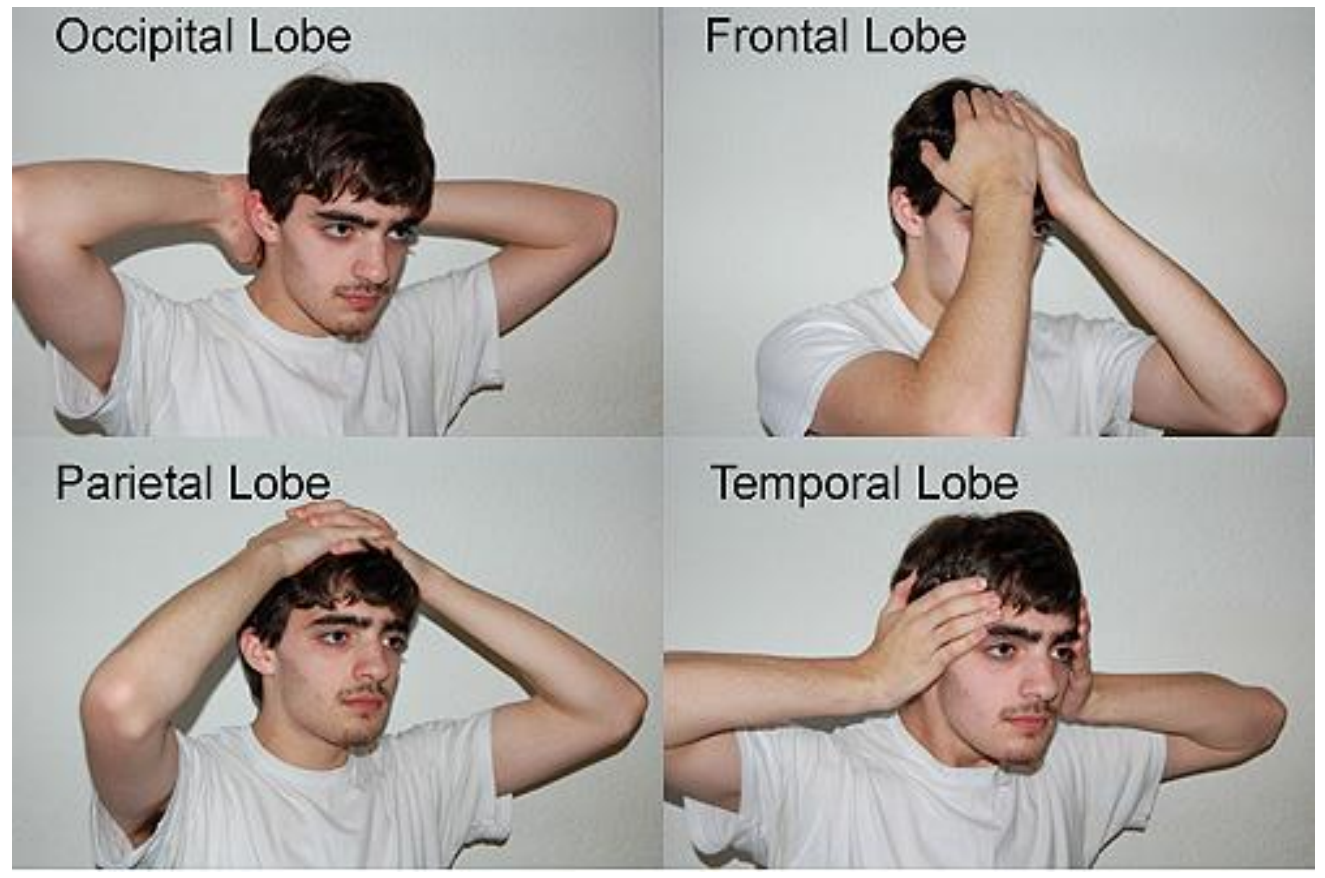

Piaget -4 stages of development https://www.khanacademy.org/science/health-andmedicine/executive\%20systems\%20of\%20the\%20brain/cognition-2014-0327T18:40:04.738Z/v/piagets-stages-of-cognitive-development 


\section{Appendix C1: Mindset Scale-pre, with SES Ladder Student Learning Survey \\ (Dweck, Chiu, \& Hong, 1995, p. 271)}

Please clearly note your Student ID \#

Your careful answers to this questionnaire will be used to understand student beliefs about learning. Your responses will be confidential: your counselor and teachers will not see your individual answers but will be given summarized reports to let them know how they can better serve you and other students.

\begin{tabular}{|l|lrlrlcc|}
\multicolumn{2}{c}{$\begin{array}{c}\text { Strongly } \\
\text { Agree }\end{array}$} & $\begin{array}{c}\text { Mostly } \\
\text { Agree }\end{array}$ & $\begin{array}{c}\text { Mostly } \\
\text { Agree }\end{array}$ & $\begin{array}{c}\text { Strongly } \\
\text { Disagree Disagree Disag }\end{array}$ \\
\hline $\begin{array}{l}\text { You have a certain amount of intelligence, and } \\
\text { you can't really do much to change it. }\end{array}$ & 1 & 2 & 3 & 4 & 5 & 6 \\
\hline $\begin{array}{l}\text { Your intelligence is something about you that } \\
\text { you can't change very much. }\end{array}$ & 1 & 2 & 3 & 4 & 5 & 6 \\
\hline $\begin{array}{l}\text { You can learn new things, but you can't really } \\
\text { change your basic intelligence. }\end{array}$ & 1 & 2 & 3 & 4 & 5 & 6 \\
\hline
\end{tabular}

\section{SES Ladder}

Think of this ladder as representing where people stand in the United States.

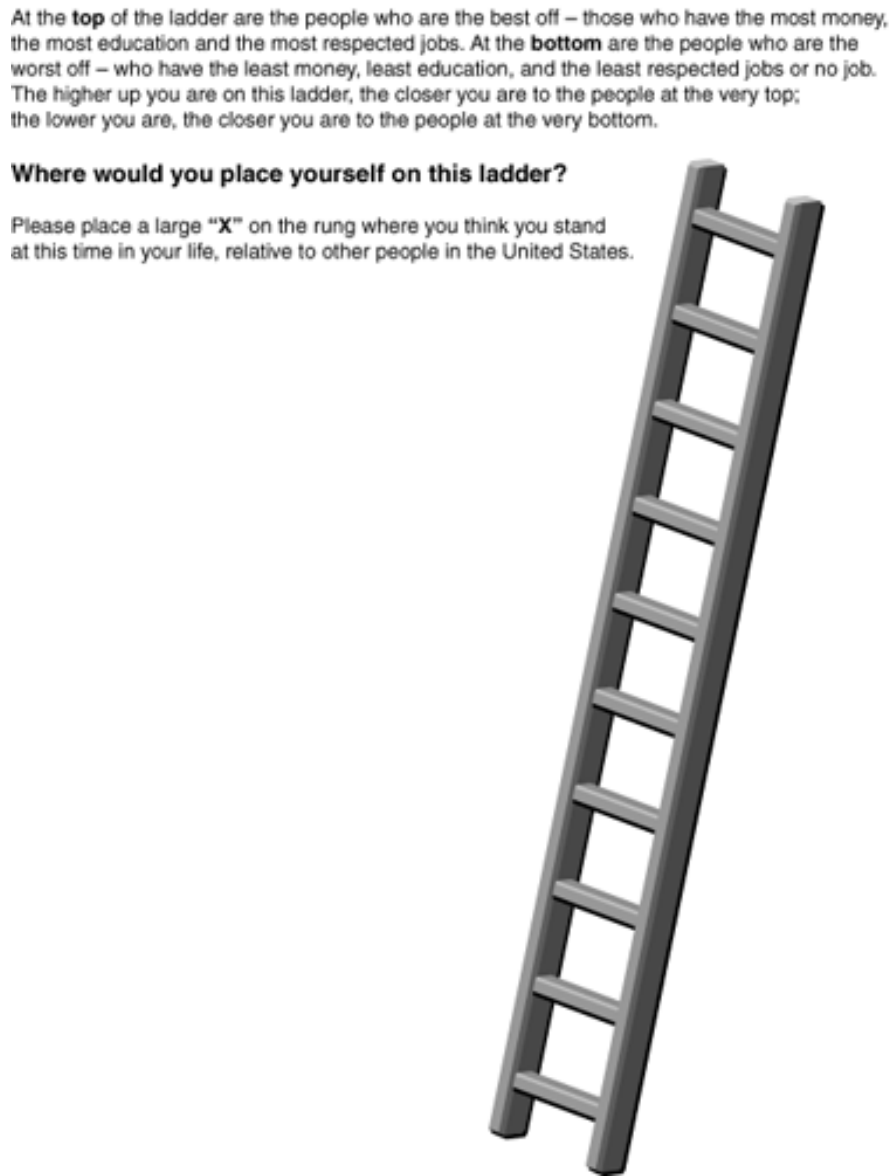




\section{Appendix C2: Mindset Scale-post}

\section{Student Learning Survey \\ (Dweck, Chiu, \& Hong, 1995, p. 271)}

Please clearly note your Student ID \#

Your careful answers to this questionnaire will be used to understand student beliefs about learning. Your responses will be confidential: your counselor and teachers will not see your individual answers but will be given summarized reports to let them know how they can better serve you and other students.

\begin{tabular}{|l|lrlrrr|}
\multicolumn{1}{c}{$\begin{array}{c}\text { Strongly } \\
\text { Agree }\end{array}$} & $\begin{array}{c}\text { Mostly } \\
\text { Agree }\end{array}$ & $\begin{array}{c}\text { Mostly } \\
\text { Agree } \\
\text { Disagree }\end{array}$ & $\begin{array}{c}\text { Strongly } \\
\text { Disagree Disag }\end{array}$ \\
\hline $\begin{array}{l}\text { You have a certain amount of intelligence, and } \\
\text { you can't really do much to change it. }\end{array}$ & 1 & 2 & 3 & 4 & 5 & 6 \\
\hline $\begin{array}{l}\text { Your intelligence is something about you that } \\
\text { you can't change very much. }\end{array}$ & 1 & 2 & 3 & 4 & 5 & 6 \\
\hline $\begin{array}{l}\text { You can learn new things, but you can't really } \\
\text { change your basic intelligence. }\end{array}$ & 1 & 2 & 3 & 4 & 5 & 6 \\
\hline
\end{tabular}


Appendix D: CASSS

\section{CHILD AND ADOLESCENT SOCIAL SUPPORT SCALE-CASSS Grades 3}

$$
-12
$$

Christine Kerres Malecki, Michelle Kilpatrick Demaray, and Stephen Elliott

Name

School

ID \#

On the other side, you will be asked to respond to sentences about some form of support or help that you might get from a teacher or a classmate. Read each sentence carefully and respond to them honestly. There are no right or wrong answers.

For each sentence you are asked to provide two responses. First, rate how often you receive the support described and then rate how important the support is to you. Below is an example. Please read it carefully before starting your own ratings.

\section{HOW OFTEN? IMPORTANT?}

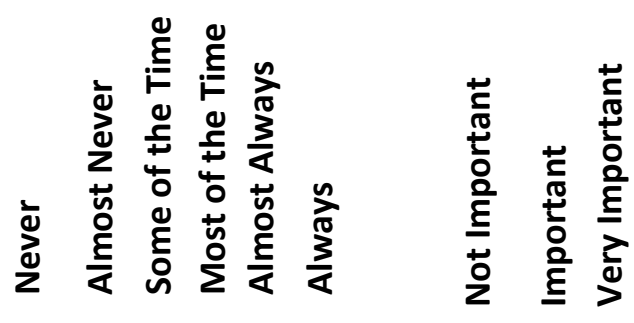

1. My teacher(s) helps me solve problems.

$\begin{array}{llllll}1 & 2 & 3 & 4 & 5 & 6\end{array}$

123

In this example, the student describes her 'teacher helps me solve problems' as something that happens 'some of the time' and that is 'important' to her.

Please ask for help if you have a question or don't understand something. Do not skip any sentences. Please turn to the next page and answer the questions.

Thank you!

Copyright 2000 
ID \#

My Teacher...

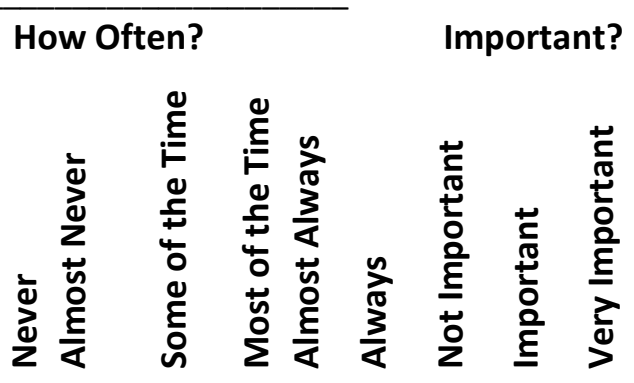

1. ...cares about me.

$\begin{array}{lllllllll}1 & 2 & 3 & 4 & 5 & 6 & 1 & 2 & 3\end{array}$

2. ...treats me fairly.

$\begin{array}{lllllllll}1 & 2 & 3 & 4 & 5 & 6 & 1 & 2 & 3\end{array}$

3. ...makes it ok to ask questions.

$\begin{array}{lllllllll}1 & 2 & 3 & 4 & 5 & 6 & 1 & 2 & 3\end{array}$

4. ...explains things that I don't understand.

$\begin{array}{lllllllll}1 & 2 & 3 & 4 & 5 & 6 & 1 & 2 & 3\end{array}$

5. ...shows me how to do things.

$\begin{array}{lllllllll}1 & 2 & 3 & 4 & 5 & 6 & 1 & 2 & 3\end{array}$

6. ...helps me solve problems by giving me information.1 $2 \begin{array}{llllllll}3 & 4 & 5 & 6 & 1 & 2 & 3\end{array}$

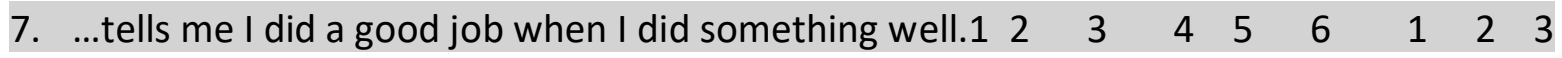

8. ...nicely tells me when I make mistakes.

$\begin{array}{lllllllll}1 & 2 & 3 & 4 & 5 & 6 & 1 & 2 & 3\end{array}$

9. ...tells me how well I do on tasks.

$\begin{array}{lllllllll}1 & 2 & 3 & 4 & 5 & 6 & 1 & 2 & 3\end{array}$

10. ...makes sure I have what I need for school. 12

11. ...takes time to help me learn to do something well.1

12. ...spends time with me when I need help.

$\begin{array}{llllllll}1 & 2 & 3 & 4 & 5 & 6 & 1 & 23\end{array}$

My Classmates...

\begin{tabular}{|c|c|c|c|c|c|c|c|}
\hline 13. ...treat me nicely. & 12 & 3 & 4 & 5 & 6 & 1 & 2 \\
\hline 14. ...like most of my ideas and opinions. & 12 & 3 & 4 & 5 & 6 & 1 & 2 \\
\hline 15. ...pay attention to me. & 12 & 3 & 4 & 5 & 6 & 1 & 2 \\
\hline 16. ...give me ideas when I don't know what to do. & 12 & 3 & 4 & 5 & 6 & 1 & 2 \\
\hline 17. ...give me information so I can learn new things. & 12 & 3 & 4 & 5 & 6 & 1 & 2 \\
\hline 18. ...give me good advice. & 12 & 3 & 4 & 5 & 6 & 1 & 2 \\
\hline 19. ...tell me I did a good job when I've done something & well.1 & 23 & 4 & 5 & 6 & 1 & 2 \\
\hline 20. ...nicely tell me when I make mistakes. & 12 & 3 & 4 & 5 & 6 & 1 & 2 \\
\hline 21. ...notice when I have worked hard. & 12 & 3 & 4 & 5 & 6 & 1 & 23 \\
\hline 22. ...ask me to join activities. & 12 & 3 & 4 & 5 & 6 & 1 & 23 \\
\hline 23. ...spend time doing things with me. & 12 & 3 & 4 & 5 & 6 & 1 & 23 \\
\hline 24. ...help me with projects in class. & 12 & 3 & 4 & 5 & 6 & 1 & 23 \\
\hline
\end{tabular}

Note: Scale formatting has been modified to fit narrower page width. Errors did not appear in actual scale that was administered! 
Appendix E: Informed Parental Consent Form

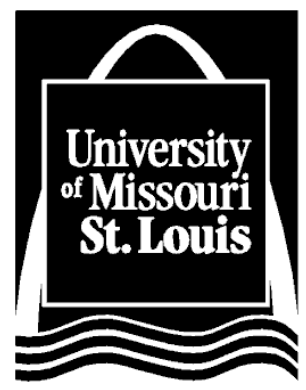

\section{Department of Counseling \& Family Therapy}

One University Blvd.

St. Louis, Missouri 63121-4499

Telephone: $314-516-3894$

Fax: 314-516-5784

E-mail: labtpc@umsl.edu

\section{Informed Consent for Child Participation in Research Activities}

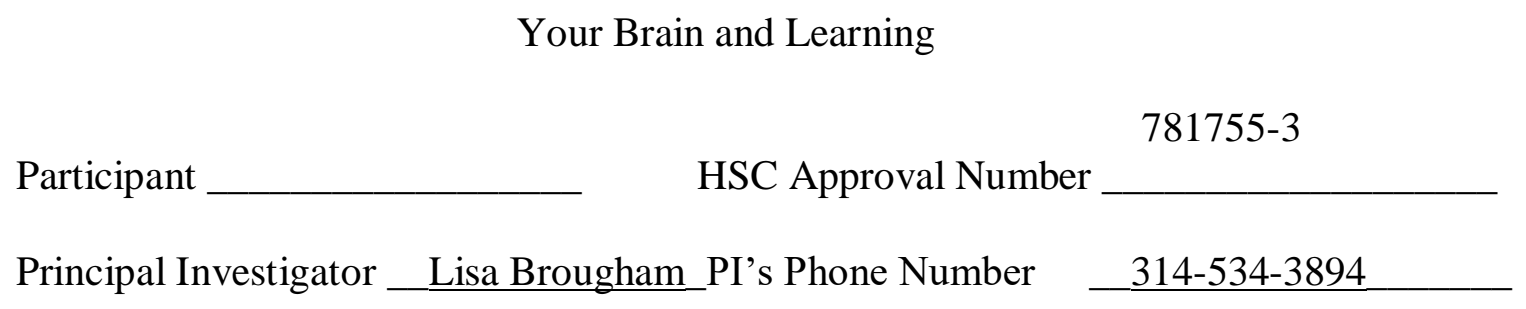

1. Your child is invited to participate in a research study conducted by Lisa Brougham (School Counselor at Metro High School) and Dr. Susan Kashubeck-West, a professor at UMSL who is supervising the research. The purpose of this research is to test if teaching students about how the brain works and how they learn helps their academic performance.

2. a) Your child's participation will involve

$>$ Answering a 28-question survey at the beginning of the study and a 3-item survey at the end of the study

Students will be randomly assigned to one of four small groups. Each group will meet for 45 minutes once a week for three weeks in the school building. These group meetings will take place during a non-academic class for your child. Some students will be in a group that does not receive the treatment and will be taught the new learning method at a later date if it turns out to be helpful. All students will learn about the brain.

Group sessions will be held in a classroom in your student's school and will be led by Ms. Brougham 
She will access school records to see how your child is doing in terms of grades and test scores.

Approximately 50 students may be involved in this research study at each site. This school is one of two SLPS schools involved in the study.

b) The amount of time involved in your child's participation will be 45 minutes each week, plus 5-10 minutes to fill out the surveys, for a total of about 2 hours and 20 minutes. The sessions will begin the week of January 25, 2016 at your child's school Students who attend all three sessions will have their name entered in a drawing for a $\$ 25$ gift card. Your student's chance of winning is 1 out of $10-15$, depending on how many students attend all three sessions.

3. There are no anticipated risks to your child associated with this research.

4. There are no guaranteed direct benefits from your child's participation in this study. However, your child might find being in this study teaches him or her something about how he or she approaches learning and may influence him or her to change study habits.

5. Your child's participation is voluntary and you may choose not to let your child participate in this research study or to withdraw your consent for your child's participation at any time. Your child may choose not to answer any questions that he or she does not want to answer. You and your child will NOT be penalized in any way should you choose not to let your child participate or to withdraw your child. To withdraw your child from the study, contact Ms. Brougham (314-534-3894) or Dr. Kashubeck-West (314-516-6091).

6. We will do everything we can to protect your child's privacy. By agreeing to let your child participate, you understand and agree that your child's data may be shared with other researchers and educators in the form of presentations and/or publications. In all cases, your child's identity will not be revealed. In rare instances, a researcher's study must undergo an audit or program evaluation by an oversight agency (such as the Office for Human Research Protection). That agency would be required to maintain the confidentiality of your child's data.

7. If you have any questions or concerns regarding this study, or if any problems arise, you may call the Investigator, Lisa Brougham at 314-534-3894, or the Faculty Advisor, Dr. Susan Kashubeck-West at 314-516-6091. You may also ask questions or state concerns regarding your child's rights as a research participant to the UMSL Office of Research Administration, at 516-5897.

\section{I have read this consent form and have been given the opportunity to ask questions. I will also be given a copy of this consent form for my records. I consent to my child's participation in the research described above.}


Parent's/Guardian's Signature

Child's Printed Name

Signature of Investigator or Designee
Date

Date
Parent's/Guardian's Printed Name

Investigator/Designee Printed Name 


\title{
Appendix F: Student Assent Form
}

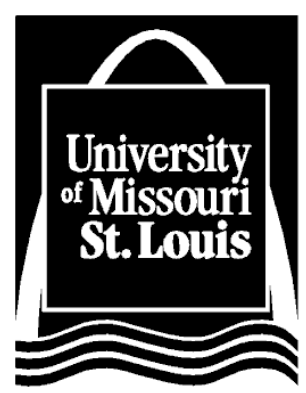

\section{Division of Counseling \& Family Therapy}

One University Blvd.

St. Louis, Missouri 63121-4499

Telephone: $314-534-3894$

Fax: 314-516-5784

E-mail: labtpc@umsl.edu

\section{Assent to Participate in Research Activities (Minors)}

\author{
Your Brain and Learning
}

1. My name is Lisa Brougham. I am the counselor for students in grades 9-11 at Metro High School.

2. I am asking you to take part in a research study because we are trying to learn more about how students learn and how that relates to academic success.

3. If you agree to be in this study you'll answer three survey questions about learning. All students who answer the survey will be considered for the second part of the study, which is three 45-minute sessions about the brain and learning. We'll meet at your school once a week during class time for three weeks. Students who attend all three sessions will have their names entered into the drawing for a $\$ 25$ gift card.

4. Being in this study should not harm you in any way, although it is possible that you might feel bad when answering a question or during a class discussion. If you do, please come and talk to me.

5. You might find being in this study teaches you something about your approach to school. In addition, the data from the whole group of students may help more students at your school pass classes.

6. If you don't want to be in this study, you don't have to participate. Remember, being in this study is up to you, and no one will be upset if you don't want to participate or if you change your mind later and want to stop. If you change your mind, please tell me.

7. Your information will be kept confidential - I will not talk about your answers or your school records with anyone who is not a part of the research team. 
8. You can ask any questions that you have about the study. If you have a question later that you didn't think of now, you can call me at 314-534-3894 during the school day or stop by my office.

9. Signing your name at the bottom means that you agree to be in this study. You will be given a copy of this form after you have signed it.

Participant's Signature

$\overline{\text { Participant's Age }}$
Date

Grade in School
Participant's Printed Name

Participant's School 


\section{Appendix G: Research Study Calendar}

\begin{tabular}{|c|c|c|c|c|}
\hline Monday & Tuesday & Wednesday & Thursday & Friday \\
\hline Jan 11 & Jan 12 & Jan 13 & Jan 14 & Jan 15 \\
\hline $\begin{array}{l}\text { 2pm } \\
\text { visit THS p4 C Dev }\end{array}$ & $\begin{array}{l}\text { 2pm } \\
\text { visitTHSp5TeenOut }\end{array}$ & $\begin{array}{l}\text { THSsigned parent } \\
\text { consent returned }\end{array}$ & $\begin{array}{l}\text { THS signed parent } \\
\text { consent returned }\end{array}$ & $\begin{array}{l}\text { pick up signed } \\
\text { forms from THS }\end{array}$ \\
\hline Jan 18 & Jan 19 & Jan 20 & Jan 21 & Jan 22 A-day \\
\hline $\begin{array}{l}\text { MLK HOLIDAY } \\
\text { no school }\end{array}$ & $\begin{array}{l}7: 30 \\
\text { visitRMHS Art\&Bus }\end{array}$ & $\begin{array}{l}1 \mathrm{pm} \\
\text { visitRMHSArt\&Bus } \\
2 \mathrm{pm} \\
\text { visit THSp4 C Dev }\end{array}$ & $\begin{array}{l}\text { Email RMHS } \\
\text { parents } \\
\text { 2pm } \\
\text { visitTHSp5TeenOut }\end{array}$ & $\begin{array}{l}\text { 7:30 } \\
\text { visitRMHS Art\&Bus } \\
2 \mathrm{pm} \\
\text { visit THS p4 C Dev } \\
\text { pick up signed forms } \\
\text { from RMHS \& THS }\end{array}$ \\
\hline Jan 25 & Jan 26 & Jan 27 & Jan 28 & Jan 29 B-day \\
\hline $\begin{array}{l}2 \mathrm{pm} \\
\text { visit THS p4 C Dev } \\
\text { Call THS students }\end{array}$ & $\begin{array}{l}\text { 7:30 } \\
\text { visitRMHS Art\&Bus } \\
2 \mathrm{pm} \\
\text { visitTHSp5TeenOut } \\
\text { Call THS students }\end{array}$ & $\begin{array}{l}\text { 1pm } \\
\text { visitRMHSArt\&Bus } \\
2 \mathrm{pm} \\
\text { visitTHS p4 C Dev }\end{array}$ & $\begin{array}{l}\text { 7:30 } \\
\text { visitRMHS Art\&Bus } \\
\text { 9\&11-visit PE } \\
2 \text { visitTHS TeenOut } \\
\text { Call RMHS stdnts }\end{array}$ & $\begin{array}{l}\text { collectRMHS forms } \\
2 \text { visitTHS TeenOut } \\
\text { Visit THS homes } \\
\text { >Saturday } \\
\text { Call THS homes } \\
\text { Visit THS homes }\end{array}$ \\
\hline Feb 1-Session 1 & Feb 2 & Feb 3 & Feb 4 & Feb 5 A-day \\
\hline $\begin{array}{l}\text { >S Sunday call } \\
\text { RMHS students }\end{array}$ & 7:30 RMHS-C & & 7:30 RMHS-T & \\
\hline $\begin{array}{l}\text { Create rosters } \\
\text { 1pm RMHS-C } \\
\text { 2:30 THS-C }\end{array}$ & 2:30 THS-C & $\begin{array}{l}\text { 1pm RMHS-T } \\
\text { 2:30 THS-T }\end{array}$ & 2:30 THS-T & \\
\hline Feb 8-Session 2 & Feb 9 & Feb 10 & Feb 11 & Feb 12 A day/B day \\
\hline & 7:30 RMHS-C & & 7:30 RMHS-T & \\
\hline $\begin{array}{l}\text { 1pm RMHS-C } \\
\text { 2:30 THS-C }\end{array}$ & 2:30 THS-C & $\begin{array}{l}\text { 1pm RMHS-T } \\
\text { 2:30 THS-T }\end{array}$ & $2: 30$ THS- $\mathrm{T}$ & $\begin{array}{l}\text { 1pm RMHS-C } \\
\text {-Session } 3\end{array}$ \\
\hline Feb 15 & Feb 16-Session 3 & Feb 17 & Feb 18 & Feb 19 A day/B day \\
\hline $\begin{array}{l}\text { PRES HOLIDAY } \\
\text { no school }\end{array}$ & 7:30 RMHS-C & $\begin{array}{l}\text { 1pm RMHS-T } \\
\text { 2:30 THS-T }\end{array}$ & 7:30 RMHS-T & 2:30 THS-C \\
\hline
\end{tabular}




\section{Appendix H: Session Journal Entries, PI, January-February 2016}

Control group journal entries:

Mon group RCp4: after lunch group/last period of A-day. Attentive, respectful, adhered to group norms...At last session, students shared very thoughtful and creative letters of encouragement to students who suffered a brain injury like the one they were assigned. After I thanked them and they started to leave, Axxx gave me a hug, and then other students did as well.

Tues group RCp5: first period of B day. ... Said were sad we weren't meeting again.

Mon TCp4: last period of the day: Attentive, respectful... Students asked throughout session, when you coming back? When we going to see you again? One asked, you going to cry?

Tues TCp8: last period of the day: This group was a bit more unruly. One student contradicted everything I said, repeatedly. He asked to read the CASSS items, I allowed it, and for the first few he read the extreme negative response. Fortunately, when I requested the second time that he refrain from sharing his opinion and/or influencing others, he acquiesced... One no-show told classmate it was boring. ... Imaging the circumstances around pretending they had a brain injury was tougher for this group. One student couldn't/wouldn't write his letter, but when it was his turn to read his story, he created a thoughtful letter extemporaneously. 
Treatment group journal entries:

Wed group RTp4: last period of A day. Very conversant, engaged ...Said were sad we weren't meeting again. A little more subdued than prior 2 sessions, ok about reading letters, after coaxing. But due to time, only 6 students got to read letters.

Thurs RTp5: first period B day. Student who just joined us [transferred in] this semester was the most vocal student with respect to participating and asking for things (Krispie Kreme donuts, skim milk, go to the restroom when she arrives late), who comes from privilege. Another student participated just as much, but she does not come from privilege. These two girls would have monopolized discussions but I tried to include others as much as possible, while being respectful of them...In the last session, it was like pulling teeth to get volunteers to read their answers from last week's worksheet, and to read their letter of encouragement. I can understand the latter more, as it contained info about a struggle they overcame, and they might not have wanted to share that. There was a low energy level, or reserved nature to the group other than the two leaders, until the end when one boy said as a result of the group he was not going to be lazy. We talked a moment about that and when I asked the group who else was lazy or suffered from procrastination, ALL 13 hands shot up with some vocalization.

Wed TTp4: last period of the day: ...but 3 girls had to leave 20 mins in for basketball game; they are cheerleaders. 2/17- 5 showed...when I casually inquired how their weekend was, after everyone answered theirs was good or ok, she said 
hers was bad: her father died over the weekend, was killed on Friday. This was the girl who almost had to go to ISS. Everyone expressed condolences; I asked if she was ok to continue, she was, and went on to write the most cogent, beautiful letter of all that session, of most sessions. When it was time to do the mindset scale, she said, oh we answered these questions before. I said yes, to which she replied, oh, you want to see if our thoughts change from before we met to after. Yes. Very impressive awareness. Sharp. When I said at one point, something I had said in many groups: let's get this finished so we can have snacks, she calmly commented: oh, that's what they used to say to us in kindergarten. And I calmly reacted an honest, "Oh wow, you're right. I had not intended it to sound like that." Thurs TTp8: ...The first day, I gave them a big thank you as I stood by door to say good-bye and shake their hands. One girl put her arms out and hugged me. Rest of group gave me hug as leaving. ... [Last session]Two basketball team girls who told me they were "buzzos" (buzzins, cuzzins, cousins) this week (but last week had said they were in an intimate relationship) were less focused on group stuff today than prior weeks. It was really difficult to reign them in/get them to focus on our topic. They did do all the activities, but it was with loud, rough conversation/banter/singing between the two of them and including others at times. ... The student who had hugged me the first session, hugged me again and thanked me. The two basketball players left 5 minutes early to talk to the coach. Their intensity really sucked a lot out of the group. I'm not sure how much this group was able to learn the GM concepts as it was a struggle to get through the material. Time will tell! 
Table 1

Comparison of Incremental and Entity Theories of Intelligence

Theories of Intelligence

$\begin{array}{lll}\text { Intelligence is: } & \begin{array}{l}\text { Incremental } \\ \text { A repertoire of skills that } \\ \text { increases through effort }\end{array} & \begin{array}{c}\text { Entity } \\ \text { A global, stable entity } \\ \text { whose adequacy is judged } \\ \text { through performance }\end{array} \\ \text { Effort is: } & \begin{array}{l}\text { An investment that in- } \\ \text { creases intelligence }\end{array} & \begin{array}{c}\text { A risk that may reveal low } \\ \text { intelligence }\end{array}\end{array}$

Goals

Learning Goal: $\quad$ Performance Goal:

Competence increase $\quad \underline{\text { Competence judgment }}$

1.Entering How can I do it: Can I do it?

Question: What will I learn? Will I look smart?

2.Focus on: Process Outcome

3.Errors: Natural, useful $\quad$ Failure

4.Uncertainity: Challenging Threatening

5.Optimal Maximizes learning Maximizes looking smart

Task:

6.Seek: (becoming smarter)

Accurate information about Flattering information ability

7.Standards: $\quad$ Personal, long-term flexible

Normative, immediate, rigid

8.Expectancy: Emphasizes effort $\quad$ Emphasizes present ability

9.Teacher: Resource, guide Judge, rewarder/punisher

10.Goal Value: Intrinsic: value of skill Extrinsic: value of judgment activity, progress

Note: From “Achievement motivation," by C. S. Dweck and E. S. Elliott, 1983, In P. Mussen and E. M. Hetherington (Eds.), Handbook of Child Psychology, p 655. Copyright 1983 by Wiley. Reprinted with permission. 
Table 2

Comparison of Math and Science Scores for Disadvantaged vs National

\begin{tabular}{|c|c|c|c|c|}
\hline \multicolumn{5}{|l|}{ NAEP Composite Scores for 12th grade-2009 } \\
\hline & Math $^{\mathrm{a}}$ & SE & Science $^{\mathrm{a}}$ & SE \\
\hline Jurisdiction & 153 & $(0.7)$ & 150 & $(0.8)$ \\
\hline \multirow[t]{2}{*}{ Student Disability } & 117 & $(1.4)$ & 119 & $(1.8)$ \\
\hline & 156 & $(0.7)$ & 153 & $(0.8)$ \\
\hline Free and Reduced Lunch Status Eligible & 137 & $(0.8)$ & 132 & $(1.0)$ \\
\hline Not Eligible & 160 & $(0.8)$ & 157 & $(0.9)$ \\
\hline Information not available & 159 & $(2.6)$ & 156 & $(2.7)$ \\
\hline Parent Education Level-Did not finishHS & 135 & $(1.0)$ & 131 & $(1.4)$ \\
\hline Graduated HS & 142 & $(0.7)$ & 138 & $(1.2)$ \\
\hline Some education after HS & 150 & $(0.7)$ & 147 & $(0.9)$ \\
\hline Graduated college & 164 & $(0.8)$ & 161 & $(0.7)$ \\
\hline Unknown & 129 & $(1.8)$ & 122 & $(2.1)$ \\
\hline Race/Ethnicity & 161 & $(0.6)$ & 159 & $(0.7)$ \\
\hline Black & 131 & $(0.8)$ & 125 & $(1.2)$ \\
\hline Hispanic & 138 & $(0.8)$ & 134 & $(1.3)$ \\
\hline \multirow{2}{*}{$\begin{array}{r}\text { Asian/Pacific Islander } \\
\text { American Indian/Alaskan Native }\end{array}$} & 175 & $(2.7)$ & 164 & $(3.0)$ \\
\hline & 144 & $(2.8)$ & 144 & $(3.7)$ \\
\hline Two or more races & 158 & $(3.0)$ & 151 & $(3.7)$ \\
\hline \multirow{5}{*}{$\begin{array}{r}\text { City } \\
\text { Suburb } \\
\text { Town } \\
\text { Rural }\end{array}$} & 152 & $(1.7)$ & 146 & $(1.8)$ \\
\hline & 157 & $(1.4)$ & 154 & $(1.4)$ \\
\hline & 151 & $(1.1)$ & 150 & $(1.2)$ \\
\hline & 151 & $(0.9)$ & 150 & $(1.2)$ \\
\hline & & advant & group & \\
\hline
\end{tabular}

Note: $\mathrm{SE}$ = standard error. Adapted from NAEP data explorer. U.S. Department of Education. Washington, DC, National Center for Education Statistics. (2015b). Retrieved from http://nces.ed.gov/nationsreportcard/lttdata/

${ }^{a}$ Scale ranges from 0 to 300 . Some apparent differences between estimates may not be statistically significant. 
Table 3

Impact of Charter School Enrollment on Learning Gains

Mathematics

Urban Overall Poverty ELL SPED Black Hispanic Asian White

$\begin{array}{llllllllll}\text { AllRegions } & 0.055 & 0.033 & 0.041 & 0.013 & 0.051 & 0.029 & 0.012 & -0.047\end{array}$

$\begin{array}{lllllllll}\text { MidwestCity } & -0.001 & -0.023 & 0.123 & 0.074 & 0.010 & 0.001 & 0.006 & 0.031\end{array}$

$\underline{\text { Reading }}$

Urban Overall Poverty ELL SPED Black Hispanic Asian White

$\begin{array}{lllllllll}\text { All Regions } & 0.039 & 0.024 & 0.071 & 0.018 & 0.036 & 0.008 & 0.001 & -0.021\end{array}$

\begin{tabular}{lllllllll} 
MidwestCity & 0.009 & -0.010 & 0.066 & -0.031 & 0.020 & -0.035 & -0.130 & 0.052 \\
\hline
\end{tabular}

Note: Adapted from "Urban Charter School Report on 41 Regions 2015," Center for Research on Education Outcomes (2015), p. 20-23. Retrieved from http://urbancharters.stanford.edu/download/Urban\%20Charter\%20School\%20Study\%20

Report\%200n\%2041\%20Regions.pdf 
Table 4

Key Metrics and Demographic Data for Schools, 2014

\begin{tabular}{|c|c|c|c|c|c|c|c|c|c|}
\hline School & Enrollment & Ethnicity & $\begin{array}{l}\text { Attend- } \\
\text { ance }\end{array}$ & $\mathrm{ACT}^{\mathrm{a}}$ & $\begin{array}{c}\text { F\&R } \\
\text { Lunch }^{b}\end{array}$ & $\begin{array}{l}\text { Disci- } \\
\text { pline }^{c}\end{array}$ & $\begin{array}{l}\text { Spec } \\
\mathrm{Ed}^{\mathrm{d}}\end{array}$ & $\begin{array}{l}\text { Grad } \\
\text { Rate }^{\mathrm{e}}\end{array}$ & $\begin{array}{c}\text { Drop } \\
\text { Out }\end{array}$ \\
\hline RMHS & 335 & $\begin{array}{c}\text { Asian }=11 \% \\
\text { Black }=46 \% \\
\text { Hisp }=5 \% \\
\text { White }=38 \%\end{array}$ & $97 \%$ & 25.1 & $42 \%$ & 0 & $<1 \%$ & $92 \%$ & $3 \%$ \\
\hline THS & 776 & $\begin{array}{c}\text { Asian }=8.1 \% \\
\text { Black }=74 \% \\
\text { Hisp }=5.4 \% \\
\text { White }=12.5 \%\end{array}$ & $86 \%$ & 14.6 & $85 \%$ & 97 & $25 \%$ & $36 \%$ & $51 \%$ \\
\hline
\end{tabular}

Note: District and Building ACT, Attendance, Discipline, Special Education, Graduation and Dropout Rates, Missouri Department of Elementary and Secondary Education, 2015, Retrieved from

http://mcds.dese.mo.gov/quickfacts/SitePages/DistrictInfo.aspx?ID=_bk8100130013005 $\underline{300130013005300}$

Free and Reduced Lunch Percentage by Building 2014. Retrieved from

https://mcds.dese.mo.gov/quickfacts/pages/district-and-school-

information.aspx? RootFolder $=\% 2$ Fquickfacts $\% 2$ FSchool $\% 20$ Finance $\% 20$ Data $\% 2$

0and $\% 20$ Reports $\% 2$ FFree $\% 20$ and $\% 20$ Reduced $\% 20$ Lunch $\% 20$ Percentage $\% 20$ by $\% 20$ Bui

lding\&FolderCTID $=0 x 012000 \mathrm{~B} 3 \mathrm{EF} 86959 \mathrm{C} 3 \mathrm{~A} 824680 \mathrm{BF} 44 \mathrm{E} 0680 \mathrm{ED} 1 \mathrm{~F} 4 \& \mathrm{View}=\{0 \mathrm{E} 81$ 3976-3BD6-4D9B-9112-5D0C54B515E8\}

${ }^{\mathrm{a}}$ Average state ACT score $=21.8$.

${ }^{\mathrm{b}}$ Free and Reduced Lunch percentage.

${ }^{\mathrm{c}}$ Discipline incidents reported.

${ }^{\mathrm{d}}$ Special Education

${ }^{\mathrm{e}}$ Graduation Rate 
Table 5

Flow of Participants Through a Three Week Intervention

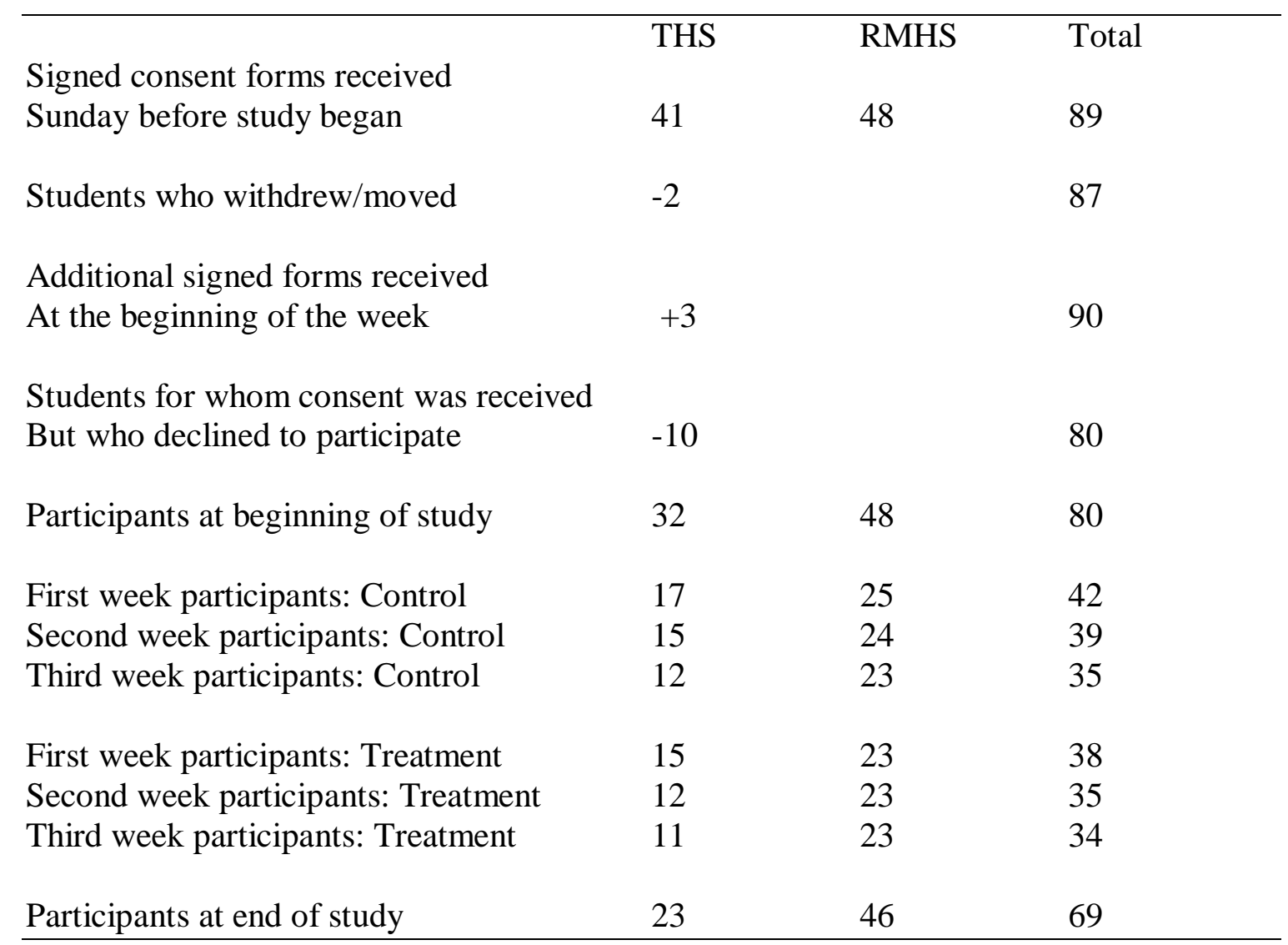

